$\# 18$

ISSN 1832-9488

$(02 / 2019-07 / 2019)$
Núm. 18

Verano 2019
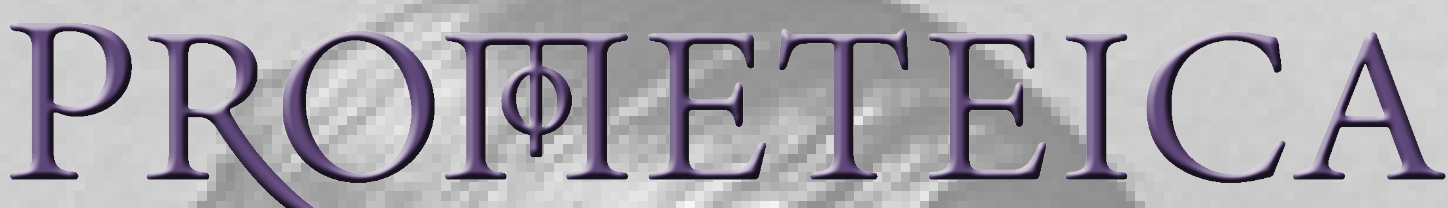

REVISTA DE FILOSOFIA Y CIENCIAS

\section{EDITORIAL}

FLAMINIO DE OLIVEIRA RANGEL - Novos horizontes

\section{ARTÍCULOS}

SANTIAGO TRUCCONE BORGOGNO | Justicia Intergeneracional y cambio climático: comentarios sobre algunas contribuciones para pensar una temática compleja.

ALICIA MORALES LAMBERTI | Derechos de la naturaleza y justicia ecológica intergeneracional

JORGE FOA TORRES | Cambio climático y populismo en América Latina: un análisis comparativo de los posicionamientos de Argentina, Ecuador, Chile y Brasil en el camino al Acuerdo de París de 2015

AGUSTIN ROTH | Cambio climático y políticas públicas: un abordaje desde la teoría social del riesgo

GEORGINA DORONI| Pasivos ambientales: un problema [inter-intra] generacional

CECILIA CARRIZO SINERO; MAURICIO BERGER | Hacia una ley para el reconocimiento y garantía de derechos de los afectados ambientales

MARTIN MIGUEL CHALUP; DIEGO EDUARDO BISSARO FAVA | Problemática jurídica de la producción ganadera sustentable como forma de mitigar el cambio climático

ENTREVISTAS

SANTIAGO TRUCCONE BORGOGNO; ROMINA FRONTALINI REKERS

Entrevista a Tim Waligore (Pace University)

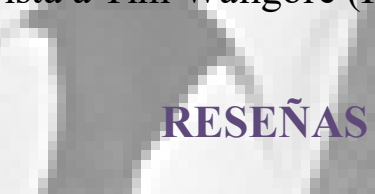

DANIEL KALPOKAS | Justicia Intergeneracional. Ensayos desde el pensamiento de Lukas H. Meyer, Universidad Nacional de Córdoba, 2017. ISBN: 978-987-707-063-7 de Santiago Truccone Borgogno (Comp.)

LAURA GARCÍA PORTELA | Climate justice and historical emissions. Cambridge University Press, 2017. ISBN: 978-110-706-953-4 DE Lukas H. Meyer \& Pranay Sanklecha 
Editor en jefe

Emiliano Aldegani (Universidad Nacional de Mar del Plata, Consejo Nacional de Investigaciones Científicas y Técnicas, Argentina)

\section{Editor invitado}

Santiago Truccone Borgogno (University of Graz / Austria)

\section{Editoras Adjuntas}

Ivy Judensnaider (Universidade Paulista, Universidade Estadual de Campinas, Brasil);

Thais Cyrino de Mello Forato (Universidade Federal de São Paulo, Brasil);

Cristina Bonfiglioli (Universidade de São Paulo, Brasil)

\section{Editor técnico en OJS}

Flaminio de Oliveira Rangel (Universidade Federal de São Paulo, Brasil)

\section{Secretaria de redacción}

María Laura Gutiérrez (Universidad de Buenos Aires, Consejo Nacional de Investigaciones Científicas y Técnicas, Argentina)

\section{Comité editorial}

Agustin Aduriz-Bravo (Universidad de Buenos Aires, Argentina), Alberto Clemente de la Torre (Universidad Nacional de Mar del Plata, Argentina), Ana Paula Bispo da Silva (Universidade Estadual da Paraíba, Brasil), Charbel Nino El-Hani (Universidade Federal da Bahia, Brasil), Fernando Santiago dos Santos (Instituto Federal de São Paulo, Brasil), Lucas Emmanuel Misseri (Universidad Nacional de Cordoba, Consejo Nacional de Investigaciones Cientificas y Técnicas, Argentina), Marco Dimas Gubitoso (Universidade de São Paulo, Brasil), Maria Elice Brzezinski Prestes (Universidade de São Paulo, Brasil), Mariano Nicolas Hochman (Universidad de Buenos Aires, Argentina), Silvia Dotta (Universidade Federal do ABC, Brasil), Vasil Gluchman (University of Prešov, Eslovaquia), y Waldmir Nascimento de Araujo Neto (Universidade de São Paulo, Brasil).

\section{Asesores académicos externos}

André Noronha (Instituto Federal de São Paulo, Brasil), Boniek Venceslau da Cruz Silva (Universidade Federal do Piauí, Brasil), Carlos Eduardo Ribeiro (Universidade Federal de São Paulo, Brasil), Carlos Roberto Senise Júnior (Universidade Federal de São Paulo, Brasil), Daniel Quaresma Figueira Soares (Universidade de São Paulo, Brasil), Denilson Cordeiro(Universidade Federal de São Paulo, Brasil), Esdras Viggiano (Universidade Federal do Triângulo Mineiro, Brasil), Francisco Ângelo Coutinho (Universidade Federal de Minas Gerais, Brasil), Guilherme Brockington (Universidade de São Paulo, Brasil), Helio Elael Bonini Viana ( Universidade Federal de São Paulo, Brasil), Luciana Caixeta Barboza (Universidade Federal do Mato Grosso, Brasil), Luciana Monteiro de Moura (Universidade Federal de São Paulo, Brasil), Luciana Zaterka (Universidade Federal do ABC, Brasil), Marco Braga, Centro Federal de Educação Tecnológica (RJ, Brasil), Maria Inês Ribas Rodrigues (Universidade Federal do ABC, Brasil), Maria Luiza Ledesma Rodrigues (Universidade Estadual Paulista, Brasil), Renato Kinouchi (Universidade Federal do ABC, Brasil), Winston Schmiedecke (Instituto Federal de São Paulo, Brasil)

\section{Formato de la publicación}

Digital: Portable Document Format (PDF), Hyper Text Markup Language (HTML), Extensible Markup Language (XML). 
Idiomas aceptados

Castellano, portugués e inglés (lenguas de la publicación).

Normas de publicación

https://www.prometeica.com/ojs/index.php/prometeica/about/submissions\#onlineSubmissions

Contacto

info@prometeica.com

Responsable

Emiliano Aldegani (Universidad Nacional de Mar del Plata, Consejo Nacional de Investigaciones Científicas y Técnicas, Argentina)

Diseño de isologo

Victoria Reyes (www.victoriareyes.com.ar) 


\section{EDITORIAL}

5 | FLAMINIO DE OLIVEIRA RANGEL - Novos horizontes ARTÍCULOS

6-12 | SANTIAGO TRUCCONE BORGOGNO | Justicia Intergeneracional y cambio climático: comentarios sobre algunas contribuciones para pensar una temática compleja.

13-23 | ALICIA MORALES LAMBERTI | Derechos de la naturaleza y justicia ecológica intergeneracional.

24-35 | JORGE FOA TORRES | Cambio climático y populismo en América Latina: un análisis comparativo de los posicionamientos de Argentina, Ecuador, Chile y Brasil en el camino al Acuerdo de París de 2015.

36-46 | AGUSTIN ROTH | Cambio climático y políticas públicas: un abordaje desde la teoría social del riesgo

47-58 | GEORGINA DORONI Pasivos ambientales: un problema [inter-intra] generacional

59-70 | CECILIA CARRIZO SINERO; MAURICIO BERGER | Hacia una ley para el reconocimiento y garantía de derechos de los afectados ambientales

71-82 | MARTIN MIGUEL CHALUP; DIEGO EDUARDO BISSARO FAVA | Problemática jurídica de la producción ganadera sustentable como forma de mitigar el cambio climático

\section{ENTREVISTAS}

83-85 | SANTIAGO TRUCCONE BORGOGNO; ROMINA FRONTALINI REKERS | Comunidades indígenas, injusticias históricas y presentes. Entrevista a Tim Waligore (Pace University)

\section{RESEÑAS}

86-89 | DANIEL KALPOKAS | Justicia Intergeneracional. Ensayos desde el pensamiento de Lukas H. Meyer, Universidad Nacional de Córdoba, 2017. ISBN: 978-987-707-063-7 de Santiago Truccone Borgogno (Comp.)

90-93 | LAURA GARCÍA PORTELA | Climate justice and historic emissions. Cambridge University Press, 2017. ISBN: 978-110-706-953-4 DE Lukas H. Meyer \& Pranay Sanklecha 


\section{NOVOS HORIZONTES}

Nascemos do desejo de um amplo diálogo internacional — interdisciplinar, público, gratuito, livre de qualquer restrição institucional e dedicado a um leitor humanista — entre a filosofia e a ciência. No início, eram apenas um pesquisador argentino ligado à Universidad de Mar del Plata, uma pesquisadora brasileira da Universidade Federal de São Paulo (UNIFESP) e um grande sonho. Aos poucos, alguns amigos de outras universidades foram se aproximando e, em 2010, a revista lançou seu primeiro número num site em HTML sediado na Argentina com artigos em português e espanhol avaliados às cegas pelos pares.

Em 2011 e 2012, novos colegas dos dois países foram agregados à equipe editorial, possibilitando enfrentarmos novos desafios. Mudamos para um domínio internacional, passamos a editar nossa revista pela plataforma Open Journal System (OJS) e começamos a ser avaliados pelos portais indexadores.

De 2013 a 2018, agregamos mais dois membros à equipe, atribuímos a um terceiro as funções de editor-chefe, nos credenciamos em novos indexadores, adotamos o sistema de navegação criptografada (https://), iniciamos o uso de programas antiplágio nas avaliações, adotamos o DOI (Digital Object Identifier) e passamos a publicar artigos também em inglês, agora em três formatos diferentes: PDF, HTML e XML.

No segundo semestre de 2018, mais maduros e mais estruturados, iniciamos negociações visando sediar nossa revista no Portal de Periódicos da UNIFESP. Todas as tratativas se deram com base no respeito institucional à linha editorial da revista, à autonomia da equipe, a seu caráter internacional, com editores ligados a universidades de diferentes países, e às regras e padrões internacionais de qualidade editorial.

Assim, é com grande satisfação que anunciamos: ao longo do primeiro semestre de 2019, a Prometeica - Revista de Filosofia e Ciências migrará para o Portal de Periódicos da Universidade Federal de São Paulo. Em consequência, passaremos a integrar o Repositório de Dados de Pesquisa (RDP) da UNIFESP e a Indexação Compartilhada de Artigos de Periódicos (ICAP). Estaremos, então, vinculados à política de preservação digital e, portanto, interligados à rede internacional de repositórios; e teremos à disposição novas ferramentas, como o Pergamum - Sistema Integrado de Bibliotecas, o antiplágio Turnitin e a versão atualizada do Open Journal System.

Com isto, o horizonte acadêmico e internacional da Prometeica se expande exponencialmente, possibilitando novas metas de crescimento, desenvolvimento e consolidação.

Flaminio de Oliveira Rangel

(Universidade Federal de São Paulo) 


\title{
JUSTICIA INTERGENERACIONAL Y CAMBIO CLIMÁTICO: COMENTARIOS SOBRE ALGUNAS CONTRIBUCIONES PARA PENSAR UNA TEMÁTICA COMPLEJA
}

\author{
INTERGENERATIONAL JUSTICE AND CLIMATE CHANGE: COMMENTS ON SOME \\ CONTRIBUTIONS TO THINK ABOUT A COMPLEX ISSUE
}

Santiago Truccone Borgogno

(University of Graz / Austria) santiago.truccone-borgogno@uni-graz.at

Recibido: 11/09/2018

Aprobado: 30/10/2018

\section{RESUMEN}

Esta introducción pretende describir y comentar algunos de los trabajos más relevantes presentados en el Congreso Internacional "Justicia Intergeneracional y Cambio Climático: aspectos jurídicos, morales y políticos" desarrollado en Córdoba en septiembre de 2017. En tal encuentro, la discusión se edificó sobre las ideas de los dos conferencistas principales invitados: Lukas H. Meyer y Alessandro Pinzani. Esta introducción pretende marcar algunos retos que deben afrontar cada una de las contribuciones a este volumen especial.

Palabras clave: Personas Futuras. Justicia. Climatica. Teoria Ideal / No Ideal. Filosofia del derecho ambiental.

\section{ABSTRACT}

In this introduction I would like to describe and to comment some of the most relevant papers presented in the International Meeting "Intergenerational Justice and Climate Change: juridical, moral and political issues" that took place in Cordoba, in September 2017. In that meeting, the discussion focused on these topics by taking into account the ideas of the two keynote speakers invited to the event: Lukas H. Meyer and Alessandro Pinzani. This introduction tends to place some challenges that each of the contributions to this special issue must face with.

Keywords: Future people. Climate Justice. Ideal / Non-ideal Theory. Philosophy of Environmental Law

\section{Introducción}

Pocas afirmaciones son tan incuestionables como la que sostiene que el ambiente debe ser protegido. Todas las personas que conocemos creen que hay algo valioso en la salvaguarda de las condiciones ambientales. Esto se evidencia no sólo en la gran cantidad de legislación -nacional, provincial, municipal y supra-nacional- que existe, sino también por las innumerables campañas existentes alrededor del mundo. No sólo las auspiciadas por grandes $\mathrm{ONG}$, sino también aquellas que, de una $\mathrm{u}$ 
otra manera, se desarrollan en cada institución cotidiana. Las escuelas, centros universitarios, comercios, industrias e incluso las asociaciones vecinales tienen, al menos la mayoría de las veces, alguna campaña de protección ambiental. Sin embargo, cuándo nos preguntamos por qué el ambiente debe ser protegido, las respuestas no son tan claras y unánimes. Asimismo, cuando la pregunta se refiere al uso del derecho con tal fin, la divergencia entre las opiniones es aún mayor.

Una de las características que hace que la problemática ambiental sea compleja es que se encuentra atravesada por muchas cuestiones intergeneracionales. Llamo cuestión intergeneracional a aquella referida a, por un lado, cómo debemos relacionarnos tanto con las generaciones pasadas como con las futuras y, por el otro, a los modos de acuerdo con los cuales nos comportamos en relación a las personas presentes en asuntos que poseen componentes que no pueden circunscribirse exclusivamente al espacio temporal en que vive quién actúa. Las generaciones pasadas incluyen a aquellos sujetos que ya no existen en el momento actual, en tanto que las generaciones futuras incluyen a aquellos que aún no existen al momento de realizar una determinada acción o diseñar una política.

Este volumen condensa versiones mejoradas de algunas de los trabajos más relevantes presentados en el Congreso Internacional: "Justicia Intergeneracional y Cambio Climático: aspectos jurídicos, morales y políticos" realizado en Córdoba (septiembre, 2017). Las contribuciones a este volumen, como se verá a través del análisis de una serie de problemáticas relacionadas tanto con la cuestión intergeneracional como con la ambiental, intentan dar respuestas a diversos interrogantes con el objetivo de obtener guías normativas de conducta en estos asuntos complejos. El volumen contiene también dos reseñas a dos de los últimos libros que han sido publicados sobre la materia. En la primera de ellas, Daniel Kalpokas comenta "Justicia Intergeneracional: Ensayos desde el pensamiento de Lukas H. Meyer", libro en idioma español, editado en 2017 por la Universidad Nacional de Córdoba. La segunda de las reseñas, realizada por Laura García Portela versa sobre el libro, también publicado en 2017, "Climate Justice and Historical Emissions" editado por Cambridge University Press. Finalmente, este número se completa con una entrevista al filósofo Tim Waligore (Pace University) sobre la importancia de responder de modo adecuado a las injusticias históricas

En esta introducción al volumen especial sobre justicia intergeneracional y cambio climático, intentaré describir y, si es posible, comentar los puntos principales de las diferentes contribuciones a este número.

\section{Derechos de la naturaleza y justicia ecológica intergeneracional}

En su contribución a este volumen, Alicia Morales Lamberti argumenta que deben reconocérsele derechos y valores intrínsecos a la naturaleza. De hecho, intenta mostrar que la naturaleza debe ser considerada sujeto de derechos. Para esto, luego de reseñar cómo tal visión puede encontrarse reflejada en decisiones de diferentes órganos institucionales, afirma que debe abandonarse el antropocentrismo. Propone que tal esquema sea suplantado por redes relacionales que integren en igual jerarquía a diversos seres vivos y demás componentes del ambiente. En apoyo a su posición, Lamberti argumenta que este punto de vista es el mecanismo más eficaz para proteger al ambiente y, además, hay objeciones morales a la posición antropocéntrica clásica. La autora afirma que, del mismo modo que se abolió la esclavitud en los seres humanos, debe ser abolida la esclavitud de la naturaleza. De hecho, la autora afirma que "la objeción contra el reconocimiento de derechos de la naturaleza en base a diversas posiciones discursivas no es más que la reiteración de la reacción que a lo largo de la historia se ha registrado ante cualquier noticia que le advierte al humano que no es tan centro ni tan privilegiado como se ha creído".

Como se observa, la contribución de Lamberti es interesante y provocativa. Sin embargo, en esta introducción quisiera realizar dos breves comentarios sobre su posición. Creo que abandonar el atropocentrismo no es ni necesario ni deseable para lograr una adecuada protección del ambiente. No es necesario porque una concepción antropocéntrica solo afirma que ningún ser humano o interés humano podrá ser subordinado, de manera justificada, a algún ente no humano. Esta caracterización de 
la tesis antropocéntrica todavía no excluye que deban considerarse algunos intereses no humanos; sólo afirma que, si ello tienen lugar, su relevancia será menor a la de los humanos. Esto no descarta para nada la posibilidad de existencia de fuertes protecciones al ambiente. De hecho, uno puede afirmar que, dado que los intereses humanos son muy importantes y para que ellos tengan un desarrollo adecuado se requiere de un ambiente sano, entonces, el mejor modo de proteger a los intereses humanos es proteger fuertemente las condiciones ambientales.

Asimismo, creo que tampoco es deseable abandonar el antropocentrismo. La posición de Lamberti es compatible tanto con lo que se ha llamado holismo ecológico como con el bio-centrismo. El holismo ecológico implica que los individuos no son importantes en cuanto a tales. De modo que a veces estaría justificado imponerles un sacrificio a ellos para salvar al todo al que están subordinados. El biocentrismo, de manera similar, justificaría imponer sacrificios a los individuos para "salvar" al ser que se cree preponderante, esto es: la tierra. Así, tanto desde una visión cómo desde la otra, el individuo principalmente el humano- puede ser subordinado a la salvaguarda de entidades distintas de él. En un caso la "biósfera" y en el otro, como parte del ecosistema. No veo que esto sea una consecuencia deseable; más aún, si uno puede tener protecciones adecuadas al ambiente sin necesidad de abandonar la importancia de los intereses y derechos humanos.

\section{Cambio climático y populismos en América Latina}

Jorge Foa Torres realiza un interesante análisis comparativo, desde la teoría política del discurso, entre las posiciones políticas de Argentina, Brasil, Chile y Ecuador en relación al cambio climático. El autor defiende que los procesos populistas, en estos países, tienden a posicionarse de manera más antagónica en relación a los países desarrollados en lo referido a la asunción de responsabilidades históricas por el cambio climático. En cambio, según Foa Torres, los procesos no populistas priorizan la facilitación del logro de acuerdos internacionales, por más que ello implique renunciar a ciertos reclamos por ser víctimas directas de la injusticia histórica que representa el hecho de que fueron los países desarrollados los que han contribuido en mayor medida al cambio climático.

El trabajo del autor es cuidadoso e importante. A través de una comparación de las posiciones adoptadas por distintos gobiernos, él describe de manera minuciosa el funcionamiento y las diferencias entre los dos esquemas (populista y no-populista) en las negociaciones climáticas. Sin embargo, aunque sea de manera implícita, el autor parece tomar una posición normativa en relación a ellos favoreciendo la perspectiva de los regímenes populistas. El autor afirma "Los populistas se orientan mayormente a la defensa de sus soberanías nacionales y el derecho al desarrollo de sus países, como así también de la necesaria adopción de mecanismos vinculantes para que los países del Norte se vean obligados a asumir su deuda ecológica generada a partir de las emisiones históricas de carbono." En esta última afirmación, el trabajo deja de ser descriptivo. Aquí Foa Torres asume que los países del Norte, dado que han emitido más en el pasado, deben cargar con mayores obligaciones que los países del sur. El problema con esta afirmación normativa es que, aunque es claro que "el Norte", como afirma el autor, ha emitido más que "el Sur", no es claro que los miembros de las generaciones presentes del "Norte" tengan que soportar obligaciones más fuertes que los miembros de las generaciones presentes de los países "del Sur".

En su construcción, Foa Torres parece asumir como criterio correcto de distribución de cargas para lidiar con el cambio climático al principio "los contaminadores pagan". Este principio afirma que aquellos que han contribuido en mayor medida al cambio climático deben, también, cargar con las mayores responsabilidades referidas a los costos de mitigación y adaptación a él. El inconveniente es que este principio es vulnerable a varias objeciones. Primero, los miembros presentes de los países del "Norte" no han emitido ellos mismos los gases de efecto invernadero que son causantes del cambio climático. Cargar a ellos con una obligación más fuerte es hacerlos pagar por lo que sus ancestros hicieron. Segundo, aun si en algunos casos eso fuera aceptable, aquí el problema es que las personas

\footnotetext{
${ }^{1}$ El resaltado me pertenece.
} 
actuales no podrían evitar lo que hicieron sus ancestros. Si no podían evitarlo, ¿por qué deberían responder por algo que estaba fuera de su alcance hacer? Tercero, parece que para hacer responsable a alguien por lo que hizo, esta persona debe conocer (o debe tener el deber de conocer) los efectos daños de lo que realiza. El problema es que las personas pasadas que emitieron gran parte de los gases que provocan el cambio climático no sabían ni podía haber sabido (al menos hasta 1990) que sus comportamientos eran causantes del cambio climático. Cuarto, tal principio se pone en jaque a través del famoso problema de la no-identidad identificado por Derek Parfit. El asunto radica en el hecho de que de acuerdo a cuál sea la acción que se realice, la identidad de la persona resultante será diferente. Como esto es así, entonces, dichas acciones no pueden empeorar el estado en el que estarán los sujetos que existirán como consecuencia de ellas; y, por tanto, parece que tales acciones no son dañosas. Si esto es aplicable a los comportamientos pasados responsables de las emisiones de gases de efecto invernadero, por más contaminado que esté el ambiente, las personas del "Sur" no pueden reclamar que el cambio climático los perjudica. Esto es así dado que, si el "Norte" se hubiese comportado de modo diferente, las personas reales que existen hoy no estarían mejor sino, sencillamente, no existirían. No estoy afirmando que estas objeciones no puedan ser contestadas. Estoy solamente afirmando que no es claro que "el Norte" deba cargar con una responsabilidad mayor que "el Sur" y que, aun si es así, no es claro que el principio "los contaminadores pagan", sea el mejor argumento para defenderla.

\section{Cambio climático y políticas públicas: un abordaje desde la teoría social del riesgo}

Agustín Roth problematiza la noción de riesgo que atraviesan las discusiones sobre cómo responder de manera adecuada al cambio climático. Tomando como punto de partida las posiciones de Ulrich Beck y Antony Giddens, el autor muestra cómo las características específicas con las que estos autores definen a la sociedad de riesgo están presentes y, quizás, tienen su expresión máxima en la discusión climática, principalmente al momento de diseñar políticas públicas. Roth pone el acento reiteradas veces en que, el hecho de que los efectos adversos del cambio climático sean inciertos $\mathrm{y}$, además, se produzcan muy probablemente muy lejos en el tiempo, dificulta la toma de decisiones en esta materia. Para contrarrestar estos problemas propone, por un lado, lo que él llama una "ecología democrática" y, por el otro, una profundización del principio precautorio ambiental. Por "ecología democrática, el autor refiere a que "las zonas de decisión [ambientales] se abran al escrutinio y debate público". La profundización del principio de precaución es propuesta por el autor como un mecanismo para reducir esa incertidumbre sobre qué efectos acarreará el cambio climático y cuándo se producirán.

Me gustaría realizar dos comentarios sobre este artículo. Primero, aunque acuerdo con el autor en que los temas "ambientales" deberían estar al alcance de las decisiones democráticas, no encuentro razón, en su trabajo, que explique qué tiene de distintivo este asunto en relación a otros donde también las decisiones deben estar también, creo, bajo la deliberación popular. Creo que todo asunto que pueda afectar a los ciudadanos debe contar con instancias donde estos puedan discutirlo públicamente. De lo contrario, tal comunidad, encontraría serios déficits deliberativos. La práctica de audiencias públicas y reuniones informativas en los parlamentos no me parece que deban ser algo exclusivo de la cuestión ambiental. Segundo, en relación al principio de precaución. Creo que el análisis debe distinguir algunos puntos. El principio de precaución es presentado con capacidad para resolver varios casos en los que conductas desplegadas son susceptibles de afectar gravemente el ambiente o el bienestar de las personas futuras. De acuerdo al principio de precaución, donde una actividad suponga una amenaza para el ambiente o la salud humana, las medidas precautorias deben tomarse incluso cuando algunas relaciones de causa y efecto no están establecidas científicamente de manera exhaustiva. Como se observa, este principio requiere que se satisfagan dos extremos: el primero, la existencia de amenaza de daño grave o irreversible; el segundo, que de la conducta se derive un daño potencial, pero donde la evaluación científica no permita precisar el riesgo con suficiente exactitud. Si esto es así, entonces, el principio precautorio solo aporta una solución allí donde lo que no se puede probar es la causalidad. Sin embargo, en aquellos casos donde no puede identificarse un daño o, aún más, en aquellos casos donde los daños son considerados irrelevantes, no tiene sentido aplicarlo. ¿Por qué habría de prevenir 
hacer algo que causará (o puede causar) cierto estado de cosas que no es dañoso o que consideramos normativamente neutro? El principio de precaución sólo exime de la prueba respecto de la relación causal entre la acción y un determinado resultado. Si dicho resultado no puede conceptualizarse como daño, el principio no puede ser aplicado.

\section{Pasivos ambientales un problema [inter-intra]generacional}

La contribución de Georgina Doroni pone el acento en la interacción entre derechos humanos y ambiente con el objeto de justificar reparaciones y compensaciones; lo que ella llama "obligación de recomponer", en referencia a pasivos ambientales. El objetivo de recomponer los pasivos ambientales, según la autora, tiene que ver no solo con el pasado, sino que, además, es una obligación que tenemos hacia las generaciones futuras. Por pasivos ambientales, Doroni entiende a una obligación legal de pagar, una deuda social, económica y ambiental, que se deriva de un daño presente o potencial en el ambiente, que responde a un legado de contaminación histórica. La estrategia de la autora, en su escrito, radica en tratar de mostrar cómo puede lograrse una solución adecuada al problema de los pasivos ambientales, tomando como punto de referencia las decisiones de los órganos públicos, sean estas leyes, tratados internacionales o decisiones judiciales.

El trabajo de la autora es convincente y, creo, de utilidad para todos aquellos que busquen soluciones prácticas a la hora de lidiar con el problema del adecuado tratamiento de los pasivos ambientales. Sin embargo, no esté exento de tensiones. Primero, Doroni trata la cuestión intergeneracional a través de la utilización de determinados patrones de justicia. Ella habla de desigualdades al considerar las "inequidades de cargas y costos socio-ambientales" y de "derecho a un ambiente sano" para luego conceptualizarlo como una precondición para el respeto de los derechos humanos básicos. Creo que aquí reside el primer problema: la primera afirmación, sobre todo por el desarrollo ulterior del texto, parece referirse a la igualdad como patrón de justicia intergeneracional. De acuerdo con esta noción, nuestras obligaciones de justicia con las generaciones futuras se cumplen en la medida en que le dejemos a ellas la misma cantidad de recursos que aquellos con los que disponemos para nuestro propio uso presente. El inconveniente es que tal noción no requiere aquello que está presente en la segunda afirmación de Doroni. Si no tenemos recursos suficientes para satisfacer nuestras necesidades, de acuerdo al igualitarismo, nuestras obligaciones de justicia para con las generaciones futuras se cumplen dejándoles a ellas exactamente lo que tenemos para nosotros, aun si ello implica dejarles un ambiente que no sea sano. En cambio, si lo que se debe dejar es un ambiente sano -como requiere su segunda afirmación- entonces no es necesario cumplir con tal pretendida igualdad. Imaginemos que tenemos abundantes recursos. Si se requiere dejar a nuestra descendencia un ambiente sano y sostenemos: 1) que la afirmación "vivir en un ambiente sano" es idéntica a la afirmación "vivir en un ambiente donde los derechos humanos básicos puedan ser satisfechos" y 2) que para eso son necesarios menos recursos que aquellos que utilizamos nosotros, entonces, 3) violar el principio de igualdad intergeneracional no implica una violación a nuestras obligaciones de justicia para con las generaciones futuras. Esto es así, sencillamente, porque si nuestras obligaciones para con las generaciones futuras están definidas en términos de suficiencia, la igualdad no juega ningún papel directo.

La segunda tensión que es posible identificar en el trabajo de la autora es más seria. Su trabajo se edifica sobre ciertos patrones de justicia con miras a que en el futuro las sociedades puedan vivir de acuerdo a cierto estándar de justicia (sea cual sea este). Sin embargo, la preocupación de la autora pasa por encontrar un modo adecuado de responder a un daño cuya acción ha tenido lugar en el pasado. E1 punto es que, a veces, los objetivos referidos a que el futuro sea "mejor" o de acuerdo a cierto estándar de justicia, entra en conflicto con las obligaciones de reparar daños históricos. Imaginemos, como en el conocido ejemplo de Jeremy Waldron, dos grupos en un desierto: $\mathrm{S}$ y N, donde hay dos pozos de agua. En un momento el grupo $\mathrm{S}$ se apropia del pozo de agua $\mathrm{P}_{\mathrm{s}}$ y el grupo $\mathrm{N}$ del pozo de agua $\mathrm{P}_{\mathrm{n}}$. Cada uno usa su pozo exclusivamente excluyendo al otro grupo de él. Sin embargo, un día en un momento $\mathrm{T}_{1}$ el grupo $\mathrm{N}$ empieza a invadir al pozo de agua del grupo $\mathrm{S}$. De hecho, en $\mathrm{T}_{1}$, debido a esta agresión, $\mathrm{N}$ y $\mathrm{S}$ 
comparten el uso del pozo $\mathrm{P}_{\mathrm{s}}$ que pertenecía a $\mathrm{S}$. Aun más el grupo $\mathrm{N}$ no permite que $\mathrm{S}$ use su propio pozo $\mathrm{P}_{\mathrm{n}}$. Esto es claramente una injusticia. Sin embargo, el tiempo pasa y ocurre un desastre natural que hace que todos los pozos de agua excepto el pozo $\mathrm{P}_{\mathrm{s}}$ se sequen. Ahora, en $\mathrm{T}_{2}$ hay un solo pozo con agua. $\mathrm{Si}$, ahora en $\mathrm{T}_{2}$ nos preguntamos cómo sería una distribución equitativa de recursos, debemos afirmar que una distribución equitativa de recursos es aquella donde los dos grupos pueden tomar agua del único pozo que quedó. Sin embargo, si afirmamos que este es el modo en que debemos evaluar nuestras obligaciones de justicia, entonces, estamos afirmando que no se requiere ninguna reparación por la injusticia pasada. Devolverle el pozo $\mathrm{P}_{\mathrm{s}}$ al grupo $\mathrm{S}$, de manera tal que ellos tengan uso exclusivo de él, como requieren los principios de justicia anclados en consideraciones históricas, ya no está permitido. Aquí, en este caso de los pozos de agua, cumplir con las demandas que exigen los patrones de justicia entra en conflicto con el cumplimiento de las demandas de reparación encarnadas en los principios históricos de justicia. Esta tensión, creo, también se encuentra en el tratamiento que Doroni le proporciona a la remediación de pasivos ambientales.

\section{Hacia una ley para el reconocimiento y garantías de derechos de los afectados ambientales}

El trabajo de Cecilia Carrizo Sineiro y Mauricio Berger es una propuesta cuidadosa sobre cómo deberían ser las leyes en materia ambiental. Los autores realizan los tres pasos que, creo, deben recorrerse cada vez que se hace una propuesta legislativa. Carrizo Sineiro y Berger, en un primer momento, definen una teoría normativa que, según ellos, aporta los criterios con los que deben ser evaluadas los estados de cosa y conductas públicas en relación a la temática ambiental. Segundo, utilizando tales criterios normativos, evalúan los marcos legales vigentes. En este momento ellos destacan sus fortalezas y debilidades. Tercero, proponen modificaciones legislativas que sean acordes al marco normativo definido en un primer momento.

Concretamente, ellos edifican su posición normativa desde los enfoques de Axel Honneth y de Nancy Fraser. Rescatan del primero lo que llaman "teoría del reconocimiento" y, de la segunda, su "giro Habermasiano y propuesta de una justicia tridimensional. De esta manera, entienden los autores, existen tres dimensiones que deben ser evaluadas: 1) las posibles situaciones estructurales de menosprecio y agravio que pueden padecer los afectados ambientales; 2) la posible desigualdad de acceso a las estructuras de representación política y de acceso a los esquemas institucionales de justicia; y 3) la posible distribución desigual y sistemática del daño, en este caso, ocurrido como consecuencia de la contaminación ambiental. En un segundo momento, los autores evalúan la manera en que la legislación vigente responde a estos tres inconvenientes. Los autores entienden que, en muchos aspectos, los esquemas legales vigentes en Argentina son insuficientes para responder de manera adecuada en las tres dimensiones que ellos evalúan. A través del análisis de esquemas legislativos comparados, ellos muestran cómo los problemas identificados pueden ser resueltos. De esta manera, sostienen, se deberían reformar las legislaciones vigentes en la Argentina de manera tal que ellas puedan estar de acuerdo con la teoría moral o normativa desde la que se ha realizado el análisis.

Independientemente de si uno acuerde o no con la teoría normativa que está detrás, el trabajo de estos autores, es de lo más interesante. Cualquiera que pretenda desarrollar un trabajo de ética normativa con el objetivo de proponer una reforma legislativa debería encontrar interesante al escrito de los autores. El trabajo de los autores proporciona un modelo que es muy beneficioso tanto para filósofos como para juristas. Esto porque realizar trabajos que sigan tal modelo, -por un lado- facilita la evaluación de la corrección o incorrección moral de determinados ordenamientos jurídicos positivos y -por otro ladoayuda a concebir ordenamientos jurídicos positivos moralmente no objetables. En síntesis, el trabajo desarrollado por ellos además de importancia para la filosofía es relevante para dos cuestiones connaturales de la discusión jurídica. Primero, el criterio normativo utilizado por ellos sirve, como puede ser apreciado en su trabajo, para evaluar moralmente ordenamientos jurídicos válidos de un determinado país. Segundo, tal criterio puede servir para justificar propuestas de reforma legislativa 
sobre diversos puntos, en su caso, una legislación integral que pueda dar cuenta y dar una solución adecuada al impacto negativo que sufren los afectados ambientales.

\section{Problemática jurídica de la producción ganadera sustentable como forma de mitigar el cambio climático}

La compatibilización de manera justa entre los intereses de las personas futuras y de aquellas que viven en el presente es un tema central en las discusiones de justicia intergeneracional. Tal tensión aparece cuando se discute si debe priorizarse o bien el desarrollo económico de las personas presentes aun cuando ello implique un detrimento en las condiciones de vida de las personas futuras o, en cambio, la salvaguarda del ambiente sano, aun a costa de impedir ciertos desarrollos económicos presentes y locales. El trabajo de Martín Miguel Chalup y Diego Eduardo Bissaro Fava, incluido en este volumen especial, toca al centro de este debate. Los autores parten, a mi entender, de considerar que las obligaciones de justicia intergeneracional deben medirse en términos suficientistas. Para el suficientismo, si una persona $\mathrm{X}$ está debajo de un umbral de suficiencia y si $\mathrm{Y}$ está en una mejor condición que $\mathrm{X}$, beneficiar a una persona $\mathrm{X}$ es más importante que beneficiar a una persona $\mathrm{Y}$. Así, en el contexto intergeneracional tal noción implica que nuestras obligaciones para con las personas futuras se cumplen en la medida en que le dejemos a ellas "lo suficiente".

Los autores, a través del análisis de una de las actividades que en la Argentina más contribuyen al cambio climático, como lo es la ganadería, reflexionan sobre cómo tal actividad debe ser regulada para que cumpla con tal criterio de justicia intergeneracional. Ellos toman como ejemplo a la provincia de Corrientes y describen el estado actual de la producción ganadera y sus efectos en las emisiones de gases de efecto invernadero. Asimismo, analizan el marco legal actual, marcando ciertas ventajas y debilidades. Ellos argumentan, finalmente, que existen medidas que pueden ser adoptadas compatibles con el marco legal argentino- para que la producción ganadera no comprometa el desarrollo económico de las personas actualmente existentes sin necesidad de violar las obligaciones de justicia que tenemos para con las personas futuras.

\section{Comentario Final}

Este volumen especial contiene varios elementos que hacen que pueda leerse como una contribución interdisciplinaria valiosa para pensar la problemática ambiental e intergeneracional. Desde diferentes puntos de partida y enfoques, los autores de los distintos trabajos intentan dar solución a, quizás, una de las problemáticas más complejas y acuciantes de la época en la que vivimos. Época en la que los efectos adversos de nuestros actos tienen la capacidad, como nunca antes, de amenazar nuestra propia supervivencia en la tierra. 


\title{
DERECHOS DE LA NATURALEZA Y JUSTICIA ECOLÓGICA INTERGENERACIONAL
}

\author{
RIGHTS OF NATURE AND INTERGENERATIONAL ECOLOGICAL JUSTICE
}

\author{
Alicia Morales Lamberti \\ (Universidad Nacional de Córdoba / Argentina) \\ amlamberti327@gmail.com
}

Recibido: $15 / 09 / 2018$

Aprobado: 30/10/2018

\begin{abstract}
RESUMEN
El reconocimiento de la función ambiental de los derechos en el ámbito del paradigma de la justicia ambiental intergeneracional, se ha visto influenciado progresivamente por la coexistencia de otro paradigma no necesariamente excluyente de aquél, basado en el reconocimiento de valores intrínsecos y derechos de la naturaleza, en el marco de una justicia ecológica intergeneracional.

Los derechos intergeneracionales y el reconocimiento de los derechos de la naturaleza, emancipada de su consideración como objeto (bien jurídico) y reconocida como sujeto de derechos, se presentan como derechos de cuarta y quinta generación que cuestionan las prevalentes concepciones antropocéntricas del derecho ambiental.

En ese marco, el análisis se centra en el progresivo reconocimiento normativo y jurisprudencial en numerosos países, de los valores intrínsecos y derechos de la naturaleza en el marco de una justicia ecológica intergeneracional, interpela acerca de los nuevos paradigmas que distinguen a actuales debates jurídicos y políticos, en torno a la relación entre los derechos humanos y el medio ambiente.
\end{abstract}

Palabras claves: Función ecológica de los derechos. Naturaleza. Justicia ambiental. Justicia ecológica.

\section{ABSTRACT}

The recognition of the environmental role of rights within the paradigm of intergenerational environmental justice has been progressively influenced by the coexistence of another paradigm not necessarily exclusive to it, based on the recognition of intrinsic values and rights of nature, within the framework of intergenerational ecological justice.

Intergenerational rights and the recognition of the rights of nature, emancipated from its consideration as an object (legal right) and recognized as subject of rights, are presented as rights of fourth and fifth generation, that challenge the prevailing anthropocentric conceptions of environmental law.

In this context, the argument will focus in the progressive legal and jurisprudential recognition in many countries of the intrinsic values and rights of nature in the framework of an intergenerational ecological justice, challenges the new paradigms that distinguish current legal and political debates, about the relationship between human rights and the environment. 
Keywords: Ecological function of rights. Nature. Environmental justice. Ecological justice.

\section{Introducción}

Hemos ingresado en un nuevo período geológico que necesita una nueva nominación: Antropoceno (Crutzen- Stoermer, 2000:17), en el que muchas condiciones y procesos vitales se ven profundamente alterados por la actividad humana.

Los últimos avances científicos subrayan la necesidad de tomar en consideración cuidadosamente el efecto agregado a largo plazo de las actividades humanas en el sistema tierra, que conforma la estructura ambiental que posibilita la vida. El sistema tierra se caracteriza por reacciones no lineales e interacciones complejas entre la biósfera viva, compuesta por los ecosistemas y las especies, y los procesos físicos.

El sistema climático no es un mero fenómeno atmosférico. Según el IPCC (2014), la temperatura media de la superficie de la Tierra aumentará entre $1,39^{\circ}$ y $5,78^{\circ}$ Celsius en los próximos 100 años, si no se reducen las emisiones de gases de efecto invernadero. Aunque un aumento de unos pocos grados pueda parecer poco importante, cabe señalar que la temperatura media de la Tierra no ha variado en más de 1 grado en los últimos 10.000 años. Unos pocos grados de variación en la temperatura media determinan la diferencia entre una era glacial y el clima actual de la Tierra.

En la era tecnológica actual, se asiste a un empobrecimiento de la relación histórica entre los seres humanos y la naturaleza. La pérdida de la biodiversidad, la desertificación, el cambio climático y la alteración de ciclos naturales son parte de los costos derivados de nuestro desprecio por la integridad de los ecosistemas y sus procesos vitales.

Ante ello, la Organización de Naciones Unidas, aboga por un cambio. Ante todo, pide que la humanidad trate al planeta con respeto. Ese respeto se materializará únicamente cuando los humanos cambien la manera de percibir su relación con la naturaleza (ONU, 2012).

En ese contexto, el reconocimiento de la función ambiental de los derechos en el ámbito del paradigma de la justicia ambiental intergeneracional, se ha visto influenciado progresivamente por el surgimiento y coexistencia de otro paradigma no necesariamente excluyente de aquél, basado en el reconocimiento de valores intrínsecos y derechos de la naturaleza, en el marco de una justicia ecológica intergeneracional.

Los derechos intergeneracionales y el reconocimiento de los derechos de la naturaleza, emancipada de su consideración como objeto (bien jurídico) y reconocida como sujeto de derechos, se presentan como derechos de cuarta y quinta generación que cuestionan las prevalentes concepciones antropocéntricas del derecho ambiental.

El progresivo reconocimiento normativo y jurisprudencial en numerosos países, de los valores intrínsecos y derechos de la naturaleza, en el marco de una justicia ecológica intergeneracional, interpela acerca de los nuevos paradigmas que distinguen a actuales debates jurídicos y políticos, en torno a la relación entre los derechos humanos y el medio ambiente.

\section{De una ontología dualista a la construcción de ontologías relacionales abiertas: estado de la legislación y jurisprudencia}

El reconocimiento de derechos para la naturaleza, se evidencia en varios países que empezaron a abandonar la visión antropocéntrica de la naturaleza que imperó durante tantos siglos. Un giro ya se vislumbra en el mismo campo del derecho ambiental, a través de la admisión de actuaciones judiciales en beneficio de entes naturales o incluso el acceso de estos mismos a la justicia mediante instituciones 
tutelares, relevantes frente al argumento usual de que no cabe reconocer derechos en favor de entidades sin capacidad para determinarse por sí mismas ni de actuar por tanto con título propio en propia defensa.

Luego del voto de William Douglas en la causa "Sierra Club" (Sierra Club v. Morton, 405 U.S. 727, 1972) y del precedente de Christopher Stone (1972), donde se argumentaba esencialmente a favor del standing de los seres, objetos o zonas naturales afectados por amenazas o daños ecológicos, pero no se excluía la posibilidad y conveniencia de otorgar personalidad jurídica al ambiente o a la naturaleza en general, en diversas normas comunales de los Estados Unidos se viene reconociendo a la naturaleza como sujeto de derechos y específicamente, "el derecho jurídicamente exigible de los ecosistemas naturales a existir y prosperar".

El concepto legal de los derechos de la naturaleza, señala la influencia de la cosmovisión de los pueblos originarios del mundo como actores políticos. Pero en esta construcción de ontologías relacionales abiertas -para distinguirlas de las perspectivas antropocéntricas que corresponderían a una ontología dualista (naturaleza/sociedad)-, no subyacen únicamente cuestiones de reivindicaciones indígenas, sino que expresa inconformidades culturales que cruzan transversalmente muchas culturas y países: con ellas las categorías personas/objetos desaparecen ya que los humanos y los no-humanos pueden ser todos ellos agentes morales, con capacidades análogas, todo integrantes de una misma comunidad expandida, sujetos de derechos y por lo tanto demandantes de justicia (Gudynas, 2010).

El dualismo del antropocentrismo, es suplantado por redes relacionales que integran en igual jerarquía a distintos seres vivos u otros componentes del ambiente (Gudynas, 2010). Se conforman así, comunidades que son tanto sociales como ecológicas, obligando a pensar desde otros puntos de partida cómo se concibe jurídicamente el mundo natural.

Entre esas nuevas concepciones jurídicas, resalta la nueva Constitución del Ecuador (2008) El artículo 71 establece que "la Naturaleza o Pacha Mama, donde se reproduce y realiza la vida, tiene derecho a que se respete integralmente su existencia y el mantenimiento y regeneración de sus ciclos vitales, estructura, funciones y procesos evolutivos", y que toda persona, comunidad, pueblo o nacionalidad podrá exigir a la autoridad pública el cumplimiento de los derechos de la naturaleza. El artículo 72 establece que "la naturaleza tiene derecho a la restauración".

Por su parte, el Estado Plurinacional de Bolivia aprobó una nueva Ley de Derechos de la Madre Tierra (Ley 071, 2010): "Para efectos de la protección y tutela de sus derechos, la Madre Tierra adopta el carácter de sujeto colectivo de interés público. La Madre Tierra y todos sus componentes incluyendo las comunidades humanas son titulares de todos los derechos inherentes reconocidos en esta Ley. La aplicación de los derechos de la Madre Tierra tomará en cuenta las especificidades y particularidades de sus diversos componentes. Los derechos establecidos en la presente Ley, no limitan la existencia de otros derechos de la Madre Tierra" (art. $5^{\circ}$ ).

Inspirada en la legislación anterior, en el Distrito Federal de México en el año 2013 entró en vigor la Ley Ambiental de Protección a la Tierra, para proteger a la Madre Tierra, que posee estatus de un ser vivo: "Art. 86 bis 1. La Tierra es un sistema viviente dinámico conformado por la comunidad indivisible de todos los sistemas de vida y los seres vivos, interrelacionados, interdependientes y complementarios, que comparten un destino común". A los fines jurídicos de su protección y tutela "la Tierra adopta el carácter de ente colectivo sujeto de la protección del interés público. En su aplicación se tomarán en cuenta las especificidades y particularidades de sus diversos componentes" (Art. 86 bis $3)$.

Como puede observarse, esas ideas presentan una ruptura revolucionaria en la comprensión antropocéntrica convencional y un realineamiento de cómo se valora el mundo natural, pero no se trata de una experiencia aislada, por cuanto se viene replicando por pueblos que tienen una comprensión de sí mismos y un punto de partida muy diferentes. 
Así, ese reconocimiento de la naturaleza como sujeto de derechos, reconoce variadas experiencias normativas, donde el entorno natural merece ser protegido en sí y por sí mismo (Suecia, 1999) por cuanto posee valor intrínseco, independiente del valor que su uso pueda tener para el hombre (Noruega, 2010).

A diferencia de Ecuador, los derechos de la naturaleza en Nueva Zelanda no están reconocidos a nivel constitucional, las comunidades nativas fueron fundamentales en la creación de nuevos marcos legales que reconocen como sujetos de derecho a territorios y ecosistemas, otorgando personalidad jurídica al Parque Te Urewara. Esto fue parte de los esfuerzos de reparación por la injusticia histórica generada cuando el Estado de Nueva Zelanda fue fundado: la conquista colonial de las tierras de los pueblos originarios. La Ley de Te Urewara (2014) reconoce al Parque como sujeto de derechos, lo declara hogar sagrado del pueblo Tuhoe y parte integral de su cultura e identidad, al mismo tiempo que es de valor intrínseco para todos los neozelandeses.

En un proceso judicial emancipador similar, una tribu maorí local ayudó al río Whanganui a obtener el estatus de persona jurídica en 2014 y se reconoció el derecho a su gestión como su guardián legítimo. Con ello, se reconoció entre otras cosas, que el río Whanganui era un ser vivo y que las personas y el río eran inseparables, y se le concedió reconocimiento legal como "entidad jurídica con capacidad procesal por derecho propio".

En relación a Ecuador, el primer caso en que se tuvo conocimiento de aplicación judicial de los derechos de la naturaleza se dio en el año 2011. La Acción de Protección, fue interpuesta en contra del Gobierno Provincial de Loja "a favor de la Naturaleza, particularmente a favor de la cuenca del río Vilcabamba". El gobierno local había iniciado un proyecto de ampliación de carreteras y vertía restos en el río, lo que afectaba a su flujo y causaba contaminación. El tribunal decidió que se habían violado los derechos constitucionales del río a fluir y obligó al gobierno provincial a reparar los daños.

En igual sentido, se han conferido diversas medidas cautelares a favor de los Derechos de la Naturaleza, debido a la fragilidad de los ecosistemas existentes en Galápagos. En un caso, se tuvo en cuenta el régimen especial que rige en esta zona insular respecto a la limitación de actividades que puedan afectar el medio ambiente, sin contar con licencia ambiental y social (Estero Wincheles en Esmeraldas). Asimismo, se hizo lugar a una Acción de Protección por desarrollo de actividades mineras sin licencia ambiental, que provocaban el deslizamiento de materiales en el Río Granobles (Río Blanco), causando su afectación.

Más recientemente (2016) la Corte Constitucional de Colombia, reconoció al río Atrato, su cuenca y afluentes como una "entidad sujeto de derechos a la protección, conservación, mantenimiento y restauración a cargo del Estado y las comunidades étnicas" en calidad de sus guardianes.

Un precedente notable fue sentado por el Tribunal Supremo de la provincia india de Uttarakhand. En su sentencia recaída en la causa T. N. Thirumulpad Godavarman v. Union of India (2017), consideró que para hacer efectiva la justicia ambiental era necesario aplicar principios ecocéntricos en vez de antropocéntricos. La Corte determinó que "la cordillera del Himalaya, sus glaciares, ríos (Ganges y Yamuna principalmente), caídas, corrientes, lagos, junglas, bosques, praderas, valles, humedales y manantiales habrían de ser considerados como personas jurídicas a fin de garantizar su sobrevivencia, seguridad, sustentabilidad y resurgimiento" y estableció expresamente que "los derechos de estas últimas debían considerarse equivalentes a los de los seres humanos y repararse de igual manera".

Por otra parte, el reconocimiento de los derechos de los animales, se ha desarrollado en forma paralela al proceso de afirmación de los derechos de la naturaleza. Valga como ejemplo, el caso de la orangutana Sandra, quien siendo reconocida como "ser sintiente" (novedosa categorización introducida por la reforma de 2015 del Código Civil francés), "es una 'persona no humana', y por 
ende, sujeto de derechos y consecuentes obligaciones hacia ella por parte de las personas humanas" (Morales Lamberti, 2017) ${ }^{2}$.

\section{Función ecológica de los derechos y derechos de la naturaleza: el hilo de Ariadna y las necesidades jurídicas insatisfechas}

El derrotero histórico de la relación hombre-ambiente estuvo constantemente marcado por un sustrato cultural o código ético adaptado a la medida del hombre: es él quien fue dictando las reglas de un antropocentrismo fuerte legitimador de cada forma de dominación.

La posibilidad de una regulación jurídica que atienda al mundo de la naturaleza, que consista en separar el todo en partes y luego realizar un ejercicio de recomposición, reuniendo todos esos factores en una sola formulación normativa, no fue fácil de construir y menos fácil de comprender. Implicaba nuevas instituciones, nuevos criterios de justicia, nuevas leyes y especialmente nuevos métodos: era necesario cambiar el microscopio jurídico sustancial y procesal pensado para la resolución de conflictos individuales patrimoniales, por el "macroscopio", apto para resolver las cuestiones complejas y holísticas que plantean los retos ambientales. Acudir al "macroscopio" entonces, es, antes que nada, un sistema de pensar y, después que nada, un sistema de pensar la naturaleza.

No escapa a este reconocimiento, que los conflictos ambientales emergen de intereses y estrategias diferenciadas de relacionamiento, apropiación y aprovechamiento de la naturaleza y por ende, de políticas públicas, que avecinan una fuerte crisis de instituciones y de sistemas jurídicos tradicionales basados en una racionalidad retórica e instrumental. Tampoco desconoce, que la lista de indicadores ambientales que cuestionaban y cuestionan la sustentabilidad de la vinculación del hombre con la naturaleza es muy vasta y que esto es un hecho antrópico y no ecológico, al cual el derecho ambiental también debe dar respuestas, porque estamos viviendo por sobre los límites de nuestra tarjeta de crédito ecológico (Morales Lamberti, 2017).

\section{El derecho a tener derechos}

La abolición de la esclavitud de la naturaleza ha sido comparada con la abolición de la esclavitud humana (Stutzin, 1984:98). Teólogos y juristas mantuvieron durante siglos la tesis que los indígenas americanos no eran personas y carecían de alma. Aun en el año 1858 un tribunal de Virginia (Estados Unidos), declaró que "un esclavo no es una persona, sino una cosa".

Así como las leyes esclavistas, que convirtieron a seres humanos en propiedad afianzaron una relación de explotación, nuestros sistemas jurídicos han mantenido en sucesivos períodos históricos, sectores relegados de la sociedad y de sus derechos, como los pueblos originarios, los negros, los gays, las mujeres... y con ellos también a la naturaleza, que también es mujer y es mujer sojuzgada.

Pero más que multiplicar ejemplos históricos o actuales, justo es reconocer que todo ello se basa en la construcción de realidades jurídicas a partir de supuestos culturales, que los juristas llamamos ficciones jurídicas. A lo largo de la historia y aún en la actualidad, la sociedad construye categorías y otorga características a todo lo que la circunda: Los modos en que categorizamos tienen su origen en la sociedad misma, y los modos de ver la realidad y de actuar sobre ella están permeados por los modos en que clasificamos esta realidad.

La construcción y la asimilación de las ficciones jurídicas son contextuales. Por ello, cada decisión legislativa o judicial en materia ambiental, es parte de distintas percepciones y diversas construcciones de la sociedad y también, del pluralismo en la construcción social de la realidad. La vieja formulación del derecho positivo de considerar sólo a los seres humanos (personas) como únicos sujetos de

\footnotetext{
${ }^{2}$ El término surge de Joël de Rosnay en "El Macroscopio", A.C., Madrid, 1977.
} 
relaciones jurídicas (posteriormente ampliada a la "ficción" de las personas jurídicas y a la subjetivación jurídica de "patrimonios de afectación"), continúa formulando resistencias al reconocimiento de los derechos de la naturaleza y su condición de sujeto de derechos.

Es que los modos categorizar y clasificar encierran relaciones de poder específicas, que a su vez pueden provocar relaciones de desigualdad, dominación y sometimiento de seres vivientes, que aún hoy deja por fuera a los indígenas, los físicamente discapacitados, la naturaleza y las generaciones futuras, entre otros.

Eso interpela ciertos modos de ver y actuar sobre la vida de los otros humanos y no humanos. Por ello, la lucha por los derechos de la naturaleza y su condición de sujeto de derechos, no es sólo un recurso técnico cuya función jurídica radica en la posibilidad de lograr soluciones a problemas nuevos mediante la utilización de construcciones creadas para enfrentar situaciones distintas, sino también una manera de hacer visible a uno entre otros tantos excluidos.

\section{El paradigma ecológico}

La modernidad transformó la naturaleza en "medio ambiente", un "entorno" objeto externo al ser humano, haciendo del hombre el centro del mismo, su dueño. Con ello perdimos el sentido del vínculo y del límite en las relaciones con la naturaleza. Vínculos como alianzas, ataduras, ligazones, anclaje y enraizamiento. Límite como lindero, umbral que no se cruza, valor límite de donde emergen dos grandes dimensiones que revelan esta relación: la que hace de la naturaleza un objeto y la que la transforma en sujeto.

Las últimas teorías científicas también ofrecen un nuevo entendimiento de la relación entre los seres humanos y su entorno. El supuesto de que nuestra especie es distinta e inherentemente superior a otras formas de vida o de que tenemos un lugar y una función privilegiados en el cosmos no tiene ninguna base científica (ONU, 2012).

En el abordaje actual, el paradigma ambiental completa la teoría de los derechos. Esta nueva "ontología" da lugar al surgimiento de deberes de protección de los bienes colectivos y a límites en el ejercicio de los derechos individuales que surgen cuando afectan al bien colectivo (ambiente) de modo irreversible (Lorenzetti, 2008). Es este el estadio de la mayoría de las leyes ambientales, que en última instancia, no hacen más que regular la velocidad a la cual la destrucción del medio ambiente puede llevarse a cabo.

Con ello, buena parte de los derechos humanos resultan incompletos, porque no logran establecer un vínculo entre la parte (el individuo) y el todo: la sociedad y la biósfera. Consecuentemente, la justicia que genera es una que se desenvuelve exclusivamente entre humanos, donde el bien ambientenaturaleza es un conjunto de objetos. Se defiende la calidad de vida de o el ambiente en función de las personas, alejados de los valores intrínsecos del ambiente ya que es parte de la perspectiva antropocéntrica.

Esas limitaciones, no han estado ajenas al Derecho Ambiental, que, como disciplina portadora del paradigma ecológico, ha encontrado resistencias en el mismo sistema jurídico prevalente, las cuales se tradujeron durante décadas, en su marginalidad académica, judicial y doctrinaria. Como heredero de dispersas disposiciones sobre el uso y explotación de los recursos naturales, sus piezas legislativas permanecieron ajenas al reconocimiento y significación de la naturaleza como sujeto de derechos.

A nivel internacional, la seguridad ecológica, no surgió sino hasta la Conferencia de Estocolmo sobre el Entorno Humano en 1972, pero signada por una visión antropocéntrica, basada en el paradigma del excepcionalismo humano, que considera que el ser humano no forma parte del medio ambiente y es el dueño del planeta. 
La Organización de las Naciones Unidas, tuvo la posibilidad de un cambio de paradigma en 1982. La iniciativa de la Estrategia Mundial para la Conservación culminó con la aprobación de la Carta Mundial de la Naturaleza. La Carta afirma que "la especie humana es parte de la naturaleza y que la vida depende del funcionamiento ininterrumpido de los sistemas naturales" (Res. AG 37/7). Desde entonces, se reconoce que la humanidad es una de las especies constitutivas de la naturaleza y que su propia existencia guarda dependencia de su simbiosis con ella, así como que toda forma de vida tiene un valor intrínseco y merece, por tanto -cualquiera que sea su utilidad-, el debido respeto por parte de la especie humana. Con ello, se incluyen los derechos de la Tierra y de todos los seres a "la vida y a existir" y a "la identidad y salud integral".

Más recientemente, una contribución a la visión biocéntrica moderada, relativa a la armonía con la naturaleza en la promoción del desarrollo sustentable, fue el reconocimiento en el documento final de la Conferencia de las Naciones Unidas sobre el Desarrollo Sostenible, de la relación entre la humanidad y la tierra, reafirmando que "la existencia humana es parte inextricable de la naturaleza".

Con la inclusión del ambiente en los derechos humanos de tercera generación, emerge el paradigma ambiental, que se basa en una idea de interacción compleja y que toma en cuenta los efectos individuales y colectivos, presentes y futuros de la acción humana (derechos de cuarta generación o generaciones futuras), que representa para los individuos, un sistema donde predominan los deberes y los límites a los derechos en razón de la protección que demanda el bien colectivo.

Progresivamente el biocentrismo, fue incorporando la mirada ecocéntrica y los valores intrínsecos, cuestionando los supuestos epistemológicos y jurídicos tradicionales que reducen la naturaleza a sus características físicas observables que posee un valor de cambio, como medida de todas las cosas.

Si la naturaleza posee valores objetivos, independientes de las valoraciones y prestación de utilidades para los seres humanos, al elenco de los conflictos ambientales de tipo distributivo y sus correlativos principios y reglas jurídicas basados en la equidad distributiva, se adicionan conflictos ontológicos que requieren ponderar la relación de orden intersubjetivo de los humanos con los elementos naturales no humanos.

Como se observa, los derechos de la naturaleza, así como los derechos humanos, derivan de la misma fuente de existencia, y resultan compatibles entre sí. Estos derechos no se oponen a los derechos humanos: como parte de la naturaleza, nuestros derechos se derivan de esos mismos derechos. El derecho humano a la vida carece de sentido si los ecosistemas que nos mantienen carecen del derecho a existir. No hay derechos humanos si no se cuenta con un hábitat donde el hombre pueda vivir con dignidad: esencia y núcleo duro de los derechos humanos.

Esa perspectiva ecocéntrica de los derechos propios de la naturaleza no invalida, sino que acompaña y refuerza, la perspectiva biocéntrica clásica de los derechos humanos que se extienden sobre el ambiente. Estos incluyen, por ejemplo, el derecho a un ambiente sano y ecológicamente equilibrado (Gudynas, 2010:52).

La inclusión de los derechos de la naturaleza en nuestros sistemas jurídicos, mediante el reconocimiento de los derechos fundamentales de los ecosistemas y las especies a existir, prosperar y regenerarse, implicaría que los sistemas jurídicos promuevan un balance ecológico vital, al equilibrar los derechos humanos frente a los derechos de los demás miembros de la comunidad biótica.

El reconocimiento de los derechos de la naturaleza, a que se respete integralmente su existencia y el mantenimiento y regeneración de sus ciclos vitales, estructura, funciones y procesos evolutivos -leído en clave política-, por una parte afirma una valencia emancipatoria de la naturaleza, según diversas cosmovisiones (dimensión epistemológica), pero también evidencia diferentes percepciones sobre una misma realidad (dimensión ontológica). 
En definitiva, la objeción contra el reconocimiento de la titularidad de derechos de la naturaleza en base diversas posiciones discursivas no es más que la reiteración de la primaria reacción que a lo largo de la historia se ha registrado ante cualquier noticia que le advierte al humano que no es tan centro ni tan privilegiado como se ha creído: desde Copérnico, pasando por Galileo Galilei, hasta Darwin o Freud viene pasando lo mismo. El narcisismo humano tiende a radicalizar las posiciones supuestamente defensoras del humanismo hacia un antropocentrismo que raya en los límites del exabrupto cartesiano (Stutzin, 1984).

\section{Justicia ambiental y justicia ecológica}

Si bien la distinción entre dos justicias -una ambiental y otra ecológica- es reciente, las múltiples disposiciones normativas que existen y el enfoque pluralista que promueve en nuestro caso, la propia Constitución Nacional, hacen que su relación (formal) sea dinámica y en permanente evolución, permitiendo la coexistencia del paradigma ambiental con el paradigma ecológico, basado en el reconocimiento de valores intrínsecos y derechos de la naturaleza, en el marco de una justicia ecológica intergeneracional.

Es posible identificar al menos tres aproximaciones teóricas que enraízan en el derecho ambiental argentino: En primer lugar el enfoque antropocéntrico (derecho a un ambiente sano, equilibrado, apto para el desarrollo humano art. $41 \mathrm{CN}$ ) y en segundo lugar, una visión biocéntrica intergeneracional, que reivindica concepciones más globales y solidarias de la responsabilidad humana, que abogan -en igual medida- por los deberes del hombre con la naturaleza y las generaciones venideras: "las actividades productivas deben satisfacer las necesidades presentes sin comprometer las de las generaciones futuras".

Pero también, se distinguen precisos enfoques ecocéntricos, que si bien conciben a la naturaleza como bien colectivo (objeto), su protección y restauración se fundamenta en valores intrínsecos propios de un sujeto de derechos, que permiten cosmovisiones plurales y alternativas a los planteamientos anteriores (el daño ambiental generará la obligación prioritaria de recomponer (art. $41 \mathrm{CN}$ ). En este sentido, la compensación ecosistémica comporta un tipo de restitución aplicada exclusivamente a la naturaleza.

Esta visión ecocéntrica, a modo de ejemplo, claramente se recepta en varias normas de la Ley General del Ambiente 25,675), entre cuyos objetivos está "mantener el equilibrio y dinámica de los sistemas ecológicos"; "posibilitar la sustentabilidad ecológica"(art. $\left.1^{\circ}\right)$; “(...) garantizar la dinámica de los sistemas ecológicos, mantener su capacidad de carga" (art. $6^{\circ}$ ); y la concepción de daño ambiental colectivo: "Se define el daño ambiental como toda alteración relevante que modifique negativamente el ambiente, sus recursos, el equilibrio de los ecosistemas, o los bienes o valores colectivos".

Más ampliamente, el art. 240 del nuevo Código Civil y Comercial, condensa una clara concepción ecocéntrica cuando establece que el ejercicio de los derechos individuales no sólo debe ser compatible con los derechos de incidencia colectiva, sino especialmente "no debe afectar el funcionamiento ni la sustentabilidad de los ecosistemas de la flora, la fauna, la biodiversidad, el agua, los valores culturales, el paisaje, entre otros, según los criterios previstos en la ley especial".

Dicho en otras palabras: el medio ambiente, las generaciones futuras y la naturaleza son un elemento transversal al derecho ambiental argentino.

Mientras la justicia ambiental se basa en los derechos a un ambiente sano o la calidad de vida, reconociendo las categorías jurídicas de bienes y derechos colectivos relativos al ambiente desde una perspectiva sujetos-objeto, y está destinada a resolver conflictos en una dimensión distributiva de desigual acceso social a recursos, bienes y servicios ambientales; la justicia ecológica parte de reconocer a la naturaleza desde sus valores propios: un objeto que quiere ser sujeto y generar relaciones intersubjetivas (sujeto-sujeto), que posee valores intrínsecos y sus propios derechos a que se 
respete integralmente su existencia, mantenimiento y regeneración de sus ciclos vitales, estructura, funciones y procesos evolutivos.

Si bien la recepción de esta perspectiva en los debates jurídicos es limitada, ya que prevalecen la perspectiva de la justicia ambiental, ésta no ofrece verdaderas soluciones en un contexto inter y multicultural donde otros saberes definen su comunidad de agentes morales y políticos de manera más amplia, integrando a los no-humanos, tal como ocurre con nuestros pueblos originarios.

La Madre Tierra, como una comunidad indivisible vital de seres interdependientes e interrelacionados con un destino común. La Madre Tierra es un ser vivo. La Madre Tierra es una comunidad única, indivisible y autorregulada, de seres interrelacionados que sostiene, contiene y reproduce a todos los seres que la componen, en la que cada ser se define por sus relaciones como su parte integrante.

Así como los seres humanos son titulares de derechos humanos, todos los demás seres de la Madre Tierra también tienen derechos que son específicos a su condición y apropiados para su rol y función dentro de las comunidades en los cuales existen. En el plano procesal, es evidente que la representación de los derechos de la naturaleza no será ejercida por olivos o delfines, sino por individuos que actúan en representación de éstos, en razón que acceso a la justicia no es el acceso al tribunal sino a los derechos.

Cuando el derecho positivo emplea el verbo "reconocer" los derechos de la naturaleza, alude a realidades ya existentes, no creadas, sino sólo declaradas por el sistema jurídico, el cual las pone de manifiesto y/o las registra, a fin de formalizar los efectos jurídicos que produce su existencia.

Como todos sabemos, el reconocimiento de derechos no proviene de un acto de conocimiento, no depende de la lógica o de la teoría jurídica, sino de la política y de los equilibrios de poder. La lucha por los derechos de la naturaleza es por eso, no sólo una lucha jurídica, sino política.

\section{Justicia ecológica intergeneracional}

Una aproximación a reglas de justicia entre los seres humanos de diferentes generaciones, puede ser entendido bajo el principio del igualitarismo diacrónico (Pontara, 1996:106), por el que los intereses de los humanos de la generación presente no cuentan más que los de los humanos de generaciones futuras $\mathrm{y}$, en consecuencia, los intereses de todos ellos deberán ser tenidos en cuenta con independencia del momento temporal en que vivan los portadores de esos intereses.

Como hemos visto, el paradigma de la justicia ambiental, aún transita la cornisa de la división naturaleza-cultura como propiedades de la realidad, con un lenguaje que aún no traduce la estrecha relación intersubjetiva que se establece entre determinado pueblo y su entorno.

Como contrapartida, el paradigma de la justicia ecológica recepta un giro ontológico que se aparta del proceso de ordenación y categorización propio de la cultura dominante. La otredad cultural "corresponde a una forma de vida particular de ser, ver y actuar en el mundo", constituida a partir de la cosmovisión y valores espirituales que emanan de una estrecha relación intersubjetiva de pueblos con sus territorios y recursos naturales, en especial los aspectos colectivos de esa relación.

Si aceptamos que la ética tiene algo que ver con la debilidad de los vulnerables y con las desigualdades de poder, y la naturaleza no escapa a esa doble situación, también las relaciones intergeneracionales son un asunto que interesa extraordinariamente a la ética, pero también al derecho.

Con ello, la asimetría sincrónica de la relación intergeneracional humana se traslada también, a los derechos humanos para la protección de los aspectos no humanos del medio ambiente. La aplicación de las obligaciones de derechos humanos a retos ambientales especialmente apremiantes, como el cambio climático, los conflictos armados y los desplazados por motivos ambientales, corren el riesgo 
de dejar de lado importantes aspectos que no se pueden reducir con facilidad a las necesidades y los intereses humanos (derechos de quinta generación o derechos de la naturaleza).

Es que son las poblaciones humanas las que son interdependientes del mundo natural -y no al contrario- y las que deben asumir las consecuencias de sus acciones y omisiones con la naturaleza. Se trata de entender esta nueva realidad sociopolítica con el objetivo de lograr una transformación, así como ha ocurrido antes con los derechos civiles y políticos (primera generación); los económicos, sociales y culturales (segunda generación), y los ambientales (tercera generación).

Las futuras generaciones (cuarta generación), se presentan vulnerables con respecto a nosotros. Estamos por completo fuera de su poder causal, mientras que ellas se hallan sometidas al nuestro. Para ello, debemos mirar a los pueblos Aymaras, quienes ponen al futuro siempre atrás, y adelante ponen al pasado, porque es el que enseña el camino.

Es hora que la naturaleza sea emancipada de su sola condición de hábitat de la especie humana, para concebirla como comunidad de seres vivientes interdependientes unos de otros, donde la justicia con la naturaleza debe ser aplicada más allá del escenario y de la reducida escala humana, para velar por la supervivencia de esta comunidad de seres vivientes.

\section{Reflexiones finales}

El sentido de los vínculos y límites jurídicos con la naturaleza, como componente ontológico del paradigma ecológico, integran tímidamente nuestro sistema jurídico. Pero aún desconocen a la naturaleza como un orden ontológico y una organización material de la que emerge la vida. Persiste en el derecho ambiental, la prevalencia de la naturaleza cosificada como soporte de recursos naturales, materias primas de un proceso productivo, que en el mejor de los supuestos, presta servicios ambientales y se instituye como condición de sustentabilidad de todo orden económico y social.

Los precedentes normativos y jurisprudenciales mencionados, sólo marcan una tendencia mundial cuyos resultados concretos requieren ser ponderados, pues debaten uno de los postulados básicos del dualismo moderno: la reducción de la naturaleza a sus propiedades físicas observables, sustituyéndolo por modelos ontológicos distintos que bajo el paradigma antropocéntrico, tradicionalmente son descartados por ser "irreales", simbólicos o míticos.

El lenguaje del derecho reconoce así, una cierta pluralidad y autodeterminación ontológica, atribuyendo propiedades a elementos naturales y capacidades de relacionamiento sujeto/sujeto, que reclaman una nueva hermenéutica jurídica.

Se trata de un diálogo difícil, donde esos vínculos y límites jurídicos con la naturaleza se traducen en conceptos jurídicos que adquieren un sentido eminentemente político, que tiene como punto de partida el conocimiento de la alteridad de la naturaleza en tanto que superación de su imagen cosificada. Es que la verdad y las formas jurídicas que le corresponden se desprenden y se construyen dentro de formas de saber y formas de poder (Foucault, 1995).

Se requiere entonces, una verdadera ética de la vida y para la vida, desde donde se asume que el hombre no sólo es titular de derechos humanos, sino igualmente titular de responsabilidades que deben ser asumidas individual y colectivamente. Un sistema de gobernanza, podría decirse, basado en un estado de derecho ecológico fundado en un sentido transformado de democracia, en el que tanto las personas como las comunidades acepten su condición de ciudadanos ecológicos del mundo y su responsabilidad de respetar los complejos engranajes de la biósfera. Este tipo de democracia restablecería los vínculos de las personas con los fundamentos ecológicos que las sustentan (ONU, 2012). 
El diálogo entre el derecho y la ecología conduce a una ecologización del derecho y a la consecuente juridización de la ecología" (Ost, 1996:109), a fin que el sistema jurídico sea permeado por una comprensión profunda de la complejidad y procesualidad de los sistemas ambientales.

La historia de los derechos de la naturaleza, como la lucha por los derechos, es un profeta con la mirada vuelta hacia atrás: por lo que fue, y contra lo que fue, anuncia lo que será.

\section{Bibliografía}

Cormac, C. (2011). ¿Tienen los humanos legitimación para negarle derechos a la naturaleza? En Derechos de la Naturaleza y la Naturaleza de sus Derechos, Serie Justicia y Derechos Humanos, Quito, Ecuador.

Crutzen, P. J. y Stoermer E. F. (2000). The Anthropocene. Global Change Newsletter, 41, 2000.

Foucault, M. (1995). La verdad y las formas jurídicas. Barcelona: Gedisa.

Grupo intergubernamental de expertos sobre el cambio climático (IPCC) (2014). Climate Change 2014: Impacts, Adaptation, and Vulnerability.

Gudynas, E. (2010, julio-diciembre). La senda biocéntrica: valores intrínsecos, derechos de la naturaleza y justicia ecológica (CLAES). Tabula Rasa, 13, 45-71. Bogotá, Colombia.

Lovelock, J. (2006). The Revenge of Gaia: Earth's Climate Crisis and the Fate of Humanity. New York: Basic Books.

Morales Lamberti, A. (2017). Derechos de la Naturaleza y justicia ecológica. En Pastorino, L. (Dir). Ciclo de Curso de Postgrado $4^{\circ}$ Curso: Las Formas de la Naturaleza y sus Formas de Regulación. La Plata: UNLP.

Morales Lamberti, A. (2016). Dimensión social y colectiva de los derechos humanos: relacionalidad e influencias del paradigma ambiental. En Cafferatta, N. (Dir). La Dimensión Social del Derecho Ambiental (pp. 407-426). Santa Fe: Rubinzal Culzoni.

ONU (2012, 17 agosto). Informe del Secretario General: Armonía con la Naturaleza. A/67/317.

Ost, F. (1996). Naturaleza y Derecho. Para un debate ecológico en profundidad. Bilbao: Mensajero.

PONTARA, G. (1996). Ética y generaciones futuras. Barcelona: Ariel.

Stone, C. D. ([1972] 2010). ¿Should Trees Have Standing? Law, Morality and the Environment. New York: Oxford University Press.

Stutzin, G. (1984). Un imperativo ecológico: reconocer los derechos de la naturaleza. Ambiente y Desarrollo, I (1), 97-114. 


\title{
CAMBIO CLIMÁTICO Y POPULISMOS EN AMÉRICA LATINA: UN ANÁLISIS COMPARATIVO DE LOS POSICIONAMIENTOS DE ARGENTINA, ECUADOR, CHILE Y BRASIL EN EL CAMINO AL ACUERDO DE PARÍS DE 2015
}

\author{
CLIMATE CHANGE AND POPULISMS IN LATIN AMERICA: \\ A COMPARATIVE ANALYSIS OF THE POSITIONS OF ARGENTINA, ECUADOR, CHILE \\ AND BRAZIL IN VIEW OF THE 2015 PARIS AGREEMENT
}

Jorge Foa Torres

(Consejo Nacional de Investigaciones Científicas y Técnicas / Argentina) jorgefoatorres@gmail.com

Recibido: 11/09/2018

Aprobado: 30/10/2018

\begin{abstract}
RESUMEN
Frente a diversas críticas a lo populista que suelen pronunciarse desde el campo ambiental, este trabajo presenta un análisis comparativo de los posicionamientos Argentina, Ecuador, Chile y Brasil en las recientes negociaciones internacionales desde la Conferencia de las Partes de Copenhague hasta el Acuerdo de París de 2015.

El artículo se ordena en función de las siguientes preguntas de investigación: ¿de qué manera las prácticas discursivas enunciadas en los foros internacionales relativos a cambio climático por Argentina, Ecuador, Chile y Brasil significan a los problemas ambientales globales, sus posibles soluciones y al rol de los Estados Latinoamericanos en tales procesos? ¿Cuáles diferencias y similitudes entre los posicionamientos discursivos de esos Estados es posible identificar? ¿De qué manera tales posicionamientos y coaliciones se vinculan a los procesos populistas latinoamericanos recientes?

La conclusión principal es que los procesos populistas tienden a tomar posicionamientos más radicalizados o antagónicos en cuanto al reclamo a los países desarrollados por la asunción de sus responsabilidades históricas en la generación del calentamiento global. Mientras los procesos no populistas tienden a hacer mayor énfasis en posturas pragmáticas facilitadoras del logro de acuerdos internacionales.
\end{abstract}

Palabras clave: Teoría política del discurso. Política ambiental. Responsabilidades comunes pero diferenciadas. Financiamiento climático.

\section{ABSTRACT}

In front of different critiques to the populist that usually pronounced from the environmental field, this paper presents a comparative analysis of the positions of Argentina, Ecuador, Chile and Brazil in the recent international negotiations regarding the Paris Agreement of 2015.

The work is based on the following research questions: how do the discursive practices enunciated in the international forums related to climate change by Argentina, Ecuador, Chile and Brazil mean global environmental problems, their possible solutions and the role of the Latin American States in such processes? What differences and similarities between the discursive positions of these States is it possible to identify? How do such positions and coalitions link to recent Latin American populist processes? 
The main conclusion is that populist processes tend to take more radicalized or antagonistic positions on the claim to developed countries for the assumption of their historical responsibilities in the generation of global warming. While non-populist processes tend to place more emphasis on pragmatic positions that facilitate the achievement of international agreements.

Keywords: Political Discourse theory. Environmental politics. Common but differentiated responsibilities. Climate financing.

\title{
Introducción
}

Diferentes críticas a lo populista han sido enunciadas desde el campo ambiental en los últimos tiempos. Veamos, en 1995 en pleno auge de la década neoliberal en América Latina, la por entonces economista superior del Banco Mundial Piritta Sorsa afirmaba que:

\begin{abstract}
En buena parte del debate político populista de hoy en día, el comercio (o mejor dicho, el libre comercio) se ha convertido en la causa de muchas deficiencias observadas o de los problemas económicos, trátese del aumento del desempleo o el deterioro del ambiente. El debate suscitado en EEUU en torno a los tratados de libre comercio muestra cuán lejos pueden llegar los argumentos populistas en contra del comercio (1995:101).
\end{abstract}

Mucho más cerca en el tiempo en una reciente publicación de la Fundación Verde Europea (GEF) de 2011 se afirmaba que

...el populismo plantea para un gran desafío para los partidos verdes en toda Europa en cuanto a revisar sus propias narrativas y conceptos políticos (...) Si ellos tienen la intención de ser importantes para el futuro de Europa, tendrán que ofrecer una alternativa real al populismo (Meijers, 2011: 12).

Desde América Latina, recientemente Maristella Svampa ha denunciado cierta articulación entre los populismos "de alta intensidad" en la región y el "paradigma extractivista". Aquellos basados en "una política confrontativa que engloba, en su lectura conspirativa, a las organizaciones ambientalistas y a sectores indígenas que hoy luchan contra el avance del extractivismo", se caracterizan por haber renunciado a la "dimensión emancipatoria de la política y la evolución hacia modelos de dominación de corte tradicional" (Svampa, 2016: 80/84).

Mientras otros orientan sus cuestionamientos a las experiencias latinoamericanas de izquierda y su "atracción populista por capitalizar los beneficios inmediatos de la explotación de los recursos naturales durante los ciclos electorales" (Edwards \& Timmons Roberts, 2015: 171).

Pero en este marco ¿a qué experiencias o posicionamientos políticos se hace referencia al nombrarlos como populistas? ¿Es lo populista una herramienta para identificar a las posturas proteccionistas o contrarias a los tratados libre comercio como señala Sorsa? ¿O acaso el populismo es esencialmente una amenaza para la causa ambiental y, por ende, para la lucha contra el cambio climático?

Es ya harto conocido y debatido el problema de la polisemia del término populista y la dificultad que reside en la ciencia política para precisar su definición ${ }^{1}$. No obstante, el objetivo de este trabajo no pasa por intervenir en tales discusiones, sino en dar cuenta de los posicionamientos efectivamente adoptados por las experiencias políticas populistas latinoamericanas. Especialmente en su diferenciación con los asumidos por países no populistas a los fines de echar luz a las relaciones entre la cuestión populista y la política ambiental.

La perspectiva para el análisis es la de la teoría política del discurso ${ }^{2}$ que articula elementos del posmarxismo y posfundacionalismo con el objetivo de comprender críticamente las prácticas socio-

\footnotetext{
${ }^{1}$ Entre otros: Laclau, 2008; Panizza, 2005; Stavrakakis, 2015; Rovira Kaltwasser, 2014a.

${ }^{2}$ Entre otros: Laclau \& Mouffe, 2004; Glynos \& Howarth, 2007.
} 
discursivas. Específicamente, este enfoque permite hacer énfasis en el carácter constitutivamente dividido de la realidad socialmente construida, es decir en la imposibilidad del acceso a un orden social pleno o a una sociedad finalmente reconciliada consigo misma (Laclau, 2000; Glynos \& Howarth, 2007). A partir de ello, especial interés se pone desde esta epistemología en el antagonismo social, en tanto síntoma o signo de esa imposible sutura o superación definitiva de la división social y los diferentes modos en que se manifiesta.

De tal manera, esta perspectiva no parte del supuesto de la existencia actual o futura de un consenso social, régimen, arquitectura u orden sobre el cual devienen determinados conflictos o desacuerdos y respecto del cual el cientista social debiera efectuar su labor de descripción y explicación. Por el contrario, todo régimen o arquitectura internacional se construye, desde la mirada posmarxista, sobre ciertos antagonismos estableciendo determinadas maneras de tratarlos, invisibilizarlos, reprimirlos o negarlos.

Por lo tanto, no se busca dar cuenta del nivel de efectividad de los regímenes internacionales sobre cambio climático sino comprender e identificar las diferentes lógicas políticas en pugna que los estructuran. Evitando caer en miradas prescriptivas que buscan (incluso en el caso del cambio climático) la superación final del antagonismo Norte-Sur en el terreno de las relaciones internacionales.

En este marco, la tesis de este trabajo es que los populismos latinoamericanos tienden, antes que a adoptar posturas poco ambiciosas o incluso negacionistas del cambio climático, a proponer soluciones vinculadas con la transformación más o menos radical del sistema económico-político internacional. Tales propuestas difieren profundamente de las derechas gobernantes y/o de las experiencias no populistas de la región que privilegian el arribo a consensos para el abordaje de la mitigación y adaptación al cambio climático, relegando la consideración de la historia de las emisiones de carbono y su vinculación con las relaciones de poder Norte-Sur.

\section{Los posicionamientos de Ecuador, Argentina, Chile y Brasil}

En este trabajo nos centraremos en las posturas de cuatro países latinoamericanos: Ecuador, Argentina, Brasil y Chile. Las fuentes documentales analizadas remiten, principalmente, a los discursos de mandatarios y representantes de cada país.

La selección de estos cuatro casos nos permite abordar el posicionamiento de las dos mayores economías de América del Sur, por un lado, y de dos países que integran activamente dos organismos regionales de gran relevancia en las negociaciones sobre cambio climático como la Alianza del Pacífico (Chile) y el ALBA (Ecuador). Pero fundamentalmente, nos posibilita comparar las diferentes miradas de las experiencias populistas, encarnadas en los casos de Ecuador y Argentina ${ }^{3}$, y no populistas, en Brasil y Chile.

Tanto los gobiernos de Néstor Kirchner y Cristina Fernández en Argentina como el de Rafael Correa en Ecuador suelen ser caracterizados por la literatura politológica como populistas. Ya sea que tales estudios asuman definiciones operativas del populismo ${ }^{4}$ o miradas que ven en la división maniquea de

\footnotetext{
${ }^{3}$ No obstante, cabe aclarar que, en el caso de Argentina, se produjo la sucesión presidencial durante la realización de la COP 21 cuestión que produjo cierto desplazamiento en la posición de nuestro país, aspecto que abordaremos más adelante.

${ }^{4}$ En base a la teoría de la hegemonía de Ernesto Laclau, la teoría política del discurso ha desarrollado un importante volumen de estudios teóricos y empíricos acerca de la cuestión populista: Laclau, 2006, 2008; Stavrakakis, 2015; entre otros. Una definición "operativa" o formal de populismo suele identificar una serie de elementos propios de la forma populista, tales como: la interpelación y articulación en torno al "pueblo" como punto nodal; una representación predominantemente antagonista de lo social, dicotomizando a la sociedad en dos grandes bloques; la articulación equivalencial de demandas populares insatisfechas; la emergencia y centralidad de la figura del líder en el lugar del ideal.
} 
la sociedad a su característica invariante ${ }^{5}$. Por otro lado, los procesos políticos recientes en Brasil y Chile, en relación con los gobiernos de Michelle Bachelet, Dilma Roussef y Luiz Inácio "Lula" da Silva, tienden a ser identificados como "izquierdas moderadas" (Rovira Kaltwasser, 2014b) o en una "posición intermedia" entre populismo e institucionalismo (Laclau, 2006).

El análisis comparativo se basa en la construcción de ejes de problematización que permiten identificar regularidades y variaciones de sentido tanto en cada uno de los casos como entre los casos estudiados. Es decir, posibilitan la caracterización del posicionamiento de cada país a través de la identificación de los puntos nodales que ciñen la significación de sus posturas en relación diferencial con otras identidades político-ideológicas en las negociaciones en cuestión. En orden a profundizar el problema de investigación, es decir, distinguir las prácticas discursivas de las experiencias populistas latinoamericanas recientes respecto de las derechas o experiencias no usualmente calificadas por la literatura politológica y de relaciones internacionales como "populistas".

Los ejes de problematización utilizados fueron:

a) Las coaliciones y grupos de negociación más relevantes política e ideológicamente de los que formaron parte: si bien los países de la región casi en su totalidad integran el Grupo de países en desarrollo más grande de Naciones Unidas denominado G 77 + China (México abandonó el grupo en el año 1994 para integrarse a la Organización y el Cooperación para el Desarrollo Económico: OCDE), también forman parte de subgrupos relevantes en las negociaciones como la Asociación Independiente de América Latina y el Caribe (AILAC), el Grupo de Países en Desarrollo con Posiciones Afines (LMDC, por sus siglas en inglés: Like Minded Group of Developing Countries), el Grupo BASIC (Brasil, Sudáfrica, India y China) y la reciente Coalición de Gran Ambición creada en París en 2015.

b) Los organismos de integración regional o extrarregional que integran: que poseen relevancia en cuanto a las concepciones político-ideológicas a las que adhieren en determinados momentos. Mientras los países de la AILAC están más vinculados a la Alianza del Pacífico, ciertos países latinoamericanos del LMDC se relacionan a la Alianza Bolivariana para los Pueblos de Nuestra América (ALBA).

c) Naturaleza del problema del cambio climático: si énfasis en las posturas está puesto en el carácter político-económico del problema, en su entidad técnico-científica o en su carácter moral.

d) Postura frente al Principio de Responsabilidades Comunes pero Diferenciadas ${ }^{6}$ : consagrado en $^{2}$ la Convención Marco de Naciones Unidas sobre Cambio Climático de $1992^{7}$ abrió el camino a diferentes interpretaciones. Los polos de esas interpretaciones varían entre posiciones fuertes vinculadas a las responsabilidades históricas en las emisiones de carbono y las pragmáticas que priorizan el consenso a cualquier costo.

e) Financiamiento y tecnologías para enfrentar al cambio climático: especialmente el modo en que los países más industrializados, y entre ellos con mayores responsabilidades históricas, debieran contribuir a financiar las medidas de mitigación y adaptación en los países menos desarrollados. Como así también, la transferencia tecnológica necesaria para el logro de una progresiva descarbonización de las economías del mundo.

f) Adaptación versus mitigación: es relevante advertir el énfasis que cada país pone ya sea a la mitigación o a la adaptación al cambio climático. Asimismo, el carácter o no voluntario de las medidas de mitigación para los países en desarrollo es un punto de interés en este eje de problematización, así como también las implicancias en términos de relaciones comerciales que el régimen internacional de lucha contra el calentamiento global puede conllevar.

\footnotetext{
${ }^{5}$ Desde este enfoque se "define al populismo como un particular discurso o ideología, el cual está basado en una distinción maniquea entre el pueblo puro y la elite corrupta, por la cual la primera es vista como una entidad virtuosa y la segunda como la fuente de todo lo malo" (Rovira Kaltwasser, 2014a: 496). Entre otros: De la Torre, 2014; Mudde \& Rovira, 2012. ${ }^{6}$ En adelante PRCPD.

7 "Las Partes deberían proteger el sistema climático (...) sobre la base de la equidad y de conformidad con sus responsabilidades comunes pero diferenciadas y sus respectivas capacidades" (NU, 1992: art. 3).
} 
g) Propuestas para hacer frente a la problemática: desde la implementación de mecanismos técnicos y de gobernanza ambiental o economía verde a la creación de tribunales internacionales de justicia ambiental y el reconocimiento de la deuda ecológica de los países del Norte.

A continuación, se desarrollarán los aspectos más destacados de los posicionamientos de cada uno de esos países en las últimas Conferencias de las Partes (en adelante COP) desde la COP 15 de Conpenhague hasta el Acuerdo de París de 2015, que luego se sintetizarán en una tabla comparativa.

Ecuador. En los últimos años Ecuador ha sido caracterizado como un inesperado pionero del desarrollo bajo en carbono (Edwards \& Timmons, 2015). Una serie de propuestas novedosas efectuadas por el país en los foros internacionales sostienen tal afirmación: el Proyecto Yasuní-ITT ${ }^{8}$, la creación de una Corte Internacional de Justicia Ambiental y la Declaración Universal de los Derechos de la Naturaleza junto a Bolivia y a la Conferencia Mundial de los Pueblos sobre el Cambio Climático y los Derechos de la Madre Tierra (Correa, 2015; Ministerio de Comunicación de Bolivia, 2015).

Pero lo que subyace al planteo de Ecuador es la crítica radical al capitalismo financiarizado: que la lucha contra el cambio climático sea la condición de posibilidad para la emergencia de una nueva estructura financiera internacional (Falconí, 2009; Correa, 2015) basada en acuerdos internacionales vinculantes que permitan hacer efectivas las responsabilidades de los países más industrializados en el calentamiento global mediante la asunción de sus deudas ecológicas para con el Sur: "El reconocimiento de la Deuda Ecológica por responsabilidades históricas de los países ricos, permitiría operativizar el concepto de las responsabilidades comunes pero diferenciadas" (Falconí, 2009).

En esta línea, Ecuador se ha posicionado en contra de que el financiamiento y las tecnologías para la mitigación sirvan a la profundización de la dependencia de los Países del Sur. Por un lado, ha planteado que tales tecnologías debieran ser declaradas internacionalmente "como bienes públicos globales, garantizando su libre acceso" (Correa, 2015). Por otro, el desarrollo de "programas innovadores sobre alivio de la deuda externa" (Sánchez \& Zambrano, 2010) y que el Fondo Verde para el Clima no se constituya en un nuevo medio para el crecimiento de las deudas externas soberanas.

En cuanto a la relación entre mitigación y adaptación, Rafael Correa ha formulado una idea por la cual se busca limitar cualquier exigencia a los países menos desarrollados para la adopción forzosa de políticas, instrumentos y tecnologías: "No será posible conservar nada en los países más pobres, si esto no tiene como resultado una mejora clara y concreta en el nivel de vida de las poblaciones" (Presidencia República del Ecuador, 2015). En este sentido, Fander Falconí ha afirmado que los países no-industrializados son "como fumadores pasivos" y que, por lo tanto, "La reducción de emisiones deben realizarla los países que están por encima del promedio mundial tolerable, que son los que han producido histórica y actualmente la mayor parte de dióxido de carbono" (Falconí, 2009).

Junto a Bolivia, Ecuador ha llevado al mundo el concepto del Sumak Kawsay (Buen Vivir) de los pueblos originarios andinos $\mathrm{y}$ ha sostenido este posicionamiento formando parte de diferentes coaliciones como el G 77 + China y el LMDC en las negociaciones de cambio climático. Asimismo, formando parte activa del ALBA ha llevado sus propuestas al seno de la Unión de Naciones Suramericanas (UNASUR) y de la Comunidad de Estados Latinoamericanos y Caribeños (CELAC).

Argentina. También nuestro país sostuvo posiciones críticas, aunque más moderadas que la de Ecuador, respecto de la desigualdad del sistema internacional y la reticencia de los países del Norte a asumir sus responsabilidades. Cabe recordar las afirmaciones del por entonces Canciller Taiana en la COP 15 de Copenhague: "los países desarrollados pretenden transferir su inmensa deuda ambiental y

\footnotetext{
${ }^{8}$ Que proponía evitar la explotación petrolera en unos de los sitios de mayor diversidad del Globo, el Parque Nacional Yasuní, a cambio de un aporte de U\$ 3.600 millones de la comunidad internacional. La propuesta finalmente fracasó en 2013 al recibir solamente USS 129 millones de aportes y Rafael Correa anunció la explotación de petróleo afirmando que "El mundo nos ha fallado (...) el factor fundamental en el fracaso es que el mundo es una gran hipocresía y la lógica que prevalece no es la de la justicia, sino la del poder" (Mena Erazo, 2013).
} 
las obligaciones que ésta conlleva a los países en desarrollo. Ésta es la razón principal que impide alcanzar un consenso" (Discurso de Taiana, 17 de diciembre de 2009). En la misma línea, en el marco de la COP 20 de Lima, el por entonces Vicepresidente Amado Boudou afirmaba que "El abordaje del cambio climático no puede desvincularse de la agenda del desarrollo, la erradicación de la pobreza y mejora de la distribución del ingreso entre países" (Discurso del Vicepresidente Amado Boudou, 10 de diciembre de 2014).

En ese sentido, para Argentina la interpretación del PRCPD debía efectuarse en base al principio de responsabilidades históricas y el derecho al desarrollo de los países del Sur: "La vigencia del principio de responsabilidades históricas, contenido en el párrafo preambular 3, será firmemente sostenida por la República Argentina como una de las formas de asegurar que los países en desarrollo puedan continuar sus procesos de desarrollo, en especial, en lo que se refiere a erradicación de la pobreza y promoción de la inclusión social” (Visión de la República Argentina, abril de 2012).

Asimismo, Argentina se pronunció en favor de la adopción de un mecanismo de pérdidas y daños para hacer efectiva la responsabilidad de los países del Norte, la transferencia masiva de tecnologías hacia el sur que, por un lado, eviten la destrucción de empleos y, por otro, no se basen en la adquisición de patentes o productos tecnológicos terminados sino en la participación en esos desarrollos.

Para sostener estas posiciones, Argentina formó parte del G77 + China pero, principalmente, se articuló a los posicionamientos de países del ALBA en la Coalición LMDC. No obstante, durante la COP 21 de París en diciembre de 2015 se produjo el cambio de signo político en el Gobierno con la asunción de Mauricio Macri por la Alianza Cambiemos. Lo que significó un importante giro en el posicionamiento de nuestro país, encabezado por el enviado presidencial Juan Carlos Villalonga ${ }^{9}$, orientado a "bajar los decibeles" de los planteos que el país venía adoptando en las negociaciones previas. Específicamente, en la apertura a la articulación con "un más amplio espectro de países" para aprovechar las "oportunidades" de formar parte de otras coaliciones que promuevan acuerdos climáticos "pragmáticos" (Nodal, 14 de diciembre de 2015; Clarín, 8 de diciembre de 2015).

Chile. Si bien ha afirmado el PRCPD, Chile ha asumido desde hace varios años una postura que prioriza el consenso y el acuerdo entre las partes: "Hacemos un llamado planteando un caso proactivo de desarrollo y de protección del clima (...) un relato constructivo que ponga de relieve la cooperación, desafiando las lógicas imperantes de Norte contra Sur, o de grande contra pequeño, las que solo antagonizan e impiden la generación de consensos" (Ministra María Ignacia Benítez, Segmento de Alto Nivel COP 18, citado en: Clavería, 2016).

De tal modo, la postura de Chile pone el acento, dada la vulnerabilidad de los países latinoamericanos al cambio climático, en la necesidad de adoptar medidas urgentes para el logro de un "acuerdo jurídicamente vinculante pare la reducción de emisiones", en el establecimiento del Fondo Verde para el Clima y la adopción de "compromisos más ambiciosos" por parte de todos los países (Intervención de Chile Plenario, Segmento Alto Nivel, COP 17). Este último punto es nodal para entender la diferencia en el posicionamiento chileno en su promoción de una interpretación flexible del PRCPD basado en que, como ha señalado Ricardo Lagos ${ }^{10}$, "las emisiones acumuladas de los países de ingreso medio en América Latina y el mundo representan un porcentaje significativo de las emisiones globales y nuestras contribuciones al cambio climático global no pueden ser ignoradas" (Lagos, 2015: x). Por lo tanto, Chile junto a AILAC es promotor de una postura pragmática que fortalezca "la acción climática por parte de todos los países antes que perpetuar una competencia hasta el fondo" (Lagos, 2015: xii), zanjando de esa manera las tensiones y antagonismos Norte-Sur.

\footnotetext{
${ }^{9}$ Villalonga, actual Diputado Nacional por Cambiemos, se auto denomina "diputado verde" y es un destacado militante de la causa ambiental que ha formado parte de organizaciones no gubernamentales como Greenpeace y Los Verdes.

${ }^{10}$ Ex presidente chileno entre los años 2000 a 2006 y enviado especial de Naciones Unidas para el cambio climático entre 2008 y 2010).
} 
La propuesta principal, en tal sentido, pasa por establecer, por un lado, mecanismos de transparencia en tanto "fundamento central de toda acción climática" y, por otro, de mostrar al mundo compromisos y presentaciones de informes y comunicaciones nacionales (Discurso de Michelle Bachelet en COP 22). Es decir, de constituirse en un caso ejemplar de la gobernanza contra el cambio climático hacia adentro de sus fronteras y, al mismo tiempo, de constituirse en un actor proactivo o "broker" del consenso ambiental internacional.

Además de AILAC, Chile promovió la creación de la denominada "Iniciativa Chile-Brasil" para el apoyo de la COP 20 de Lima y en aras del Acuerdo finalmente alcanzado en París en $2015^{11}$. Tal iniciativa fue determinante, junto al "Diálogo de Cartagena" y la "Alianza de Amigos del Futuro" para el fortalecimiento de la Coalición de Gran Ambición que finalmente en 2015 logrará el Acuerdo de París quebrando la oposición del LMDC (Hirsch, 2016).

Brasil. Para algunos autores Brasil es un país que ha adoptado, a lo largo de los quince años de negociaciones climáticas, posiciones ambiguas o contradictorias. En ciertos momentos como país líder de las negociaciones y en otras como un "spoiler" o saboteador de acuerdos. Al tiempo que se suele destacar sus logros en materia de reducción de emisiones a partir de reducción de deforestación y sus posturas "progresistas" al promover compromisos internacionales ambiciosos, también se señala su tendencia a "bloquear el progreso en defensa de su soberanía nacional bajo la bandera de los principios básicos de la CMNUCC" (Edwards \& Timmons, 2015: 69).

Pero en este trabajo buscamos no reducir los posicionamientos al par progresistas/saboteadores ni a asumir el supuesto de tal oposición: que la efectividad de la lucha contra el cambio climático depende más de la adopción de instrumentos de gobernanza climática que de la transformación del sistema político-económico internacional. Por lo tanto, nos interesa dar cuenta de la posición brasilera en base a los ejes de problematización antes propuestos.

Brasil ha sido un país pionero en la defensa del posicionamiento de los países menos desarrollados como promotor del principio de responsabilidades históricas de los países más industrializados, ya sea integrando el G77 + China o la Coalición BASIC. Como señalaba Luiz Inazio Lula da Silva en la COP 15 , el hecho de que ciertos países emergentes hayan experimentado en los años 2000 un crecimiento y desarrollo importante no se debe perder de vista que los países del BASIC siguen teniendo altos niveles de pobreza, por lo cual se debe "mantener el desarrollo de los países en desarrollo" porque "Pasamos un siglo sin crecer, mientras que otros crecían mucho. Ahora que empezamos a crecer, no es justo que volvamos a hacer el sacrificio" (Discurso do presidente Luiz Inácio Lula da Silva, COP-15).

Como así también, que la causa climática y la transparencia demandada por los países del Norte para el financiamiento no deben ser utilizadas para la "intrusión" de éstos en los países más pobres ya que "La experiencia que tenemos, ya sea del Fondo Monetario Internacional o del Banco Mundial en nuestros países, no es recomendable que continúe en el siglo XXI" (Discurso do presidente Luiz Inácio Lula da Silva, COP-15).

No obstante, la articulación de Brasil a la mencionada Iniciativa Chile-Brasil junto a la Alianza de Amigos del Futuro y la Coalición de Gran Ambición lo ha acercado en los últimos años a las posturas de AILAC en alianza con países como Chile y México. En una postura mucho más conciliadora que su antecesor, Dilma Roussef señalaba en la COP 21 que el PRCPD es piedra angular del Acuerdo y que: "Corresponde al acuerdo de París propiciar las condiciones para que todos los países en desarrollo puedan recorrer los caminos de la economía de bajo carbono superando la extrema pobreza y reduciendo las desigualdades".

\footnotetext{
${ }^{11}$ Esta iniciativa cuenta con el apoyo de la CEPAL, el PNUMA y el financiamiento de la Comisión Europea a través del programa EUROCLIMA y de la cooperación francesa (EUROCLIMA, 24 septiembre 2014).
} 
Tabla comparativa: posicionamientos de Ecuador, Argentina, Chile y Brasil en recientes negociaciones internacionales sobre cambio climático

\begin{tabular}{|c|c|c|c|c|}
\hline Países & \multirow[b]{2}{*}{ Ecuador } & \multirow[b]{2}{*}{ Argentina } & \multirow[b]{2}{*}{ Chile } & \multirow[b]{2}{*}{ Brasil } \\
\hline $\begin{array}{l}\text { Ejes de } \\
\text { problematización }\end{array}$ & & & & \\
\hline $\begin{array}{l}\text { 1) Coaliciones y grupos } \\
\text { más relevantes que } \\
\text { integran }\end{array}$ & G77 + China, LMDG & $\begin{array}{l}\text { G77+China, LMDG } \\
\text { (desde el cambio de } \\
\text { Gobierno en } 2015 \\
\text { abandona el } \\
\text { LMDG) }\end{array}$ & $\begin{array}{l}\text { G77+China, AILAC, } \\
\text { Iniciativa Chile-Brasil, } \\
\text { Coalición de Gran } \\
\text { Ambición }\end{array}$ & $\begin{array}{l}\text { G77+China, BASIC, } \\
\text { Iniciativa Chile-Brasil, } \\
\text { Coalición de Gran } \\
\text { Ambición }\end{array}$ \\
\hline $\begin{array}{l}\text { 2) Organismos de } \\
\text { integración regional o } \\
\text { extra regional que } \\
\text { integran }\end{array}$ & $\begin{array}{l}\text { ALBA, UNASUR, } \\
\text { CELAC }\end{array}$ & $\begin{array}{l}\text { UNASUR, } \\
\text { CELAC, } \\
\text { MERCOSUR }\end{array}$ & $\begin{array}{l}\text { Alianza del Pacífico, } \\
\text { UNASUR, CELAC }\end{array}$ & $\begin{array}{l}\text { BRICS, UNASUR, } \\
\text { CELAC, MERCOSUR }\end{array}$ \\
\hline $\begin{array}{l}\text { 3) Naturaleza del } \\
\text { problema del cambio } \\
\text { climático }\end{array}$ & $\begin{array}{l}\text { Problema político } \\
\text { antes que técnico } \\
\text { basado en desigualdad } \\
\text { de sistema } \\
\text { internacional y } \\
\text { provocado por } \\
\text { emisiones históricas } \\
\text { de países del Norte }\end{array}$ & $\begin{array}{l}\text { Problema que no } \\
\text { debe verse aislado } \\
\text { de temas como } \\
\text { seguridad } \\
\text { alimentaria, } \\
\text { desarrollo, pobreza } \\
\text { y desigualdad entre } \\
\text { países. Causado por } \\
\text { emisiones históricas } \\
\text { de países } \\
\text { desarrollados }\end{array}$ & $\begin{array}{l}\text { Énfasis en } \\
\text { vulnerabilidad al } \\
\text { cambio climático por } \\
\text { parte de países } \\
\text { Latinoamericanos. } \\
\text { Urgencia en adoptar } \\
\text { medidas para no } \\
\text { sobrepasar los } 2 \text { grados } \\
\text { centígrados }\end{array}$ & $\begin{array}{l}\text { Causado por países del } \\
\text { Norte. Primero debe } \\
\text { asegurarse el derecho al } \\
\text { desarrollo de todos los } \\
\text { países. }\end{array}$ \\
\hline $\begin{array}{l}\text { 4) Interpretación al } \\
\text { Principio de } \\
\text { Responsabilidades } \\
\text { Comunes pero } \\
\text { Diferenciadas (PRCPD) }\end{array}$ & $\begin{array}{l}\text { Interpretación fuerte } \\
\text { en base a } \\
\text { responsabilidades } \\
\text { históricas y principio } \\
\text { de equidad. Deuda } \\
\text { ecológica de Países } \\
\text { del Norte }\end{array}$ & $\begin{array}{l}\text { Interpretación } \\
\text { fuerte en base a } \\
\text { responsabilidades } \\
\text { históricas de países } \\
\text { del Norte }\end{array}$ & $\begin{array}{l}\text { Interpretación flexible: } \\
\text { la acción climática debe } \\
\text { ser efectuada por todos } \\
\text { los países evitando } \\
\text { perpetuar el } \\
\text { antagonismo Norte-Sur }\end{array}$ & $\begin{array}{l}\text { De interpretación fuerte a } \\
\text { interpretación flexible: } \\
\text { acuerdo que permita } \\
\text { desarrollo de todos los } \\
\text { países basado en } \\
\text { economías bajas en } \\
\text { carbono }\end{array}$ \\
\hline $\begin{array}{l}\text { 5) Financiamiento para } \\
\text { enfrentar al cambio } \\
\text { climático }\end{array}$ & $\begin{array}{l}\text { Deuda ecológica de } \\
\text { países del Norte para } \\
\text { con los del Sur. } \\
\text { Cambio climático no } \\
\text { debe servir para } \\
\text { endeudamiento de } \\
\text { países pobres }\end{array}$ & $\begin{array}{l}\text { Contra } \\
\text { imposiciones de } \\
\text { países del Norte } \\
\text { que permitan } \\
\text { trasladar sus } \\
\text { responsabilidades a } \\
\text { países del Sur }\end{array}$ & $\begin{array}{l}\text { Apoya creación de } \\
\text { Fondo Verde para el } \\
\text { Clima. Énfasis en } \\
\text { transparencia en } \\
\text { financiamiento } \\
\text { climático }\end{array}$ & $\begin{array}{l}\text { En favor del } \\
\text { financiamiento, pero } \\
\text { contra intromisión de } \\
\text { organismos multilaterales } \\
\text { de crédito }\end{array}$ \\
\hline $\begin{array}{l}\text { 6) Tecnologías para } \\
\text { enfrentar el cambio } \\
\text { climático }\end{array}$ & \begin{tabular}{|l|} 
Tecnologías de \\
mitigación deben ser \\
de acceso libre. Contra \\
privatización del \\
conocimiento
\end{tabular} & $\begin{array}{l}\text { Transferencia } \\
\text { masiva de } \\
\text { tecnologías a países } \\
\text { en desarrollo }\end{array}$ & $\begin{array}{l}\text { Transferencia de } \\
\text { tecnologías ambiciosa a } \\
\text { través de financiamiento } \\
\text { de organismos } \\
\text { multilaterales de crédito }\end{array}$ & $\begin{array}{l}\text { Transferencia de } \\
\text { tecnologías en base al } \\
\text { respeto de soberanías } \\
\text { nacionales }\end{array}$ \\
\hline $\begin{array}{l}\text { 7) Adaptación y } \\
\text { mitigación al cambio } \\
\text { climático }\end{array}$ & \begin{tabular}{|l|} 
La reducción de \\
emisiones deben \\
realizarla los países \\
que están por encima \\
del promedio mundial \\
tolerable. Carácter \\
voluntario de acciones \\
de mitigación para el \\
Sur. Énfasis en
\end{tabular} & $\begin{array}{l}\text { Carácter voluntario } \\
\text { de acciones de } \\
\text { mitigación de } \\
\text { países en desarrollo } \\
\text { dependientes del } \\
\text { financiamiento } \\
\text { provisto por países } \\
\text { desarrollados. } \\
\text { Promueve incluir y }\end{array}$ & $\begin{array}{l}\text { Énfasis en mitigación } \\
\text { con acciones concretas } \\
\text { dentro de sus fronteras }\end{array}$ & $\begin{array}{l}\text { En favor de carácter } \\
\text { voluntario de acciones de } \\
\text { mitigación para países en } \\
\text { desarrollo y poderes } \\
\text { emergentes }\end{array}$ \\
\hline
\end{tabular}




\begin{tabular}{|c|c|c|c|c|}
\hline & adaptación & $\begin{array}{l}\text { dar prioridad a } \\
\text { adaptación }\end{array}$ & & \\
\hline $\begin{array}{l}\text { 8) Propuestas o vías de } \\
\text { acción para hacer frente } \\
\text { a problemática }\end{array}$ & $\begin{array}{l}\text { Nueva estructura } \\
\text { financiera } \\
\text { internacional. } \\
\text { Declaración Universal } \\
\text { de los Derechos de la } \\
\text { Naturaleza. } \\
\text { Tecnologías de } \\
\text { mitigación declaradas } \\
\text { bienes públicos } \\
\text { universales de libre } \\
\text { acceso. Mecanismos } \\
\text { para hacer efectivas } \\
\text { las pérdidas y daños y } \\
\text { la responsabilidad de } \\
\text { emisores históricos de } \\
\text { carbono. Corte } \\
\text { Internacional de } \\
\text { Justicia Ambiental. }\end{array}$ & $\begin{array}{l}\text { Adecuación a } \\
\text { tecnologías no por } \\
\text { adquisición de } \\
\text { patente sino por } \\
\text { participación en su } \\
\text { desarrollo. } \\
\text { Afirmación del } \\
\text { Protocolo de Kyoto. } \\
\text { Cambio en sistema } \\
\text { productivo no debe } \\
\text { afectar puestos de } \\
\text { trabajo. }\end{array}$ & $\begin{array}{l}\text { Compromiso con la } \\
\text { adopción de un nuevo } \\
\text { régimen climático. } \\
\text { Promueve posturas } \\
\text { pragmáticas a nivel } \\
\text { regional orientadas al } \\
\text { logro de consensos } \\
\text { internacionales. } \\
\text { Acciones de adaptación } \\
\text { y mitigación nacionales. } \\
\text { Para países } \\
\text { latinoamericanos: rol de } \\
\text { "brokers" que permitan } \\
\text { superar tensiones Norte- } \\
\text { Sur }\end{array}$ & $\begin{array}{l}\text { Proponente originario de } \\
\text { principio de } \\
\text { responsabilidades } \\
\text { históricas de grandes } \\
\text { emisores globales. } \\
\text { Modelo brasilero de } \\
\text { reducción de emisiones a } \\
\text { partir de freno a } \\
\text { deforestación. De } \\
\text { afirmación de protocolo } \\
\text { de Kioto a postura } \\
\text { pragmática en Coalición } \\
\text { de Gran Ambición. }\end{array}$ \\
\hline
\end{tabular}

\section{Consideraciones finales}

Este trabajo ha permitido dar cuenta de las diferencias en los posicionamientos de los populismos frente a las derechas o experiencias no populistas en América Latina. Mientras los primeros suelen tener posturas más radicalizadas y críticas para con el sistema económico-político internacional, los segundos tienden a asumir el rol de mediadores o brokers para el logro de consensos políticos internacionales.

Los populistas se orientan mayormente a la defensa de sus soberanías nacionales y del derecho al desarrollo de sus países, como así también de la necesaria adopción de mecanismos vinculantes para que los países del Norte se vean obligados a asumir su deuda ecológica generada a partir de sus emisiones históricas de carbono. Asimismo, propugnan la creación de innovadoras formas de financiamiento y transferencia de tecnología que eviten la revictimización de los países menos desarrollados en la lucha contra el cambio climático.

Por lo tanto, a partir de este análisis, los populismos no se presentan como puras amenazas para la causa ambiental o meras expresiones de una diplomacia irracional, sino como experiencias que han dado vida al debate internacional de los últimos años, visibilizando el antagonismo Norte-Sur presente desde los orígenes de la historia ambiental contemporánea ${ }^{12}$. Cabe destacar que tal visibilización no aparece como antojadiza sino como una causa legítima que, en función de una significación diversa de los problemas ambientales, es capaz de ofrecer al mundo propuestas innovadoras para hacer frente al calentamiento global, la desigualdad y la pobreza.

Por lo tanto, desde nuestra perspectiva, no se trata de identificar los obstáculos al logro de acuerdos o a la eficacia del régimen internacional de cambio climático, sino a la comprensión crítica de estas discusiones y las diferentes lógicas políticas en pugna.

\footnotetext{
${ }^{12} \mathrm{Al}$ respecto ver: Foa Torres, 2017a, 2017b.
} 
Cabe advertir, por último, que el campo de los debates ambientales es un terreno propicio para concepciones que intentan negar el carácter constitutivo del antagonismo social y reducirlo a un mero conflicto de índole técnica. Por lo tanto, es necesario profundizar los estudios desde perspectivas latinoamericanas y críticas que eviten suponer a los populismos como regímenes políticos esencialmente contrarios a acuerdos internacionales o, incluso, antiambientalistas; para avanzar hacia los fundamentos que sostienen tales posturas, usualmente sostenidos en la complejidad política de las vinculaciones entre política ambiental, comercio internacional, desigualdad entre países y desigualdad hacia adentro de los países del Sur.

\section{Bibliografía}

Bodansky, D. \& Rajamani, L. (2016). Evolution and Governance Architecture of the Climate Change Regime. In Sprinz, D. and Luterbacher, U. (eds). International Relations and Global Climate Change. London: MIT Press.

Bueno, P. (2017). El Acuerdo de París: ¿una nueva idea sobre la arquitectura climática internacional? Relaciones Internacionales, 33, 75-95.

Clavería, L. (2016). De Copenhague a París: análisis de los discursos de Brasil, Chile y Ecuador en las conferencias de las partes (2009 - 2015). Direitos Emergentes na Sociedade Global, 5(2), 94-115.

De La Torre, C. (2014). The People, Democracy, and Authoritarianism in Rafael Correa's Ecuador. Constellations, 21 (4), 457-466.

Edwards, G. \& Timmons R. J. (2015). A fragmented continent. Latin America and the Global Politics of Climate Change. Cambridge: The MIT Press.

Foa Torres, J. (2017a). Neoliberalismo, deuda y ambiente. En: Piñero, M.T y Bonetto, M. S. (comps.) Tensiones en la democracia argentina: Rupturas y continuidades en torno al neoliberalismo. Córdoba: CEA-FCS-UNC.

Foa Torres, J. (2017b). Lógica del riesgo y patrón de desarrollo sustentable en América Latina Políticas de gestión ambientalmente adecuada de residuos peligrosos en la ciudad de Córdoba. Córdoba: Editorial del Centro de Estudios Avanzados.

Glynos, J. \& Howarth, D. (2007). Logics of Critical Explanation in Social and Political Theory. U.K.: Routledge.

Hirsch, T. (2016). El papel de las alianzas en la política internacional de lucha contra el cambio climático tras París. Berlín: Friedrich-Ebert-Stiftung.

Laclau, E. (2006). La deriva populista y la centroizquierda latinoamericana. Nueva Sociedad, 205, 5661.

(2008). La razón populista. Buenos Aires: Fondo de Cultura Económica.

Laclau, E. \& Mouffe, C. (2004). Hegemonía y estrategia socialista. Hacia una radicalización de la democracia. Buenos Aires: Fondo de Cultura Económica.

Mudde, C. \& Rovira Kaltwasser, C. (2012). Populism in Europe and the Americas: Threat or Corrective for Democracy? Cambridge: Cambridge University.

Meijers, E. (2011). Populism in Europe. Vienna: Green European Foundation. 
Panizza, F. (2005). Unarmed Utopia Revisited: The Resurgence of Left-of-Centre Politics in Latin America. Political Studies, 53, 716-734.

Rovira Kaltwasser, C. (2014a). Latin American Populism: Some Conceptual and Normative Lessons. Constellations, 21(4), 494-504.

(2014b). La derecha en América Latina y su lucha contra la adversidad.

Nueva Sociedad, 254, 34-45.

Sorsa, P. (1995). El medio ambiente en el contexto del comercio internacional. En SELA/UNCTAD: Comercio y medio ambiente, 101-109. Caracas: Nueva Sociedad.

Stavrakakis, Y. (2015). Populism in power: Syriza's challenge to Europe. Juncture, 21(4), 273-280.

Svampa, M. (2016). "América Latina: Fin de ciclo y populismos de alta intensidad". En A.A.V.V.: Rescatar la esperanza. Más allá del neoliberalismo y el progresismo, 63-90. Barcelona: Entre Pueblos.

\section{Fuentes Documentales}

Clarín (2015). Giro en la posición argentina sobre el calentamiento global, 9 de diciembre de 2015.

Discurso del Presidente Rafael Correa ante COP 21 (2015), 30 Noviembre de 2015, París.

Discurso del Ministro Jorge Taiana en la COP 15 (2009), 17 diciembre de 2009.

Discurso do presidente Luiz Inácio Lula da Silva (2009), COP 15, 18 de diciembre de 2009, sessão plenária de debate informal $15^{\mathrm{a}}$ Conferência das Partes da Convenção das Nações Unidas sobre Mudança do Clima.

Discurso de Michelle Bachelet en COP 22 Marruecos (2016), 15 de noviembre de 2016.

Discurso del Vicepresidente Amado Boudou en COP 20 de Lima (2014), 10 de diciembre de 2014.

EUROCLIMA (2014). Reunión de Jefes Negociadores de Cambio Climático, 24 septiembre 2014. Recuperado de: http://www.euroclima.org

FALCONÍ, F. (2009), Discurso del Ministro de Relaciones Exteriores Fander Falconí, COP15, Copenhague.

Intervención de Chile Plenario, Segmento Alto Nivel, COP 17.

Lagos, R. (2015), "Foreword", in: Edwards \& Timmons Roberts: A fragmented continent. Latin America and the Global Politics of Climate Change, Cambridge: The MIT Press.

Mena erazo, P. (2013), “Por qué fracasó el proyecto ambiental de Yasuní en Ecuador?”, BBC Mundo, 16 agosto 2013.

Ministerio de Comunicación de Bolivia (2015), Preferimos estar sometidos al pueblo y no a los imperios, Discurso del Presidente Evo Morales Ayma, Conclusiones de la CMPCC-Tiquipaya, $n^{\circ}$ 701, martes 13 de octubre de 2015.

Nodal (2015). Juan Carlos Villalonga, jefe de la delegación argentina en la COP21: "El gran logro de la Cumbre fue político: ganó el pragmatismo", 14 de diciembre de 2015.

NU (1992). Convención Marco de las Naciones Unidas sobre el Cambio Climático, Río de Janeiro. 
Presidencia República del Ecuador (2015). Ponencia del Presidente Ecuatoriano Rafael Correa Delgado en el taller sobre la dimensión moral del cambio climático. Estado Vaticano, 28 de abril de 2015.

Sanchez M. \& ZAmbrano, M. (2010). Retos para el Ecuador y la Comunidad Internacional frente al cambio climático. AFESE $n^{\circ} 54,155-174$.

Visión de la República Argentina (2012). Grupo de Trabajo Ad-Hoc para la Plataforma de Durban para Acción Mejorada, abril de 2012. 
https://doi.org/10.24316/prometeica.v0i18.250

\title{
CAMBIO CLIMÁTICO Y POLÍTICAS PÚBLICAS: UN ABORDAJE DESDE LA TEORÍA SOCIAL DEL RIESGO
}

\author{
CLIMATE CHANGE AND PUBLIC POLICIES: AN APPROACH FROM THE THEORY OF \\ RISK SOCIETY
}

Agustin Roth
(Universidad Nacional de Córdoba / Argentina)
rothagustin@gmail.com

Recibido: $19 / 09 / 2018$

Aprobado: 30/10/2018

\begin{abstract}
RESUMEN
El presente artículo aborda una problemática central de nuestros tiempos: el cambio climático. Este fenómeno produce en el presente consecuencias negativas y dañinas, y se espera que a futuro sus impactos vayan en aumento, amenazando no solamente la economía, el desarrollo y la naturaleza, sino la vida humana misma. El abordaje aquí propuesto será desde la "teoría de la sociedad del riesgo", desarrollada por Beck y Giddens, quienes postulan que la sociedad contemporánea se enfrenta a enormes riesgos y amenazas: riesgos ambientales, nucleares, bélicos, etc.

Dicho panorama, plantea un difícil desafío a las políticas públicas, ya que será fundamental diseñar nuevas políticas estratégicas que estén a la altura del problema, y puedan dar respuesta a los problemas que más preocupan al mundo.

Se propone, por tanto, hacer un recorrido reflexivo por la teoría social del riesgo, y por los desafíos que enfrentan actualmente la política pública y el derecho ambiental para gestionar el cambio climático.
\end{abstract}

Palabras claves: Democracia Ambiental. Percepción de Riesgos. Principio Precatorio Ambiental.

\begin{abstract}
The article proposes an analysis of one of the most crucial problems of nowadays: global climate change. This phenomenon is producing negative and severe consequences, and it is expected to continue and to increase in the future, so climate change represents itself a strong threat not only to economy, development and nature, but also to human kind. The approach of the present paper is based on Beck and Gidden's Risk Society Theory, which mainly states that society is constantly facing many risks: environmental ones, nuclear and warlike as well.

The described situation implies a demanding challenge to public policies makers, because new and strategic policies will have to be designed, in order to manage the most urgent problems and threats.

Hence, the paper proposes a wide reflection regarding to risk society theory, and the challenges that climate change represents to public policies and environmental law.
\end{abstract}


Keywords: Environmental Democracy. Environmental Precautionary Principle. Risk Perception.

\section{Introducción}

En la actualidad una de las mayores amenazas ante las cuales nos enfrentamos es el cambio climático y sus consecuencias negativas sobre la humanidad y el medio ambiente. La comunidad científica en su generalidad, nucleada ante el Grupo Intergubernamental de Expertos sobre el Cambio Climático (IPCC) $)^{1}$, admite que el cambio climático existe, que tiene un determinado componente de causas humanas, y que ya se están produciendo (y seguirán a futuro) alteraciones climáticas que implican desafíos de adaptación y modificación de las formas tradicionales de vida.

Las políticas públicas se enfrentan en el presente al enorme desafío de gestionar adecuada y estratégicamente la amenaza del cambio climático. Pero este fenómeno climático no es igual que otros problemas ambientales o ecológicos: es un problema de escala global, con efectos locales, y genera muchas -demasiadas- incertidumbres sobre sus causas reales, sobre sus efectos actuales y sobre su panorama a futuro.

Son muchos los efectos negativos que ya se están produciendo por el cambio climático, y en nuestro país podemos nombrar, conforme fuera publicado en la "Tercera Comunicación Nacional de la República Argentina a la Convención Marco de las Naciones Unidas sobre el Cambio Climático" 2, a las olas de calor, a las tormentas y precipitaciones extremas, a las inundaciones con mayor frecuencia, el derretimiento de glaciares y del permafrost, sequías e incendios, etc. Y estos daños al medio ambiente y a las personas dejan entrever la incapacidad de las políticas públicas "tradicionales" para hacer frente a la gestión de la crisis ecológica actual y futura.

Sin embargo, el cambio climático global no es la única amenaza actual y futura, sino que en la sociedad moderna y contemporánea se están produciendo y reproduciendo otros riesgos y amenazas de gravedad, como el armamento y energía nucleares, el terrorismo, la contaminación de suelos, agua y aire, la expansión de enfermedades, etc. Vivimos en un mundo convulsionado, cada vez más conectado, tecnificado y cientifizado, donde por todos los frentes aparecen riesgos al ambiente, a la salud y a la forma de producción y trabajo.

En este marco, autores como Ulrich Beck y Anthony Giddens desarrollaron, dos décadas atrás, lo que se conoce como la teoría social del riesgo, que, a grandes rasgos, enuncia que los riesgos (ej. ambientales) representan consecuencias dañinas incalculables e inmanejables, señalando que el avance del conocimiento científico y técnico ya no es capaz de contenerlos. Al contrario de lo que se podría suponer, sostienen que en las sociedades postradicionales "la producción de riesgos es consecuencia de los esfuerzos científicos y políticos por controlarlos o minimizarlos" (Beck, 1998:505), ya que dichos riesgos son un resultado de la intervención humana en el medio ambiente. Ante este panorama, cabe

\footnotetext{
${ }^{1}$ El IPCC fue creado en 1988 para que facilitara evaluaciones integrales del estado de los conocimientos científicos, técnicos y socioeconómicos sobre el cambio climático, sus causas, posibles repercusiones y estrategias de respuesta. Fue creado por el Programa de las Naciones Unidas para el Medio Ambiente (PNUMA) y la Organización Meteorológica Mundial (OMM) en 1988 para ofrecer al mundo una visión científica clara del estado actual de los conocimientos sobre el cambio climático y sus posibles repercusiones medioambientales y socioeconómicas. En el mismo año, la Asamblea General de las Naciones Unidas hizo suya la decisión de la OMM y del PNUMA de crear conjuntamente el IPCC. Consultado en: http://www.ipcc.ch/home_languages_main_spanish.shtml

2 Presentada por nuestro país en noviembre de 2015 (elaboración a cargo de la Secretaría de Ambiente y Desarrollo Sustentable de la Nación hoy jerarquizado en Ministerio homónimo). Estas comunicaciones responden a las obligaciones impuestas por los artículos 4 y 12 de la Convención Marco de las Naciones Unidas sobre el Cambio Climático, normas que obligan a las partes a presentar información sobre el logro de los objetivos de la Convención, y en particular, sobre sus inventarios nacionales de emisiones antropogénicas de GEI (no controladas por el Protocolo de Montreal). Por otra parte, en dicha Comunicación se debe informar sobre los planes de mitigación y adaptación al Cambio Climático. Estas Comunicaciones se erigen en fuentes de datos estadísticos y cualitativos en torno al cambio climático y la postura de nuestro Gobierno Nacional.
} 
preguntarse sobre la real eficacia y estrategia de las clásicas políticas públicas y formas de diseño institucional de los Estados. ¿Son dichas políticas y formas de respuesta suficientes y eficaces para abordar los riesgos a los que se enfrente la humanidad en el presente y hacia el futuro?

Por todo ello, la presente ponencia intentará reflexionar sobre el desafío que el cambio climático significa para la política pública ambiental, teniendo como trasfondo la sociedad del riesgo delineada por Beck y Giddens. En un primer lugar, se abordarán los principales conceptos de la sociedad del riesgo y los caracteres del riesgo; y luego se reflexionará sobre el rol de las políticas públicas y el derecho ambiental frente al gran desafío que implican los riesgos del cambio climático.

\section{La sociedad del riesgo}

En primer lugar, para Beck (2006) la aparición de la sociedad del riesgo implicó una ruptura en la modernidad, diferenciándose esta de la anterior sociedad tradicional decimonónica, también conocida como sociedad industrial. El autor, en su obra, constantemente señala diferencias entre estas dos sociedades, y a continuación se enumera las más llamativas:

- Concepción de la naturaleza: mientras que en la sociedad tradicional o industrial se concibe a la naturaleza como algo externo y escindido de la sociedad, en la actual sociedad del riesgo la naturaleza es algo interior al sistema industrial, "como consecuencia de su transformación técnico-industrial y de su comercialización mundial" (Beck, 2006: 13).

- Idea de progreso: mientras que en la sociedad industrial clásica (S. XIX-XX) había una especie de fe ciega en el automatismo del progreso, en la actualidad los riesgos que el mismo progreso fue generando, hace socavar su fundamento y se lo cuestiona.

- Beck explica que "el concepto de sociedad industrial o de clase (en el sentido más amplio de Marx y Weber) giraba en torno a la cuestión de cómo se puede repartir la riqueza producida socialmente de una manera desigual y al mismo tiempo legítima" (2006: 30). Pero, en la sociedad del riesgo, si bien la idea de clase no desaparece, emerge el problema de la definición y reparto de riesgos producidos, y no solo de las riquezas-miserias.

- En la sociedad tradicional de clases el valor de igualdad es central en su dinámica de desarrollo, mientras que en la sociedad del riesgo el valor más prevaleciente es el de seguridad, y Beck indica que "mientras que la utopía de la igualdad contiene un multitud de fines positivos de los cambios sociales, la utopía de la seguridad es peculiarmente negativa y defensiva: en el fondo, aquí ya no se trata de alcanzar algo 'bueno', sino sólo de evitar lo peor" (2006:69).

- A diferencia de la sociedad tradicional, en la sociedad del riesgo "el pasado pierde la fuerza de determinación para el presente. En su lugar aparece como 'causa' de la vivencia y de la actuación presentes el futuro, es decir, algo no existente, construido, ficticio" (Beck, 2006:48). Todo esto obliga a organizar una acción presente en base a un futuro incalculable y amenazante, donde se erige la problemática de las generaciones futuras.

- Beriain, citando a Luhmarm y Beck, habla de la omnipotencia del peligro, queriendo significar que existe una "angustia de los grupos sociales ante los peligros de la energía nuclear, las guerras y la pobreza no es ninguna evaluación del riesgo, sino que afecta a la comunidad entre la tierra, las plantas, los animales y los seres humanos de tal manera que existe una solidaridad de los seres vivos porque todos estamos «en el mismo barco» y el mar es el mismo para todos, este compartir el mismo Kosmos kairos nos une en la democracia del peligro" (1996: 25).

En segundo lugar, Giddens también da cuenta de ciertas diferencias en la sociedad contemporánea, y postula que "el mundo en el que vimos actualmente no está sometido a un dominio estricto por parte de los humanos [...] Casi al contrario, es un mundo de confusión e incertidumbre" (1998: 13). El autor hace hincapié en que el conocimiento humano y la intervención en la naturaleza, en vez de crear más certeza y seguridades, ha tenido un efecto totalmente contrario, donde se han ido generando 
incertidumbres fabricadas e imprevisibilidades debido justamente a esta intervención y avance del conocimiento.

En relación a la incertidumbre fabricada, Giddens explica que lo que ha cambiado es el origen y el alcance de los riesgos y amenazas, indicando que "el riesgo fabricado es resultado de la intervención humana en las condiciones de la visa social y la naturaleza" (1998:13-14). Podemos afirmar entonces, que los peligros de catástrofes ecológicas no son -simplemente- consecuencias del cambio climático (como algo externo), sino que tienen una relación directa con la intervención del hombre en la naturaleza.

Para comprender aún más a la sociedad del riesgo, vale tener en cuenta la explicación que dan estos autores sobre el porqué del avance de las incertidumbres creadas y los riesgos, y en ese sentido señalan que se debe principalmente a tres factores. El primero, la universalización, donde se transforma el espacio y el tiempo y se la define como acción a la distancia, donde "mi decisión de comprar cierta prenda de vestir tiene repercusiones no sólo en la división internacional del trabajo sino en los ecosistemas terrestres" (Giddens, 1997: 14).

El segundo factor, es la destradicionalización o sociedad post tradicional, donde en realidad las tradiciones no desaparecen, sino que se transforman y se abren a preguntas y debates, a cuestionamientos morales y cosmopolitas.

Por último Giddens señala que "el tercer cambio esencial que influye en las sociedades contemporáneas es la expansión de la capacidad social de reflexión", lo cual genera "la discrepancia entre el conocimiento y el dominio de la situación, un elemento que constituye una fuente esencial de incertidumbre fabricada" (1998: 16). Beck explica que "la modernidad se vuelve reflexiva, es decir, preocupada por sus consecuencias no intencionales, sus riesgos y sus fundamentos" (Beck, Giddens y Lash, 1994: 513).

Es así que ambos autores señalan con agudeza que en la sociedad actual, post tradicional, más conocimiento no significa más control y gestión de un problema ${ }^{3}$, en este caso ambiental. Todo lo contrario: a causa de todo el conocimiento y tecnologías desarrolladas, vivimos en un mundo más contingente y con riesgos incalculables, o en otras palabras, vivimos en un mundo más abierto y desconocido a la vez.

Las diferencias remarcadas con respecto a la sociedad industrial-clásica y "de clases" es lo que va configurando las características de la nueva sociedad del riesgo, donde el futuro amenazante y el reparto de riesgos y responsabilidades aparecen como central.

\section{Caracteres de riesgo}

Para esquematizar y organizar la lectura, se señalan a continuación los caracteres de la noción de "riesgo" más notorios según Beck (2006):

Los riesgos de la sociedad actual no reconocen fronteras ni se limitan a ciertos Estados nacionales, sino que tienen una tendencia globalizadora ${ }^{4}$; tampoco son específicos de una clase social, sino que todos se ven afectados por ellos, incluso los propios productores de riesgos y

\footnotetext{
${ }^{3}$ Beck dice: "Muchos sociólogos (incluyendo a Foucault o Adorno y Horkheimer, teóricos críticos de la escuela de Frankfurt) concibieron la modernidad como una cárcel de conocimiento técnico. (...). Sin embargo, la sociedad de riesgo, al contrario de la imagen que ofrece el término, constituye un mundo mucho más abierto y contingente de lo que podría sugerir cualquier concepción clásica de la sociedad moderna y es así precisamente debido a y no a pesar de todo el conocimiento que hemos generado acerca de nosotros mismos y del entorno material" (1998: 503-504).

4 Beck dice que los riesgos "son un producto global de la maquinaria del progreso industrial y son agudizados sistemáticamente con su desarrollo ulterior" (2006:33).
} 
las clases ricas y poderosas 5 . En este sentido, Beck señala que "objetivamente los riesgos despliegan dentro de su radio de acción y entre los afectados por ellos un efecto igualador" (2006: 52). Sin embargo, el autor aclara en reiteradas oportunidades que muchos riesgos siguen la suerte de las capas o clases sociales, produciéndose, en sus palabras, un "solapamiento entre la sociedad de clases y la sociedad del riesgo [...] las riquezas se acumulan arriba, los riesgos abajo" (2006: 50).

> Los riesgos actuales (por ejemplo las sustancias químicas nocivas para la salud humana presentes en el agua, aire y alimentos) suelen permanecer "invisibles", ya que son imperceptibles a los sentidos de las personas, y en el momento de hacerse conscientes, suelen generar incertezas, desacuerdos y, tristemente, daños irreversibles a la salud.

$>$ Beck, señala con agudeza que "los riesgos se refieren a un futuro que hay que evitar" (2006: 48). Lo que quiere significar el autor con dicha frase, es que los riesgos a los cuales nos enfrentamos no son solamente actuales sino que tienen una "gran cuota" a futuro de peligros y amenazas que si bien no se sabe si se van a producir o no, ni cuándo ni cómo, pero sí generan una reacción en la sociedad que reclama actuar hoy para mitigar y evitar los daños futuros. Este carácter tiene una influencia muy importante en la configuración de las políticas públicas contra el cambio climático.

Son innumerables los casos donde se generan situaciones de riesgos con las características señaladas, pero basta con reflexionar sobre el preocupante caso que alarmó a la ciudad de Córdoba a comienzos del año 2017, cuando a raíz de una inundación, el agua ingresó a la planta de residuos peligrosos "Taym”, y luego fluyó hacia el canal Dique Los Molinos. Automáticamente la sociedad cordobesa se vio presa del riesgo y del miedo de que agua contaminada, tóxica y peligrosa llegara a su casa por la red de agua. A esta inseguridad y catástrofe se le sumó el desconocimiento general sobre la temática de la sanidad del agua, la disputa entre activistas ambientales, expertos científicos, responsables de la planta de tratamiento y los funcionarios políticos. Versiones cruzadas, incertezas, miedo, desconcierto, medios de comunicación, política y ciencia, se vieron todas inmersas en un triste episodio que, en cuestiones de segundos, hizo generar una situación de riesgo grave para miles de personas.

Luego de interrumpirse el suministro de agua, se hicieron análisis científicos y los mismos dieron como resultado que el agua se encontraba "dentro de los parámetros admitidos por la legislación vigente". El temor se fundamentaba por la posible presencia de metales pesados y otros tóxicos en el agua. Y si bien los análisis arrojaron que el agua se encontraba "dentro de los parámetros de la ley", ¿no sería razonable seguir dudando ante un accidente de tal magnitud? ¿En base a qué certeza las leyes establecen parámetros mínimos de contenido de tóxicos en los alimentos o el agua? ¿Tienen en cuenta las leyes la posibilidad de que la sumatoria de "tóxicos en cantidades mínimas e inocuas" provoquen daños en nuestra salud? Este caso, demuestra con firmeza que el conocimiento científico por sí solo no alcanza ya para resolver los problemas, y que los riesgos actuales generan incertidumbre, inseguridades y posibles daños invisibles a las personas.

\section{Cambio climático y políticas públicas}

El cambio climático es un fenómeno mundial sobre el cual existen variadas posiciones, que a su vez, representan prácticas discursivas con todo un telón de fondo representativo de relaciones de podersaber. A fines ilustrativos, tenemos dos grandes posturas: por un lado los negacionistas del fenómeno actualmente liderados por el presidente de los Estados Unidos Donald Trump- (Fresneda, 2016), y por otro lado, a los que admiten que el cambio climático está sucediendo y afectando a la humanidad (postura encabezada por la Organización de las Naciones Unidas y el Grupo Intergubernamental de Expertos sobre el Cambio Climático).

\footnotetext{
${ }^{5}$ Con mayor precisión Beck expresa que "tampoco los ricos y poderosos están seguros ante ellos. Y esto no sólo en tanto que los peligros para la salud, sino también en tanto que peligros para la legitimación, la propiedad y la ganancia" (2016:34).
} 
Nuestro país se enrola mayormente, y ante la Comunidad Internacional, en la postura que admite al fenómeno, ya que en 1993, mediante ley 24.295 fue aprobada la Convención Marco de las Naciones Unidas sobre el Cambio Climático (en adelante, CMNUCC), la cual define en su artículo 1, párrafo 2 al "cambio climático" como un "cambio de clima atribuido directa o indirectamente a la actividad humana que altera la composición de la atmósfera mundial y que se suma a la variabilidad natural del clima observada durante períodos de tiempo comparables" (artículo 1, párrafo 2, CMNUCC). Dicha definición no solo admite la existencia del fenómeno, sino que también atribuye sus causas a las actividades antropogénicas.

Ante este panorama, nuestro país ha venido desarrollando diversas políticas públicas para hacer frente al cambio climático, como por ejemplo y solo por nombrar algunas: el fomento de energías renovables $^{6}$; la creación, en la órbita de la Jefatura de Gabinete de Ministros, del Gabinete Nacional de Cambio Climático ${ }^{7}$; la aprobación del Acuerdo de Paris, celebrado en París (Francia), en el marco de la Conferencia de las Partes $\mathrm{N}^{\circ} 21$ (reuniones anuales en el marco de la CMNUCC) ${ }^{8}$; la creación del Programa Nacional de Escenarios Climáticos", teniendo por funciones las de "llevar a cabo estudios sobre la vulnerabilidad de los sistemas humanos naturales al cambio y la variabilidad climática y sobre su capacidad para adaptarse a los mismos" (artículo 2, resolución 248/2005, Secretaría de Ambiente y Desarrollo Sustentable); etc. Es decir que frente a un fenómeno que es considerado como un problema ambiental, el Estado se encuentra con la necesidad de gestionarlo mediante el dictado y ejecución de variadas políticas públicas ambientales.

\section{La problemática de las políticas públicas ambientales en el marco de la sociedad del riesgo}

Como se indicó en párrafos anteriores, el cambio climático es percibido por nuestro Estado como un riesgo, y consecuentemente se elaboran desde hace décadas diversas políticas públicas ambientales para intentar gestionar y hacer frente a la situación de amenaza.

Beck indica que en la sociedad del riesgo "no está claro qué tipo de política y de instituciones políticas está en condiciones" de dominar el riesgo, surgiendo "un vacío de competencia e institucionalidad políticas, incluso de ideas respecto a cómo enfrentar y gestionar las amenazas a futuro" (2006:68). Giddens, por su parte, indica que a los nuevos riesgos "no se les pueden aplicar viejos remedios; pero tampoco responden a la receta de la Ilustración: a más conocimiento, más dominio" (1998: 14). A su vez, este último señala que los riesgos "expresan una causalidad y temporalidad de tanta amplitud, difusión y extensión que se escapan a los modos ortodoxos de atribución. No sabemos cómo abordar adecuadamente este tipo de amenazas" (1997: 158).

Y precisamente ese es el gran dilema actual: las políticas públicas ambientales que tradicionalmente se vienen aplicando ¿son lo suficientemente adecuadas para gestionar semejante riesgo? Es una pregunta que el futuro sabrá responder, pero permite ilustrar lo complejo que es intentar aplicar políticas para solucionar un problema del cual ni siquiera se conoce con exactitud sus dimensiones, consecuencias, extensión de posibles daños, etc.

Para complejizar aún más la situación, Barros y Camilloni ${ }^{10}$ sostienen que como muchos efectos nocivos del cambio climático son esperables a un futuro (relativamente) lejano, hace que se quite urgencia "a la toma de decisiones en materia de mitigación de las emisiones, por cuanto esta solo será

\footnotetext{
${ }^{6}$ Tenemos a la ley N ${ }^{\circ}$ 26190, del año 2006, titulada: "Régimen de Fomento Nacional para el uso de fuentes renovables de energía destinada a la producción de energía eléctrica".

${ }^{7}$ Mediante decreto del Poder Ejecutivo nacional 891/2016.

${ }^{8}$ Aprobación por ley $\mathrm{N}^{\circ} 27.270$, proponiendo: "mantener el aumento de la temperatura media mundial muy por debajo de 2 ${ }^{\circ} \mathrm{C}$ con respecto a los niveles preindustriales, y proseguir los esfuerzos para limitar ese aumento de la temperatura a $1,5^{\circ} \mathrm{C}$ con respecto a los niveles preindustriales, reconociendo que ello reduciría considerablemente los riesgos y los efectos del cambio climático".

${ }^{9}$ Por resolución 248/2005 de la entonces Secretaría de Ambiente y Desarrollo Sustentable (actual Ministerio).

${ }^{10}$ Expertos del CONICET en temáticas de cambio climático.
} 
efectiva más allá de la mitad del siglo, y resulta muy difícil para cualquier sociedad admitir sacrificios en beneficio de las generaciones futuras" (2016: 60).

En relación a la incertidumbre que significa el cambio climático para los Estados, Beck sostiene que los Estados (de bienestar) tradicionalmente gestionaron riesgos sobre los cuales puede hacerse cierto cálculo de previsibilidad, como ser "la creación de los esquemas de compensación y seguro para accidentes y lesiones en el trabajo y para el desempleo" (1998: 508). Sin embargo, frente a los riesgos creados por el cambio climático y sus características de incalculables e inciertos, dichas formas tradicionales de administrarlos y compensarlos, ya no funcionan. No es comparable un riesgo de desempleo o accidentes laborales, que riesgos derivados de posibles catástrofes climáticas, en cualquier lugar y en cualquier momento.

\section{1. "Crisis de la ciencia"}

Debemos agregar otro desafío para los gestores de políticas públicas (quizás, uno de los mayores), el cual podríamos denominar como "la crisis de la ciencia" en un doble sentido. En primer lugar, debido a que, como ya se señaló, más conocimiento técnico-científico no implica mayor control de los riesgos, sino todo lo contrario ${ }^{11}$. En un segundo sentido, y es el que se quiere resaltar en este apartado, se habla de "crisis de la ciencia" en tanto que la construcción y dotación de significado del término "riesgo" ya no es una tarea exclusivamente de los expertos (científicos), sino que la sociedad en general, al sentirse amenazada, se introduce de lleno en la disputa por la construcción del concepto de riesgo ${ }^{12}$.

En este sentido, Ciselli (2011:4) propone que "construimos determinadas categorías culturales a partir de ciertas posiciones sociales, por lo tanto la noción de riesgo es una noción construida culturalmente que enfatiza algunos aspectos del peligro y que descarta otros", asimismo "dado el carácter de categoría social que tiene la noción de riesgo, respecto a su aceptabilidad nadie es un experto sino que la construcción del mismo depende de la percepción cultural de los peligros" (2011: 5). Es decir, que en sintonía con lo propuesto por Ciselli, se puede pensar que el Estado argentino se ve ante la urgencia de diseñar políticas públicas contra el cambio climático no solamente por recomendación de la ciencia, sino porque la interacción social y cultural del país ha llevado a visibilizar ciertos peligros y amenazas, entre las que se encuentran los desastres meteorológicos como inundaciones (en ciudades y en zonas rurales), sequías, derretimiento de glaciares, olas de calor, etc., atribuidos en mayor medida al fenómeno del cambio climático. Y considerando los aportes de Beck ${ }^{13}$ y Giddens, podemos pensar que la sociedad argentina universalizada, destradicionalizada y reflexiva, percibe culturalmente al cambio climático como un riesgo actual e inminente.

\section{En sintonía con la propuesta de Ciselli, Beck sostiene que los}

riesgos que se generan en el nivel más avanzado del desarrollo de las fuerzas productivas (ej. radiactividad) [...] se basan en interpretaciones causales, por lo que sólo se establecen en el saber (científico o anticientífico) de ellos, y en el saber pueden ser transformados, ampliados o reducidos, dramatizados o minimizados, por lo que están abiertos en una medida especial a los procesos sociales de definición. Con ello, los medios y las posiciones de la definición del riesgo se convierten en posiciones sociopolíticas clave (2006: 33-34).

\footnotetext{
${ }^{11}$ Ver apartado 1, p. 5 de esta ponencia.

12 A los fines de facilitar la claridad se contrasta entre saber científico y saber social, pero el panorama es de mayor complejidad, teniendo en cuenta que dentro de cada saber o racionalidad, existen asimismo disputas y contradicciones. En el saber científico se plantean siempre "aseveraciones y perspectivas rivales y contradictorias procedentes de una variedad de actores y grupos afectados que definen el riesgo de formas muy distintas" (Wynne citado en Beck, 1998: 506).

${ }^{13}$ Beck explica que "las constataciones del riesgo son una simbiosis aún desconocida, no desarrollada, entre ciencias de la naturaleza y ciencias del espíritu, entre racionalidad cotidiana y racionalidad de los expertos, entre interés y hecho"; y concluye diciendo que "[las constataciones del riesgo] ya no pueden ser aisladas por uno u otro especialista y ser desarrolladas y fijadas de acuerdo con los propios estándares de racionalidad. Presuponen una colaboración más allá de las trincheras de las disciplinas, de los grupos ciudadanos, de las empresas, de la administración y de la política, o (lo cual es más probable) se resquebrajan entre éstas en definiciones opuestas y luchas de definiciones" (2006:42).
} 
De aquí se derivan dos importantes preceptos: en primer lugar, queda claro que los riesgos no son algo dado o estáticos, sino que su configuración además de ser influida por el saber científico, dependen en gran medida de la sociedad, de los interese económicos y de la política que los someten a procesos de definición, percepción y transformación. En segundo lugar, se podría pensar que toda política pública ambiental tendrá como trasfondo una particular elaboración y concepción propia del riesgo que quiere gestionar. Con lo cual, queda en evidencia la trascendencia que tiene el poder dominar y controlar el proceso social de definición de los riesgos ambientales, ya que del resultado de dicho proceso, se diseñarán y ejecutarán ciertas políticas públicas, en desmedro de otras.

Esta crisis de la ciencia, en su segundo sentido de disputa con otros saberes y prácticas, pone en jaque a los gestores de políticas públicas. Imagínese que el Estado debe decidir sobre la apertura o no de una central nuclear en una población. Aquí se podría pensar qué posición asumiría la racionalidad científica versus la racionalidad social. Por un lado, se acudirá al asesoramiento de expertos, quienes, según Beck se limitarán a valorar "determinados riesgos cuantificables en el caso de accidentes probables"; pero, por otro lado la racionalidad de la sociedad apuntará y denunciará al "potencial de catástrofe de la energía nuclear", ya que "una probabilidad de accidente mantenida en el mínimo es demasiado elevada allí donde un accidente significa el exterminio" (2006: 36).

Del ejemplo dado se infiere que el saber científico puede brindarle a los gestores ciertos datos probabilísticos de posibles riesgos, y como evitarlos, pero la pregunta que la ciencia no puede responder es ¿cuánto riesgo es tolerable por la sociedad? ¿Cuál es el límite de tolerancia acerca de vivir expuestos a riesgos, por más que se mantengan en "los parámetros científicos"? Estas disputas hacen que los políticos ya no puedan acudir únicamente a una fuente de información científica para basar sus decisiones, y deban buscar y encontrar en la sociedad, la legitimación que la ciencia ya no otorga.

\section{Dos posibles soluciones}

Frente al panorama problemático planteado ut supra, y aceptando que la ciencia ya no representa una legitimación directa y exclusiva para tomar decisiones políticas, debemos preguntarnos si existen algunas soluciones o herramientas de la que puedan valerse no solo las políticas públicas ambientales, sino también el derecho ambiental. Se proponen dos: una "ecología democrática" y una profundización del principio precautorio ambiental.

\subsection{Ecología democrática}

Ciselli expresa que:

si bien el discurso científico de los expertos es el que se prioriza al momento de tomar una decisión, resultaría altamente beneficioso dar lugar a otras voces no expertas, a otros discursos sociales que podrían ser oídos en el proceso judicial y por ende a otras esferas del conocimiento. La visibilización del conflicto ambiental, su discusión en diversos espacios sociales, abre la posibilidad a numerosas innovaciones jurídico-institucionales dado que es a partir de las 'crisis, las catástrofes, los accidentes' cuando el campo del derecho se modifica (2011: 7).

En nuestro ordenamiento jurídico ambiental es frecuente la exigencia de realizar audiencias públicas (por ejemplo, en el marco de evaluaciones de impacto ambiental) cuando se quieren emprender obras de relevancia, o introducir cambios en el ambiente. Así, la ley 10208 de la Provincia de Córdoba: "La Autoridad de Aplicación instrumentará como parte integrante de todo procedimiento administrativo de Evaluación de Impacto Ambiental, con carácter obligatorio y previo al otorgamiento o denegatoria de la Licencia Ambiental, audiencias públicas u otros mecanismos que aseguren la participación ciudadana de acuerdo a lo que establece la presente Ley" (artículo 13) (el resaltado me pertenece). 
Queda clara la importancia de incluir y tener en cuenta otros actores y otras visiones del mismo problema ambiental, como el cambio climático. En este mismo sentido, Beck introduce el concepto de democracia ecológica, donde lo ideal sería que "las zonas de decisión deben abrirse al escrutinio y debate públicos. Las decisiones económicas corporativas, las agendas de investigación científica, los planes de desarrollo y el despliegue de nuevas tecnologías deben abrirse todos a un proceso generalizado de discusión y debe desarrollarse un marco legal e institucional para su legitimación democrática" (1998: 513).

Giddens postula que debido a la imponderabilidad de la incertidumbre, las políticas públicas no pueden imponerse "desde arriba" sino que debe existir un compromiso reflexivo con diversos sistemas de la sociedad. Es especialmente interesante la propuesta de Giddens (1997: 25) cuando señala la "necesidad de impulsar formas más radicales de democratización", introduciendo el concepto de democracia dialogante en sintonía con la democracia ecológica de Beck. Explica el autor que cuando en una sociedad los niveles de reflexividad son mayores, es necesario resolver los problemas en un espacio público en el cual realmente se dialogue, dejando de lado las tradicionales formas de legitimidad política basadas, por ejemplo, en simbolismos de poder prestablecidos.

Por último, Giddens señala el rol clave de los movimientos sociales (piénsese en los movimientos ambientalistas) para impulsar la democracia dialogante, logrando "forzar la introducción, en el terreno de debate, de aspectos de la conducta social que anteriormente no tenían discusión, o se 'resolvían' con arreglo a las prácticas tradicionales" (1997:26).

\subsection{Profundización del principio precautorio ambiental}

Como posible solución al dilema de la toma de decisiones de políticas, tiene un fuerte peso en la legislación y -cada vez más- en la jurisprudencia, la aplicación del principio precautorio ambiental, el cual es definido por el art. 4 de la ley nacional 25.675 (Ley General del Ambiente) en los siguientes términos: "Cuando haya peligro de daño grave o irreversible la ausencia de información o certeza científica no deberá utilizarse como razón para postergar la adopción de medidas eficaces, en función de los costos, para impedir la degradación del medio ambiente". La importancia de este principio radica en que se reconoce la posibilidad de que exista incertidumbre científica, y que, pese a ello, el Estado de todos modos deba actuar en pos de la defensa del medio ambiente y la evitación de daños.

El mentado principio tiene además una importancia trascendental, debido a que su correcta aplicación constituye una herramienta jurídica estratégica para evitar daños por riesgos que son, en principio, invisibles a los sentidos. Recordemos que uno de los caracteres de los riesgos que brinda Beck es el de ser muchas veces imperceptibles-invisibles, como podría ser el peligro cancerígeno del contacto con algún agroquímico, aplicado por trabajadores agrarios, o bien ciertas emisiones de químicos que contaminan el aire sin que nos demos cuenta. El principio precautorio ambiental viene precisamente a frenar este tipo de situaciones, y debe ser utilizado para tomar medidas que eviten daños a la población y al ambiente, por más que los peligros estén rodeados de un halo de incertidumbre o invisibilidad en los términos de Beck.

En relación a los riesgos que implica el cambio climático, se sostiene que el principio precautorio ambiental justifica y legitima las políticas públicas para luchar contra el mismo, por más que haya ciertas voces en contra y que dudan de su real existencia y causas antrópicas.

En último lugar, cabe reflexionar sobre qué otro rol puede desempeñar el derecho ambiental ante los riesgos de la modernidad: además de la función precautoria y de prevención, Beck señala la necesidad de "redefinir los estándares (de responsabilidad, seguridad, control, limitación de daños y distribución de las consecuencias del daño)" (1997: 19-20). Es importante que el derecho ambiental tenga en cuenta a la realidad amenazante y futura ante la cual nos encontramos, y regule conforme a ella, limitando los posibles daños y consecuencias irreversibles, y brindando herramientas efectivas de control y seguridad. 


\section{Reflexiones finales}

Podríamos decir que frente al socavamiento de la legitimidad de la ciencia para fundar decisiones políticas, se podrían impulsar procesos que profundicen a la democracia, o en otras palabras, salvando la redundancia, impulsar "la democratización de la democracia". En este sentido, se considera que en la política ambiental argentina están dadas las bases jurídicas-normativas para comenzar dicho proceso de profundización, ya que tenemos una legislación ambiental completa y extensa, donde se recepta el ya mencionado principio precautorio, y donde se le da mucha relevancia a las audiencias públicas y evaluaciones de impacto ambiental como elementos previos y necesarios para fundar decisiones de política ambiental.

Pero, pareciera que no alcanza con contemplar y receptar jurídicamente dichos elementos, sino que es necesario y urgente adoptar dos tipos de medidas: por un lado, dar un impulso y reforma institucional que permita acercar a la ciudadanía las herramientas de información y participación ambientales, y por otro lado, educar y fomentar para que las personas y movimientos sociales ejerzan su derecho de participar en el terreno de las decisiones políticas frente al cambio climático. Ya que sin instituciones preparadas y sin una ciudadanía participativa que dialogue y dispute los límites de riesgos tolerables, la democracia ecológica de Beck no es más que una utopía.

Por último, y en relación a las políticas públicas contra el cambio climático, se destaca que el carácter a futuro de los riesgos y la voluntad de evitarlos, constituyen el motor y la esencia de las políticas públicas contra el cambio climático, principalmente las políticas de mitigación y adaptación.

\section{Bibliografía}

Barros, V. y Camilloni, I. (2016). La Argentina y el cambio climático: de la física a la política. Buenos Aires: Eudeba.

Beck, U. (2006). La sociedad del riesgo: hacia una nueva modernidad. Barcelona: Paidós. (1997). La política de la sociedad de riesgo. Oxford: Oxford Polity Press.

Beck, U., Giddens, A. y Lash, S. (1997). Modernización reflexiva: política, tradición y estética en el orden social moderno. Madrid: Alianza Editorial.

Beriain, J. (1996). El doble 'sentido' de las consecuencias perversas de la modernidad. En Beriain J. (comp.). Las consecuencias perversas de la modernidad: modernidad, contingencia y riesgo (7-29). Barcelona: Anthropos.

Ciselli, G. (2012). Una reflexión sobre la governancia de los riesgos ambientales: El caso de la mega minería en Esquel (Chubut). Revista Hermeneutic, 11, 1-13

Fresneda, C. (2016, 9 de Septiembre). Cambio climático: 'un cuento chino'. El mundo. Recuperado de http://www.elmundo.es/internacional/2016/11/09/58236dede2704ebc6a8b4575.html

Giddens, A. (1998). Introducción. En Más allá de la izquierda y la derecha (11-30). Madrid: Catedra.

------------. (1998). Política generativa y bienestar positivo. En Más allá de la izquierda y la derecha (157-179). Madrid: Cátedra.

Grupo Intergubernamental de Expertos sobre el Cambio Climático. (2014). Cambio climático 2014: Informe de síntesis. Ginebra: PNUMA. Recuperado de: http://www.ipcc.ch/pdf/assessmentreport/ar5/syr/SYR_AR5_FINAL_full_es.pdf 
Ley de Aprobación de la Convención Marco de las Naciones Unidas sobre el Cambio Climático, $\mathrm{N}^{\circ}$ 24295 (1993)

Ley de Aprobación del Acuerdo de París hecho en París el 12 de Diciembre de 2015 sobre Cambio Climático, $\mathrm{N}^{\circ} 27270$ (2016)

Ley de Política Ambiental Provincial (Córdoba), № 10208 (2014)

Ley de Régimen de Fomento Nacional para el Uso de Fuentes Renovables de Energía Destinada a la Producción de Energía Eléctrica, Nº 26190 (2006)

Ley General del Ambiente, $N^{\circ} 25675$ (2002).

Secretaría de Ambiente y Desarrollo Sustentable de la Nación. (2015). Tercera Comunicación Nacional de la República Argentina a la Convención Marco de las Naciones Unidas sobre el Cambio Climático. Buenos Aires: Secretaría de Ambiente y Desarrollo Sustentable de la Nación. Recuperado de: http://www.msal.gob.ar/salud-y-desastres/index.php/riesgos-de-desastres-en-argentina/principalesamenazas/ola-de-calor 


\title{
PASIVOS AMBIENTALES: UN PROBLEMA [INTER-INTRA] GENERACIONAL
}

\author{
ENVIRONMENTAL LIABILITIES: A PROBLEM [INTER-INTRA] GENERATIONAL
}

Georgina Doroni

(Universidad Nacional de Córdoba / Argentina)

georginadoroni@gmail.com

Recibido: 18/09/2018

Aprobado: 30/10/2018

Deberían exasperarnos las enormes inequidades que existen entre nosotros, porque seguimos tolerando que unos se consideren más dignos que otros [...] Seguimos admitiendo en la práctica que unos se sientan más humanos que otros, como si hubieran nacido con mayores derechos ${ }^{1}$.

\section{RESUMEN}

A través del presente trabajo se analiza la necesaria relectura e interacción entre los derechos humanos y el derecho ambiental a los fines de garantizar y fortalecer la incorporación de la dimensión colectiva o social. A partir de la obligación imperativa que "el daño ambiental generará prioritariamente la obligación de recomponer" ${ }^{2}$ se aborda la problemática de los pasivos ambientales, que (en algunos casos) debe ser resuelta por el Estado para evitar seguir traspasándolos a las generaciones futuras. Se analiza el derecho de reparación integral y garantía de no repetición como medidas para abordar las inequidades en la distribución de las cargas y costos socio-ambientales de una contaminación histórica que es arrastrada hacia tiempos presentes y se manifiesta como un potencial problema para las generaciones futuras, lo que requiere de una interpretación hermenéutica del complejo engranaje de sistema de fuentes.

Palabras claves: Derecho humano. Medio ambiente. Garantía de no repetición. Reparación integral. Remediación.

\section{ABSTRACT}

This work analyzes the necessary re-reading and interaction between human rights and environmental law in order to guarantee and strengthen the incorporation of the collective or social dimension. From the imperative obligation that "environmental damage will primarily generate the obligation to recompose" addresses the issue of environmental liabilities, which must be resolved by the State to avoid further transferring them to future generations. It analyzes the right of integral reparation and guarantee of non-repetition as measures to address inequalities in the distribution of socio-environmental costs and burdens of a historical contamination that is drawn to present times and manifests itself as a potential problem for future generations, through a hermeneutic interpretation of the complex system of sources.

Keywords: Human right. Environment. Integral reparation. Assurances of non-repetition. Remediation.

\footnotetext{
${ }^{1}$ Francisco: Encíclica Laudato Sí, nota 90.

${ }^{2}$ Según texto del artículo 41 de la $\mathrm{CN}$.
} 


\section{Introducción}

Podemos afirmar la necesaria relectura e interacción entre los derechos humanos y el derecho ambiental; una visión integrada y armoniosa entre el sistema de derechos humanos y el medio ambiente resulta a todas luces imperiosa y conveniente, a los fines de garantizar y fortalecer la incorporación de la dimensión colectiva o social del derecho humano al medio ambiente sano (Morales Lamberti: 2015: 148).

como base de una integración e interpretación hermenéutica de las obligaciones que se derivan a los Estados en la concreción y protección del derecho humano al ambiente; ambiente que se revela como medio y entorno vital no sustituible, como "base física que materializa la posibilidad de otros derechos humanos y frecuentemente no reparable en su integridad en caso de daño, refuerza la inevitable interconexión entre el ambiente y los derechos humanos" (Pezzano, Doroni, 2017) ${ }^{3}$.

En este contexto, se plantea la problemática de la remediación de los pasivos ambientales ${ }^{4}$, que debe ser resuelta por el Estado, quien si bien no fue el generador del PA, debe brindar soluciones para evitar seguir traspasando los problemas a las generaciones futuras, atento la alta incidencia social del problema. El concepto de PA

tiene importancia social, en tanto que su existencia, cuantificación y necesidad de remediación se está afirmando cada vez más en diferentes contextos de lucha de la sociedad civil y colectivos sociales. Desde una dimensión social, una primera relación que aparece evidente en el tema de pasivos ambientales y sitios contaminados es con la pobreza: estos tienden a coincidir espacialmente (Morales Lamberti, 2008: $6)$.

En el presente trabajo se estudiarán las siguientes aristas: a) se realiza un análisis del reconocimiento del derecho al ambiente sano como derecho humano que materializa la posibilidad de otros derechos humanos y refuerza la inevitable interconexión entre el ambiente y los derechos humanos desde una dimensión social (apartado II), en virtud de una interpretación integrada del complejo engranaje de fuentes enriquecido a la luz de los estándares del Sistema Interamericano de Derechos Humanos (SIDH) (apartado III). b) Se aborda la obligación imperativa que el daño ambiental generará prioritariamente la obligación de recomponer con especial referencia a la problemática de los PA (apartado IV), analizando en dicho marco el derecho de reparación integral y garantía de no repetición (apartado V) como medidas para abordar las inequidades en la distribución de las cargas y costos socio-ambientales de una contaminación histórica, que es arrastrada hacia tiempos presentes y se manifiesta como un potencial problema para las generaciones futuras.

\section{Interrelación entre los derechos humanos y el ambiente. Dimensiones de análisis}

"El derecho a un ambiente sano brinda un cimiento o base a la hora de enfrentar los problemas ambientales, desde un punto de vista tanto formal como de fondo" (Morales Lamberti: 2015: 142), para alcanzar niveles óptimos de protección.

Los derechos humanos se basan en el respeto de atributos humanos fundamentales, inherentes y naturales a la condición de persona humana - vida, salud, calidad de vida digna- y su realización y posibilidad de real concreción depende indefectiblemente de la existencia de un medio ambiente saludable que permita el desarrollo de esos atributos, sin lo cual serían de difícil e imposible realización y disfrute de otros derechos (Pezzano, Doroni, 2017) ${ }^{5}$.

\footnotetext{
${ }^{3}$ Esta consagración del derecho a un ambiente sano no es más que el reconocimiento de un derecho preexistente, es una condición previa, un prius y prerrequisito para la realización y disfrute de otros derechos humanos. Cfr. Sticca, M. A. (2013). Algunas reflexiones acerca del derecho al medio ambiente sano como derecho humano". En REY CARO, E. J. (Coord.). El Derecho Internacional Público como norma de conducta de los Estados. Córdoba: Gráfica Trejo.

${ }^{4}$ En adelante PA (pasivo ambiental).

${ }^{5}$ Derecho a un medio ambiente sano en la medida que permita el efectivo disfrute de otros derechos reconocidos a la persona humana, tal como lo señala Kiss (1987).
} 
Esta consagración del derecho a un ambiente sano no es más que el reconocimiento de un derecho preexistente, es una condición previa para el disfrute de los derechos humanos, es un prius, base y prerrequisito para la realización de los otros derechos humanos (Sticca, 2013: 338).

"El medio ambiente adecuado precede lógicamente al propio derecho: sin medio ambiente adecuado no hay vida humana, ni sociedad, ni Derecho" (Rota, 1998: 58).

"En la actualidad es difícil negar la categorización del derecho al medio ambiente sano como un derecho humano básico y esencial, en tanto su ejercicio apareja a su vez el goce y disfrute de los restantes derechos de los individuos" (Doroni, 2017). "Existe una relación innegable entre la protección del medio ambiente y la realización de otros derechos humanos" (Corte IDH, 2009) ${ }^{67}$.

\begin{abstract}
Los derechos humanos y el medio ambiente se relacionan entre sí de forma explícita e implícita, contribuyendo de manera importante al disfrute de los derechos humanos a un medio ambiente saludable. Varios problemas ambientales han buscado expresión en el lenguaje de los derechos humanos (cambio climático, discriminación ambiental, refugiados ambientales, daños transfronterizos, etc.), lo cual no resulta sorprendente y es incluso inevitable, por cuanto los derechos humanos y la protección de medio ambiente son inherentemente interdependientes para el derecho a la vida y salud (Morales Lamberti, 2009: 410).
\end{abstract}

El punto de convergencia e irrupción del derecho al medio ambiente se traduce, por un lado, en la expresión clásica e individualista del derecho a un ambiente sano como derecho humano natural e individual, ínsito a la condición de ser humano pero, por otro lado, implica también un derecho de indudable e innegable dimensión social (emplazamiento social del derecho) y colectiva (la defensa de los derechos humanos responde a un interés público y en este caso con una vocación colectiva): el campo social es el ámbito característicos de los conflictos ambientales, éstos no ocurren en vacíos sociales. "Entre la esfera pública y la privada hay una esfera social donde ubicamos a los bienes colectivos, lo cual instaura una regla de precedencia lógica en el caso de conflictos en bienes colectivos e individuales" (Lorenzetti, 2008: 12).

La dimensión colectiva, social, es consustancial al derecho ambiental y amplia los derechos jurídicos tutelados. Este es un cambio importantísimo en la cultura de los derechos humanos, a través de la institucionalización del paradigma ambiental que consagra una nueva relación que rompe con la lógica clásica de la supremacía de lo individual, reconduciendo la flecha de lo colectivo a lo individual" (Doroni, 2017: 113).

y que "se basa en una idea de interacción compleja, que toma en cuenta los efectos individuales y colectivos, presentes y futuros de la acción humana (derechos de cuarta generación o generaciones futuras) y que representa para los individuos un sistema donde predominan los deberes y límites a los derechos en razón de la protección que demanda el bien colectivo" (Lorenzetti, 2008: 11).

"La Constitución Nacional tutela al ambiente de modo claro y contundente y esta Corte Suprema ha desarrollado esa cláusula de un modo que permite admitir la existencia de un componente ambiental del estado de derecho. Por esta razón, cabe señalar que la efectividad que se reclama para todos los derechos fundamentales, también debe ser predicada respecto de los de incidencia colectiva y en particular del ambiente" 8 .

\footnotetext{
${ }^{6}$ Corte IDH: Caso Kawas Fernández vs. Honduras, sentencia de 3 de abril de 2009 (Fondo, Reparaciones y Costas. Serie C No. 196. párr. 148.). El derecho a un ambiente sano es una "condición" para el goce de otros derechos: varios derechos de rango fundamental requieren, como una precondición necesaria para su ejercicio, una calidad ambiental mínima, y se ven afectados en forma profunda por la degradación de los recursos naturales.

${ }^{7}$ Afirmado también por las Naciones Unidas, al adoptar la Agenda 2030 para el Desarrollo Sostenible, la Asamblea General reconoció que el alcance de los derechos humanos de todas las personas depende de la consecución de las tres dimensiones del desarrollo sostenible: la económica, social y ambiental. Cfr. Asamblea General de las Naciones Unidas, Resolución 70/1, titulada "Transformar nuestro mundo: la Agenda 2030 para el Desarrollo Sostenible", 25 de septiembre de 2015, Doc. ONU A/RES/70/1, preámbulo y párrs. 3, 8, 9, 10, 33, 35 y 67.

${ }^{8}$ CSJN, "Asociación Argentina de Abogados Ambientalistas de la Patagonia e/ Santa Cruz, Provincia de y otros/ amparo ambiental", Sentencia de fecha 24 de abril de 2016, CSJ 5258/2014.
} 
En el ámbito del medio ambiente existe un papel creciente de las Administraciones públicas, que constituye un campo de ensayo de técnicas e instrumentos jurídicos nuevos. La Administración sirve con objetividad los intereses generales. En materia de medio ambiente existe una no desdeñable peculiaridad. Ese servicio objetivo, que es uno de los pilares de nuestro Estado social, tiene como destinatarios a las generaciones presentes y futuras (Jordano Fraga, 2007: 102).

\section{Integración e interdependencia en el sistema de fuentes}

Con inusitada transcendencia para el derecho ambiental el Código Civil y Comercial integra una "comunidad de principios entre la Constitución", el derecho privado y el derecho público (Fundamentos del Anteproyecto) ${ }^{9}$. Los tratados de derechos humanos deben ser tenidos como fuente ${ }^{10}$, y juegan un rol clave en la labor de interpretación y aplicación de la norma-según lo estipulado por el artículo segundo ${ }^{11}$ - adquiriendo especial relevancia (de modo explícito) el régimen de derechos humanos, al brindar estándares de integración hermenéutica en el mandato de un análisis completo y coherente de todo el ordenamiento.

Se observa una clara comunicación y relación entre el derecho ambiental y el derecho general, lo que invita a una relectura de los derechos individuales a la luz de los derechos de incidencia colectiva ${ }^{12}$, a través de una fuente de coordinación-compatibilización ("conformidad en el ejercicio de los derechos individuales con los derechos de incidencia colectiva") establecida en el artículo $240^{13}$ y otra de subordinación (límite al ejercicio abusivo del derecho individuales cuando pueda afectar al medio ambiente) en el artículo 14 (Morales Lamberti,2015: 140).Claramente se observa un criterio de compatibilización del derecho individual para con los derechos de incidencia colectiva (en lo que aquí respecta el medio ambiente). En tercer lugar, encontramos una fuente de internalización de la normativa de presupuestos mínimos ${ }^{14}$ como así también de aquellas normas locales- nacionales, provinciales y municipales- complementarias ${ }^{15}$, lo que importa la necesidad de un diálogo de fuentes (Morales Lamberti, 2015: 140).

El complejo engranajes de fuentes requiere una consonancia del sistema de derechos y garantías reconocidas a nivel constitucional (control de constitucionalidad) en un único bloque de constitucionalidad que se integra con el sistema de derechos humanos (control de convencionalidad) ${ }^{16}$,

\footnotetext{
${ }^{9}$ Se establece una constitucionalización del derecho privado, al internalizar los tratados en general, en particular los de derechos humanos y los derechos reconocidos en todo el bloque de constitucionalidad. Puede afirmarse que existe una reconstrucción de la coherencia del sistema de derechos humanos con el derecho privado. Cfr. Fundamentos del Anteproyecto de Código Civil y Comercial, Comisión Redactora creada por decreto $N^{\circ}$ 191/2011.

${ }^{10}$ Art. 1: Fuentes y aplicación. Los casos que este Código rige deben ser resueltos según las leyes que resulten aplicables, conforme con la Constitución Nacional y los tratados de derechos humanos en los que la República sea parte. A tal efecto, se tendrá en cuenta la finalidad de la norma. Los usos, prácticas y costumbres son vinculantes cuando las leyes o los interesados se refieren a ellos o en situaciones no regladas legalmente, siempre que no sean contrarios a derecho.

11 "La ley debe ser interpretada teniendo en cuenta sus palabras, sus finalidades, las leyes análogas, las disposiciones que surgen de los tratados sobre derechos humanos, los principios y los valores jurídicos, de modo coherente con todo el ordenamiento".

${ }^{12}$ Es un código de los derechos individuales y colectivos. En su mayoría, los códigos del derecho privado comparado regulan sólo los derechos individuales. El Anteproyecto da una importancia relevante a los derechos de incidencia colectiva, en consonancia con la Constitución Nacional. Esto tiene un impacto significativo en el modo de relacionamiento con los recursos naturales. Fundamentos del Anteproyecto de Código Civil y Comercial, Comisión Redactora creada por decreto $\mathrm{N}^{\circ} 191 / 2011$.

13 "El ejercicio de los derechos individuales debe ser compatible con los derechos de incidencia colectiva. Debe conformarse a las normas del derecho administrativo nacional y local dictadas en el interés público y no debe afectar el funcionamiento ni la sustentabilidad de los ecosistemas de la flora, la fauna, la biodiversidad, el agua, los valores culturales, el paisaje, entre otros, según los criterios previstos en la ley especial".

${ }^{14}$ EL artículo 241 expresa que cualquiera sea la jurisdicción en que se ejerzan los derechos, debe respetarse la normativa sobre presupuestos mínimos que resulte aplicable.

${ }^{15}$ Debe conformarse a las normas del derecho administrativo nacional y local dictadas en el interés público (art. 240).

${ }^{16}$ Para efectos de determinar la compatibilidad con la CADH, no sólo se debe tomar en consideración el tratado, sino que también la jurisprudencia de la Corte IDH y los demás tratados interamericanos de los cuales el Estado sea parte. En esta tarea, el Poder Judicial debe tener en cuenta no solamente el tratado, sino también la interpretación que del mismo ha hecho la Corte Interamericana, intérprete última de la Convención Americana. Conforme Corte IDH. Caso Almonacid Arellano y
} 
lo que propicia una relectura de las interacciones entre los derechos humanos y el medio ambiente, enriquecido y fortalecido a través del SIDH (Morales Lamberti, 2015: 141).

En este sentido,

la norma convencional que deben aplicar los estados es el resultado de la interpretación de las disposiciones del Pacto de San José (y sus protocolos adicionales, así como otros instrumentos internacionales). Las interpretaciones que realiza la Corte IDH se proyectan hacia dos dimensiones: (i) en lograr su eficacia en el caso particular con efectos subjetivos, y (ii) en establecer la eficacia general con efectos de norma interpretada ${ }^{17}$.

En resumen, podemos determinar los siguientes criterios para el alcance, ejercicio y compatibilidad de los derechos (en su dimensión individual y colectiva): a) adecuación a la Constitución Nacional y a las disposiciones y estándares que surgen de los tratados internacionales de derechos humanos; b) conformidad con el SIDH; c) compatibilidad y coordinación con los derechos de incidencia colectiva un ejercicio no abusivo-; d) conformidad con el ordenamiento jurídico que debe ser interpretado de manera congruente, lo que implica tener en cuenta las normas de fondo y forma contenidas en nuestra Ley General del Ambiente (LGA) y demás normativa de protección sectorial y con las normas locales complementaria - que deben ser congruentes y acordes a los presupuestos mínimos- (orden público ambiental) (Morales Lamberti,2015: 141).

\title{
IV. Mandato imperativo de recomponer el daño ambiental. El problema de los pasivos ambientales
}

El sistema de responsabilidad tiene como principal objetivo la prevención y anticipación de los daños ${ }^{18}$, ocurrido el daño ambiental colectivo se pretende la cesación del daño y evitación de su agravamiento. Seguidamente,

\begin{abstract}
"las medidas de reparación y/o restauración tienen por objeto reponer uno o más de los componentes o elementos del medio ambiente y/o servicios ambientales afectados a una calidad similar a la que tenían con anterioridad o, al menos, restablecer sus propiedades y condiciones básicas" (Morales Lamberti, 2008: 185),
\end{abstract}

operando la indemnización sustitutiva como la última ratio del sistema ${ }^{1920}$.

otros Vs. Chile.Excepciones Preliminares, Fondo, Reparaciones y Costas. Sentencia de 26 de septiembre de 2006. Serie C No. 154, párr. 124; Cfr.Corte IDH. Caso La Cantuta Vs. Perú. Fondo, Reparaciones y Costas. Sentencia de 29 de noviembre de 2006. Serie C No. 162, párr. 173.

${ }^{17}$ Voto concurrente razonado del juez Ferrer Mac-Gregor a la Resolución de la Corte Interamericana de Derechos Humanos de 20 de marzo de 2013. (Caso Gelman Vs. Uruguay. Supervisión de Cumplimiento de Sentencia).Ver "Control de Convencionalidad". Cuadernillo de Jurisprudencia de la CIDH N7, 16-17. Caso Gelman Vs. Uruguay. Supervisión de Cumplimiento de Sentencia. Resolución de la Corte Interamericana de Derechos Humanos de 20 de marzo de 2013 , párr. 67-69.

${ }^{18}$ Receptada esta ampliación de las funciones de la responsabilidad, en el art. 1708: Las disposiciones de este Título son aplicables a la prevención del daño y a su reparación”. En los fundamentos del nuevo Código Civil y Comercial se dice que: "en los derechos de incidencia colectiva, surge con claridad que la prevención es prioritaria y precede a la reparación, sobre todo cuando se trata de bienes que no se pueden recomponer fácilmente (...)".

${ }^{19}$ En ese sentido Pizarro manifiesta que "La finalidad perseguida es prevenir los atentados ambientales y, producidos éstos, exteriorizar una reacción vigorosa del sistema en todos los planos: penal, resarcitorio y administrativo. Urge implementar técnicas adecuadas para desmantelar los efectos de los ilícitos ambientales, que actúen como instrumentos eficaces de prevención, neutralización, reparación y punición del daño ambiental”. Cfr. PIZARRO, Ramón Daniel. "Responsabilidad civil por daño ambiental", Tutela Jurídica del Medio Ambiente, Ediciones de la Academia Nacional de Derecho y Ciencias Sociales de Córdoba, Volumen XLV, año 2008, ISBN 978-987-1123-48-3, pág. 156.

${ }^{20}$ Respecto a esto la CSJN ha manifestado que "en la tutela del bien colectivo configurado por el ambiente, tiene una prioridad absoluta la prevención del daño futuro, en segundo lugar debe perseguirse la recomposición de la polución ambiental ya causada y finalmente, para el supuesto de daños irreversibles, se tratará del resarcimiento"(...) para la tutela de un bien colectivo, el que por su naturaleza jurídica, es de uso común, indivisible y está tutelado de una manera no disponible por las partes, primero corresponde la prevención, luego la recomposición y, en ausencia de toda posibilidad, se 
No se trata de una reparación meramente pecuniaria, sino una reparación en especie, que implica restablecer las cosas al estado en que se encontraban antes de la producción del hecho dañoso. Esta primitiva obligación de recomponer el daño ambiental tiene fuente constitucional (art. 41), el mandato imperativo determina que "el daño ambiental generará prioritariamente la obligación de recomponer, según lo establezca la ley" (artículo 41 de la Constitución Nacional).

"Conforme nuestro régimen vigente, daño ambiental, equivale a daño ambiental de incidencia colectiva (lesión de intereses y derechos de incidencia colectiva en términos constitucionales)" (Morales Lamberti,2008:12). "Nuestro régimen de responsabilidad ambiental promueve la evitación de nuevos y futuros PA y se constituye en un instrumento eficaz para la reparación de daños ambientales colectivos" (Morales Lamberti,2008:11). Pero no comprendería en un sentido estricto, desde un punto de vista técnico-jurídico, la responsabilidad por remediación de PA (preexistente y residual) (Morales Lamberti,2008:11), surgiendo la problemática de ¿quién debe cargar con los costes (sociales y ambientales) de la contaminación del pasado?

El conflicto que plantean los PA es su inserción en nuestro sistema normativo de responsabilidad ambiental, de esto se desprende el siguiente interrogante: ¿cómo abordar técnica y jurídicamente a los PA en el marco normativo de atribución de responsabilidad? Plausiblemente del mandato de la LGA surge a través del principio de responsabilidad que "el generador de efectos degradantes del ambiente, actuales o futuros, es responsable de los costos de las acciones preventivas y correctivas de recomposición (...)" (artículo 4, Ley 25.675), pero no abarca aquellos sitios con contaminación histórica, cuyos efectos se manifiestan en el presente pero su causa fuente de gestación es pretérita.

Sin embargo, la primera cuestión a dilucidar es ¿qué entendemos por PA? Antes que nada hay que destacar que un PA no es necesariamente daño ambiental; dicho de otro modo, no se sigue que un pasivo ambiental se exteriorice en un daño. Esto encierra un problema conceptual porque si puede que no haya daño, ¿por qué se lo define constantemente (en la doctrina y en la legislación) como una especie de daño o conjunto de daños ${ }^{21}$

Esto se debe a que es necesario identificar y diferenciar la categoría de PA configurado y PA contingente de acuerdo al grado de configuración (conforme al grado de certeza de su ocurrencia). En el primer caso al PA sí se lo puede categorizar como una especie o categoría de daño ambiental especial, que generará prioritariamente su recomposición, restauración o eventualmente su compensación (Morales Lamberti,2008:8). En el segundo caso, el PA refiere a la probabilidad de que un daño ocurra (en términos potenciales), pero no se conoce a ciencia cierta si eso ocurrirá ${ }^{22}$.

dará lugar al resarcimiento (art. 28, ley 25675)”. CSJN, autos Mendoza, Beatriz Silvia y otros c/ Estado Nacional y otros s/ daños y perjuicios (daños derivados de la contaminación ambiental del Río Matanza - Riachuelo) M. 1569. XL; ORI Pronunciamiento de fecha 20/06/2006.

${ }^{21}$ A modo de ejemplo dentro del sistema encontramos algunas normativas provinciales que abordan el tema. La Ley $\mathrm{N}^{\mathrm{o}}$ 14.343 - Ley de Regulación de Pasivos Ambientales de la Provincia de Buenos Aires- brinda una definición legal de pasivo ambiental “... se entenderá por pasivo ambiental al conjunto de los daños ambientales, en términos de contaminación del agua, del suelo, del aire, del deterioro de los recursos naturales y de los ecosistemas, producidos por cualquier tipo de actividad pública o privada, durante su funcionamiento ordinario o por hechos imprevistos a lo largo de su historia, que constituyan un riesgo permanente y/o potencial para la salud de la población, el ecosistema circundante y la propiedad, y que haya sido abandonado por el responsable". En un sentido concordante encontramos la Ley 10208 - Ley de Política Ambiental de la Provincia de Córdoba- que en su artículo 89 estipula que "se entiende por pasivo ambiental al conjunto de impactos ambientales negativos e irreversibles que impliquen el deterioro de los recursos naturales y de los ecosistemas, producidos por cualquier tipo de actividad pública o privada, durante su funcionamiento ordinario o por hechos imprevistos a lo largo de su historia, que constituyan un riesgo permanente o potencial para la salud humana, el ecosistema o la propiedad".

${ }^{22}$ Se asocia a la idea de riesgo, por ejemplo un depósito de residuos peligrosos es un potencial riesgo de daño ambiental, ya que si no es debidamente tratado, si no se realiza la correcta disposición, operación de cierre, pos cierre o si permanecen acumulados en estado de abandono, esos hechos generan un pasivo ambiental, que no implica, necesariamente, que el daño ambiental colectivo -en los términos del art. 27 de la LGA- esté materializado o configurado. 
"El término PA tiene orígenes empresariales" (Russi y Martínez-Alier, 2002:108). "El "pasivo" es una de las dos partidas fundamentales en el balance de una compañía o en la contabilidad departida doble. En inglés es liability and assets; en español, pasivos y activos" (Cardoso, 2016: 94).

En ese sentido, el PA se plasma en un asiento contable (existencia, reconocimiento del PA), materializado como una obligación de incurrir en un gasto (erogación). Puede que se conozca el alcance del PA (costo cierto), o que sea una posible obligación (contingente), ya que el cumplimiento o exigencia puede o no ocurrir; el PA está identificado en uno y otro caso (sea configurado o contingente). La diferencia radica en la probabilidad de que la erogación deba efectivamente efectuarse, con grado de exactitud al tratarse de un PA configurado o con un halo de incertidumbre al tratarse de un PA contingente ${ }^{23}$, constituyendo una obligación posible "cuya existencia puede ser consecuencia, con cierto grado de incertidumbre, de un suceso futuro o no ser susceptible de cuantificación en un determinado momento" (Morales Lamberti, 2008: 119).

En términos jurídicos se podría decir que "un PA es una obligación legal de pagar una suma de dinero o incurrir en un gasto, por lo que subyace la idea de que un pasivo supone necesariamente la existencia de un responsable" (UPME, 2002: 2). "Es una obligación -una deuda social, económica y ambientalque se deriva de la mitigación, recomposición, remediación por un impacto no mitigado" (Morales Lamberti, 2008: 303) o por el potencial riesgo de que un daño ambiental se configure, que responde a un legado de contaminación histórica ${ }^{24}$.

La gestión de pasivos ambientales genera un problema intergeneracional, porque fácticamente nos encontramos ante sitios contaminados en un estado de deterioro y degradación, generalmente en estado de abandono o inactivos, sin ningún tipo de medida de mitigación y remediación. Dicha situación constituye un riego potencial y permanente, que configura la probabilidad de que un daño ambiental se materialice. "Su configuración exige siempre como obligación ambiental y social su saneamiento" (Morales Lamberti, 2008: 303), lo que implicará la obligación de incurrir en un gasto (sea de prevención, gestión, remediación del sitio contaminado).

Se debe incorporar al análisis el factor temporal porque es una contaminación que se comenzó a originar en el pasado pero sus efectos se trasladan a la actualidad; si bien se empezó a gestar en un momento anterior tiene actualidad al no encontrarse debidamente (en términos técnicos y jurídicos) remediado. Por lo tanto, encontramos una "conjunción de momentos temporales distintos": por un lado, el momento de la gestación del PA y por otro el momento en que se comienzan a evidenciar sus posibles efectos, lo que plantea una proyección temporal: es un hecho que se origina en una causa de gestación pretérita pero cuyos efectos están presentes y latentes, no solo en la actualidad sino con la posibilidad de seguir arrastrando ese legado de contaminación hacia el futuro.

Si no es posible identificar al causante del PA o si el mismo resulta insolvente, el Estado debe asumir una posición en torno a la problemática, es por eso que se genera una responsabilidad subsidiaria del Estado, quien termina absorbiendo los PA, para evitar seguir traspasándolos generacionalmente. Los PA constituyen un riesgo fiscal, ya que esos costos no internalizado por el causante se convierten en pasivos fiscales del presente (Morales Lamberti: 2008, 228).

Se genera un conflicto temporo-espacial por las propias condiciones que presentan los PA, ya sea por materializase o por representar un riesgo potencial y permanente de DA, que lo sufrieron en el pasado, se sufre en el presente y se puede trasladar hacia el futuro, lo que conlleva la necesidad de una visión

\footnotetext{
${ }^{23}$ El término surge del concepto contable de pasivo, que engloba todas las obligaciones que asume una entidad (persona física o jurídica con obligación de llevar libros contables). A este término se le añade el adjetivo contingente, que a su vez procede de contingencia, en el sentido de que dicha obligación no es segura, pero puede producirse en un futuro previsible. Conforme Morales Lamberti, Alicia (2008). Pág. 119.

${ }^{24}$ El ministerio de ambiente de Colombia los define como "impactos ambientales negativos, ubicados y delimitados geográficamente, que no fueron oportuna o adecuadamente mitigados, compensados, corregidos o recuperados; causados por actividades antrópicas y que pueden generar un riesgo a la salud humana o al ambiente" (Minambiente-Innova, 2015, p. 28).
} 
diacrónica por los efectos intergeneracionales que se evidencian. Indubitablemente la cuestión es compleja: la afección recae en derechos de incidencia colectiva, "de predominante base social, que requiere inexorablemente una mirada hacia el pasado que se arrastra hacia el futuro". "Este concepto de tiempo y espacio ayuda a entender la herencia del pasado y las relaciones o interconexiones con el futuro. Estamos esencialmente vinculados a otras generaciones, pasadas y futuras" (George, 2012: 33).

\title{
V. Reparación Integral y Garantía de no repetición. ¿Cómo se enriquece nuestro sistema con los estándares de protección del SIDH?
}

Como se puede observar la reparación es un derecho con estatus constitucional ${ }^{25}$ y requiere ser releído (en el engranaje de nuestro sistema de fuentes) con un contenido predominante social y colectivo $^{26}$. La propia $\operatorname{CSJN}^{27}$ precisó el contenido del derecho de reparación: "todo aquel que cause daño ambiental es responsable de restablecer las cosas al estado anterior a su producción (art. 41 de la Constitución Nacional, art. 27 de la ley 25.675)".

De allí que la máxima reparación integral se reafirma, refuerza e enriquece en la interconexión del medio ambiente y los derechos humanos, por medio de una interpretación hermenéutica y progresiva: "la interrelación entre los derechos humanos y el medio ambiente, y los derechos humanos afectados por causa de la degradación del medio ambiente, incluyendo el derecho a un medio ambiente sano" (Corte Interamericana de Derechos Humanos) ${ }^{28}$.

\begin{abstract}
El derecho humano a un medio ambiente sano se ha entendido como un derecho con connotaciones tanto individuales como colectivas. En su dimensión colectiva, el derecho a un medio ambiente sano constituye un interés universal, que se debe tanto a las generaciones presentes y futuras. Ahora bien, el derecho al medio ambiente sano también tiene una dimensión individual, en la medida en que su vulneración puede tener repercusiones directas o indirectas sobre las personas debido a su conexidad con otros derechos, tales como el derecho a la salud, la integridad personal o la vida, entre otros (Corte Interamericana de Derechos Humanos) $)^{29}$.
\end{abstract}

"La propia CIDH ha reconocido la necesidad de tutelar los derechos económicos, sociales, culturales y ambientales (DESCA)" (Morales Lamberti, 2015: 146) ${ }^{30}$, no sólo en su dimensión individual sino

\footnotetext{
${ }^{25}$ Como destaca el Dr. de Lázzari, la Corte Nacional brindó sustento constitucional al derecho a la reparación en los fallos "Santa Coloma” (Fallos: 308:1160), “Gunther" (Fallos: 308:1118) y "Luján” (Fallos: 308:1109) del 5/08/86, que extrajo del "alterum non laedere" del art. 19 de la C.N. (conceptos "entrañalablemente unidos" según la Corte). No es el único fundamento. También, como ha señalado Sagüés ("Notas sobre el derecho constitucional a la reparación", E.D. del 2/06/03) se lo ha considerado derecho inferido de los arts. 14 y 17 de la C.N. (C.S.J.N., "Motor Once", E.D. 134-411), derivado del fin de afianzar lajusticia contenido en el preámbulo ("Santa Coloma"), o como derecho implícito o no enumerado del art.33 de la C.N.. Y, a partir de la reforma constitucional de 1994, inferido de disposiciones de tratados de derechos humanos, como el art. 10 de la C.A.D.H. que reconoce el derecho a la reparación del que ha sido condenado penalmente y luego absuelto en un juicio de revisión, del art. 13 que reconoce la reparación de daños a la reputación de las personas causados por la prensa, o el art. 63 de la misma convención que establece que la Corte Interamericana puede disponer que se reparen las consecuencias de la medida considerada violatoria de los derechos por ella tutelados. Cfr. Expte. Nro. 110.669- Sala I Cámara de Apelación en lo Civil y Comercial del Departamento Judicial Mercedes de la Pcia. de Buenos Aires- Autos: Acevedo, Hilda y ots. c/ Hosp. Municip. M. y L. De la Vega y otros. s/ Daños y perjuicios. Sentencia del 12 de Junio de 2007.

${ }^{26}$ En este sentido, a su vez corresponde justipreciar las consecuencias que afecten a la víctima, tanto desde el punto de vista individual como desde el social, lo que le confiere un marco de valoración más amplio. Cfr. CSJN Ramírez, Juan Carlos c/ Entidad Nacional Yaciretá. Sentencia de fecha 11 de julio de 2007.

${ }^{27}$ Cruz, Felipa y Otros c/ Minera Alumbrera Limited y otro s/ Sumarísimo de fecha 23 de febrero de 2016.

${ }^{28}$ CHID, Opinión Consultiva OC-23/17, párrf.46, de 15 de noviembre de 2017, solicitada por la República de ColombiaMedio ambiente y derechos humanos

${ }^{29}$ CHID, Opinión Consultiva OC-23/17, párrf.59, de 15 de noviembre de 2017, solicitada por la República de ColombiaMedio ambiente y derechos humanos.

${ }^{30}$ El preámbulo del Protocolo Adicional a la Convención Americana sobre Derechos Humanos en materia de Derechos Económicos, Sociales y Culturales (en adelante "Protocolo de San Salvador"), resalta la estrecha relación entre la vigencia de los derechos económicos, sociales y culturales -que incluye el derecho a un medio ambiente sano - y la de los derechos civiles y políticos, e indica que las diferentes categorías de derechos constituyen un todo indisoluble que encuentra su base en el reconocimiento de la dignidad de la persona humana, por lo cual exigen una tutela y promoción permanente con el
} 
también en su dimensión colectiva, redireccionando las pautas y estándares mínimos en materia de derechos humanos y el alcance (ampliación) de las reparaciones ante reclamos de tinte colectivo.

La especial naturaleza del derecho a un ambiente sano encuentra su fuente en los derechos de incidencia colectiva o en aquellos en los cuales prevalecen aspectos ligados a intereses colectivos o grupales" (...) "Son procesos en que el bien jurídico ambiental comprometido es colectivo, supraindividual, indivisible, impersonal y no fraccionable en cuotas adjudicables a cada uno de sus titulares en el sentido concordemente definido por esta Corte (...). Se trata, pues, únicamente de aquellos casos en que los derechos cuya tutela se persigue corresponden a un bien que pertenece a la esfera social y transindividual $^{31}$.

Esto "pone en evidencia que la línea directriz hermenéutica en estos casos se centra en la protección del medio ambiente como bien social de disfrute general e intergeneracional (...) este tipo de cuestiones deben examinarse a la luz del principio de equidad intergeneracional, en cuanto dispone que los responsables de la protección ambiental deberán velar por el uso y goce apropiado del ambiente por parte de las generaciones presentes y futuras ${ }^{32}$.

La reparación ha de ser integral, plena y eficaz ${ }^{33}$ lo que implica que debe (como ideal) eliminar los efectos del hecho y restablecer a la situación anterior, tratando de borrar o hacer desaparecer los efectos que la acción dañosa ha generado ${ }^{34}$. En ese sentido, la CIDH ha manifestado que "la reparación, como la palabra lo indica, está dada por las medidas que tienden a hacer desaparecer los efectos de la violación cometida" 35 . La CSJN ha manifestado que se deben realizar "todas las acciones que resulten necesarias para la recomposición integral de los daños colectivos ambientales causados" $" 36$.

La jurisprudencia internacional, y en particular de la Corte IDH, ha establecido reiteradamente que "la sentencia constituye per se una forma de reparación" 37 . Los estándares fijados en SIDH han delineado la obligación de reparación integral y garantía de no repetición estipulada en el art. 63 de la CADH.

La CIDH ha indicado que "toda violación de una obligación internacional que haya producido daño comporta el deber de repararlo adecuadamente y que esa disposición recoge una norma consuetudinaria que constituye uno de los principios fundamentales del Derecho Internacional contemporáneo sobre responsabilidad de un Estado. La reparación del daño requiere, siempre que sea posible, la plena restitución, que consiste en el restablecimiento de la situación anterior.

De no ser esto factible, como ocurre en la mayoría de los casos de violaciones a derechos humanos, el Tribunal determinará medidas para garantizar los derechos conculcados y reparar las consecuencias que las infracciones produjeron. Por tanto, la Corte ha considerado la necesidad de otorgar diversas medidas de reparación, a fin de resarcir los daños de manera integral, por lo que además de las compensaciones

objeto de lograr su vigencia plena, sin que jamás pueda justificarse la violación de unos en aras de la realización de otros. (CHID, Opinión Consultiva OC-23/17, de 15 de noviembre de 2017, solicitada por la República de Colombia- Medio ambiente y derechos humanos).

${ }^{31}$ CSJN: Asociación de Superficiarios de la Patagonia c/ Y.P.F. S.A. y otros s/ daño ambiental. Sentencia de fecha 29 de agosto de 2006.

${ }^{32}$ Ibídem.

${ }^{33} \mathrm{El} \mathrm{CCyC}$ establece en su art.1740que la reparación del daño debe ser plena. Consiste en la restitución de la situación del damnificado al estado anterior al hecho dañoso (...).

${ }^{34}$ Incluso en daños inconmensurables como lo es el daño al medio ambiente lo que se pretende es conmensurarlos, cumpliendo una función compensatoria.

35 Cfr. Caso Velásquez Rodríguez Vs. Honduras. Reparaciones y Costas, párr. 25, y Caso López Lone y otros Vs. Honduras. Excepción Preliminar, Fondo, Reparaciones y Costas. Sentencia de 05 de octubre de 2015. Serie C No. 302, párr. 286. Caso Garrido y Baigorria Vs. Argentina Sentencia de 27 de agosto de 1998 (Reparaciones Y Costas), párr. 41.

${ }^{36}$ Asociación de Superficiarios de la Patagonia c/ Y.P.F. S.A. y otros s/ daño ambiental. Sentencia de fecha 29/08/2006

${ }^{37}$ Cfr. Caso Neira Alegría y otros Vs. Perú. Reparaciones y Costas, párr. 56, y aso de personas dominicanas y haitianas expulsadas Vs. República Dominicana. Excepciones Preliminares, Fondo, Reparaciones y Costas. Sentencia de 28 de agosto de 2014. Serie C No. 282, párr. 448. Caso de los Pueblos Indígenas Kuna de Madungandí y Emberá de Bayano y sus miembros vs. Panamá. Sentencia de 14 de octubre de 2014(Excepciones Preliminares, Fondo, Reparaciones y Costas), párr. 206. Pueblo indígena Kichwa de Sarayaku vs. Ecuador sentencia de 27 de junio de 2012 (Fondo y Reparaciones), párr. 285. Caso del Pueblo Saramaka vs. Surinam. Sentenciadel 28 de noviembre de 2007 (Excepciones Preliminares, Fondo, Reparaciones y Costas), párr. 195. Caso Claude Reyes y otros Vs. Chile Sentencia de 19 de septiembre de 2006 (Fondo, Reparaciones y Costas), párr. 156. 
pecuniarias, las medidas de restitución, satisfacción y garantías de no repetición tienen especial relevancia por los daños ocasionados ${ }^{38}$.

La remediación de un PA tiene efectos en el presente y persigue una finalidad generacional: por un lado, se determina la atribución de responsabilidades derivadas de conductas adoptadas en el pasado y, por otro lado, el objeto de la decisión se orienta hacia el futuro, para evitar el traspaso de legados de contaminación a las generaciones futuras y apreciar (ponderadamente) las alteraciones que puedan producirse en el ambiente y en la sociedad (actual y futura). De allí que toda medida que se adopte debe tener indefectiblemente en cuenta esta temporalidad intergeneracional.

En este sentido, la garantía de no repetición, pretende que violaciones similares no vuelvan a ocurrir. Llevan ínsitamente una "vocación transformadora de dicha situación, de tal forma que las mismas tengan un efecto no sólo restitutivo" 39 (remediar la situación del pasado que se traslada a días de hoy) "sino también correctivo hacia el futuro" ${ }^{40}$. En propias palabras de la CIDH, "las garantías de no repetición adquieren una mayor relevancia como medida de reparación, a fin de que hechos similares no se vuelvan a repetir y contribuyan a la prevención"41.

De esto se sigue, que la garantía de no repetición indica un expreso mandato positivo al Estado (más allá de que se determine o no el causante del PA) de sanear el arrastre de un legado de contaminación y de actuar para evitar el agravamiento del PA (nueva acumulación) y nueva generación de PA -cese, paralización y evitación de los posibles efectos negativos que se pueden sobrevenir- ${ }^{42}$, lo que implica una mira generacional del problema, remediación de PA generados en el pasado con una proyección hacia el presente (evitando que el PA ocasiona efectivamente un daño) y futuro (desde un accionar preventivo y precautorio en la generación de nuevos PA).

\section{expresión}

Por último, corresponde analizar la fijación de una indemnización. La CIDH señaló que la

justa indemnización' utilizada en el artículo 63.1 de la Convención es 'compensatoria y no sancionatoria' y que el Derecho internacional desconoce la imposición de indemnizaciones 'ejemplarizantes o disuasivas'. Igualmente, expresó que el derecho internacional de los derechos humanos no tiene por objeto imponer penas a las personas culpables de sus violaciones, sino amparar a las víctimas y disponer la reparación de los daños que les hayan sido causados ${ }^{43}$.

La CSJN ha determinado "que resulta inconstitucional una indemnización que no fuera "justa", puesto que "indemnizar es [...] eximir de todo daño y perjuicio mediante un cabal resarcimiento", lo cual no se logra "si el daño o el perjuicio subsisten en cualquier medida" (...) En definitiva, negar una indemnización integral, justa y equitativa no se encontraría en armonía con uno de los principios

\footnotetext{
${ }^{38}$ Cfr. Caso Velásquez Rodríguez Vs. Honduras. Reparaciones y Costas, párr. 25 y Caso López Lone y otros Vs. Honduras. Excepción Preliminar, Fondo, Reparaciones y Costas. Sentencia de 05 de octubre de 2015. Serie C No. 302, párr. 286. Caso Castillo Páez Vs. Perú. Reparaciones y Costas, párr. 50, y Caso López Lone y otros Vs. honduras, párr. 286. comunidad garífuna triunfo de la cruz y sus miembros vs. honduras. Sentencia de 8 de octubre de 2015 (Fondo, Reparaciones y Costas), párr. 254-255. Pueblo Indígena Kichwa de Sarayaku vs. Ecuador. Sentencia de 27 de junio de 2012 (Fondo y Reparaciones), párr. 279-280. Caso Claude Reyes y otros Vs. Chile. Sentencia de 19 de septiembre de 2006 (Fondo, Reparaciones y Costas), párr. 150-151.

${ }^{39}$ Corte IDH, Atala Riffo y Niñas c. Chile, sentencia de fondo, reparaciones y costas. Sentencia del 24 de febrero de 2012 , párr.267.

${ }^{40}$ Ibídem.

${ }^{41}$ Caso Luna López vs. Honduras. Sentencia de 10 de octubre de 2013 (Fondo, Reparaciones y Costas), párr. 234. En igual sentido, Caso Claude Reyes y otros Vs. Chile. Sentencia de 19 de septiembre de 2006 (Fondo, Reparaciones y Costas), párr. 151: Es necesario añadir las medidas de carácter positivo que el Estado debe adoptar para asegurar que no se repitan hechos.

${ }^{42}$ Ciclo que se observa en el art. 1710 del CCyC: deber de prevención del daño. Toda persona tiene el deber, en cuanto de ella dependa, de: a) evitar causar un daño no justificado; b) adoptar, de buena fe y conforme a las circunstancias, las medidas razonables para evitar que se produzca un daño, o disminuir su magnitud; c) no agravar el daño, si ya se produjo.

${ }^{43}$ Caso Velásquez Rodríguez, Indemnización Compensatoria, supra 40, párr. 38 y Caso Godínez Cruz, Indemnización Compensatoria, supra 40, párr. Caso Fairén Garbi y Solís Corrales, Sentencia del 15 de marzo de 1989. Serie C No. 6, párr. 136. Caso Garrido y Baigorria Vs. Argentina Sentencia de 27 de agosto de 1998 (Reparaciones y Costas), párr. 44.
} 
señeros de nuestra Constitución Nacional y del derecho Internacional de los derechos humanos, como es el de la justicia social" 44 .

La gestión de los PA implica remediar, sanear, efectuar una correcta disposición final para alcanzar niveles tolerables en la capacidad de auto regeneración del ambiente afectado. Sin embargo, aún si ello fuere posible no podremos afirmar que se logró una recomposición integral ${ }^{45}$, sobre todo cuando estamos en presencia de efectos irreversibles. Incluso cuando la recomposición no resulte técnicamente factible se prevé la indemnización sustitutiva de carácter compensatorio, cuya determinación se torna sumamente complejo debido a que sería necesario conocer y fijar el valor o utilidad social y ambiental - para las generaciones actuales y futuras- del conjunto de los recursos y flujo de servicios ambientales46.

\section{Reflexiones Finales}

El análisis anterior ha procurado delinear la necesaria interacción entre los derechos humanos y el medio ambiente, enriquecido desde una dimensión social del derecho, a través de una interpretación integrativa y sistemática de nuestro sistema de fuentes, haciendo énfasis en la problemática de los PA, con referencias a la reparación integral y garantías de no repetición.

Se genera un conflicto temporo-espacial por las propias condiciones que presentan los PA, ya sea por materializase o por representar un riesgo potencial y permanente de daño ambiental, que lo sufrieron en el pasado, se sufre en el presente y se puede trasladar hacia el futuro, lo que conlleva la necesidad de una visión diacrónica por los efectos intergeneracionales que se evidencian.

Desde esta perspectiva, medidas de no repetición, garantizan hacia el futuro que esos hechos que lesionan, amenazan, restringen o alteren los derechos y garantías reconocidos no se repetirán. Es un modo de subsanar y compensar los errores hacia el pasado, como así también de evitar el agravamiento y nueva generación de PA - cese, paralización y evitación de los posibles efectos negativos que se pueden sobrevenir-. Lo que implica una mira generacional del problema: remediación de PA generados en el pasado con una proyección hacia el presente (evitando que el PA ocasiona efectivamente un daño) y futuro (desde un accionar preventivo y precautorio en la generación de nuevos PA).

Por otro lado, las medidas de remediación y/o recomposición integral pretenden brindar una solución al problema en un sentido dialógico pasado-presente-futuro, compensando una deuda social y ambiental que se arrastra de tiempos pretéritos, que perjudica por sobre todo a sectores vulnerables y desprotegidos, evitando que el PA devenga en un DAC con efectos presentes y futuros, lo que en última instancia implica un corte del traspaso del problema hacia las generaciones futuras (de generación en generación).

"Si se tiene presente que los derechos humanos se centran en las personas excluidas, marginadas o que se encuentran en una situación de riesgo" (Morales Lamberti, 2015: 161) y vulnerabilidad, la interacción entre los derechos humanos y el medio ambiente brinda nuevas herramientas y garantías para enfrentar este tipo de problemas intergeneracionales, enriquecido con una visión integral y

44 Ramírez, Juan Carlos c/ Entidad Nacional Yaciretá. Sentencia de fecha 11 de julio de 2007.

${ }^{45}$ Que implica tener en cuenta el estado de los recursos naturales y flujos de servicios ambientales desde que se produjo el daño hasta el momento en que la reparación aproxime al máximo a esos recursos y servicios a su estado original -teniendo en cuenta un nivel cuantitativo y cualitativo-. Entre la remediación y la recomposición habrá una relación de graduación.

46 "Lo censurable es precisamente el fundamentalismo neoconservador de querer absolutizar el mercado, reduciendo de esa forma todo el desafío de la sustentabilidad a una cuestión de asignación de "precios correctos" a la naturaleza. Por supuesto, es mejor tener alguna noción del valor económico que poseen los bienes y servicios ambientales, por más arbitraria que sea ésta, que no disponer de ninguna herramienta que asista a la toma de decisiones en esa área. Como dice Paul Hawken, "mientras no existe ningún modo 'correcto' para valorar un bosque o un río, sí existe una forma incorrecta, que es no asignar ningún valor" (Prugh et al., 1995: XV)”. Guimarães, R. La ética de la sustentabilidad y la formulación de políticas de desarrollo. Pág. 57. 
amplificada de los derechos (de una faz netamente individual a una mirada social-colectiva), como es el derecho de una reparación plena, integral y efectiva de quienes están afectados y discriminados socio-territorialmente, por arrastrar un legado de contaminación histórica, tendientes a revertir esa desigualdad ambiental y garantizar que esa situación de desprotección no se vuelva a repetir (Morales Lamberti, 2015: 161).

\section{Bibliografía}

Cardoso, A. (2016). Pasivos ambientales de la minería de carbón en Colombia: una aproximación desde la ecología política. Ecología Política, 94-98.

DoronI, G. (2017, enero-marzo). ¿Podemos hablar del principio de estado de derecho ambiental? Revista de Derecho Ambiental, 49, 109-122. Abeledo Perrot.

Doroni, G. (2017, 17 agosto). Hacia la posible configuración del principio de Estado de Derecho Ambiental (Parte I), Diario DPI-Diario Ambiental, 165.

Doroni, G.; Pezzano, L. (2017, noviembre). Hacia la posible configuración de un orden público ambiental internacional. Revista Iberoamericana de Derecho Internacional y de la Integración, 47.

George, C.J (2012). Justicia intergeneracional: la satisfacción de las necesidades y no de la codicia. Recuperado en http://www.socialwatch.org/sites/default/files/JusticiaIntergeneracional2012_esp.pdf

Jordano Fraga, J. (2007, Madrid-mayo). La administración en el Estado Ambiental de Derecho. Revista de Administración Pública, 173, 101-141. Madrid.

Loperena Rota, D. (1998). Los principios del Derecho Ambiental. Madrid: Civitas.

Lorenzetti, R. (2008). Teoría del Derecho Ambiental. Buenos Aires: La Ley.

Morales lamberti, A. (2008). Gestión y Remediación de Pasivos Ambientales. Estudios de Derecho Ambiental, 1(1), 3-237. Córdoba.

(2015). Dimensión social y colectiva de los derechos humanos: relacionalidad e influencias del paradigma ambiental. En Cafferatta, N. (Dir.), Derecho Ambiental-Dimensión social (407-429). Santa Fe: Rubinzal-Culzoni.

(2015, Junio-Septiembre). Los derechos humanos en el Código Civil y Comercial, como fuente de integración hermenéutica y reconocimiento axiológico en la aplicación del derecho ambiental. En Revista de Derecho Ambiental, 45, 140-163.

Pizarro, R. D. (2008). Responsabilidad civil por daño ambiental. Tutela Jurídica del Medio Ambiente, Ediciones de la Academia Nacional de Derecho y Ciencias Sociales de Córdoba, XLV, 149-195.

Russi, D. y Martínez-Alier, J. (2002). Pasivos ambientales. Debates ambientales, (S/D) 107-112.

Sticca, María Alejandra (2013). Algunas reflexiones acerca del derecho al medio ambiente sano como derecho humano. En Rey Caro, E. (Coord.). El Derecho Internacional Público como norma de conducta de los Estados (311-338). Córdoba: Gráfica Trejo.

Unidad de Planificación Minero Energética (UPME) (2002). Metodología para la valorización de pasivos ambientales en el sector eléctrico. Colombia. 


\title{
HACIA UNA LEY PARA EL RECONOCIMIENTO Y GARANTÍA DE DERECHOS DE LOS AFECTADOS AMBIENTALES
}

\author{
TOWARDS A LAW FOR THE RECOGNITION AND RIGHTS GUARANTEE FOR \\ ENVIRONMENTALLY AFFECTED PEOPLES
}

\author{
Cecilia Carrizo Sineiro \\ (Universidad Nacional de Córdoba / Argentina) \\ cecicarrizosineiro@gmail.com \\ Mauricio Berger \\ (Universidad Nacional de Córdoba / Argentina) \\ mauricio.berger@unc.edu.ar
}

Recibido: $14 / 09 / 2018$

Aprobado: 30/10/2018

\section{RESUMEN}

Inscribimos nuestro trabajo dentro de los desarrollos contemporáneos de la Teoría Crítica y la Justicia Ambiental, entendiendo a ésta como la ampliación e institucionalización de relaciones de reconocimiento ante la creciente conculcación de derechos e intereses colectivos en situaciones de contaminación ambiental. Desde una perspectiva pragmatista, apostamos a una Justicia tridimensional para la estructuración de un proceso de elaboración de ley que parta de casos concretos, de la experiencia y producción de saberes y conocimientos para la resolución de este problema público.

Reconocimiento, Representación y Redistribución (Compensación o Resarcimiento) constituyen las tres dimensiones consideradas claves para responder a los reclamos por daños individuales, colectivos, intereses difusos.

Desde este marco en primer lugar analizamos críticamente aspectos del Código Civil y Comercial de la Nación; en segundo lugar acudimos al análisis de legislación afín en la región, de México y Colombia, que avanzan en la conformación de un sistema institucional para el resarcimiento integral de víctimas. La presentación constituye un informe de avance de un trabajo que realizamos con una metodología de co-investigación, en un proceso dialógico con grupos de afectados ambientales de la provincia de CórdobaArgentina, académicos, operadores jurídicos, legisladores y otros ciudadanos, de manera consistente con el carácter deliberativo y público de la Justicia Ambiental.

Palabras clave: Justicia Ambiental. Reconocimiento. Ley. Resarcimiento. Afectados Ambientales.

\section{ABSTRACT}

We inscribe our work within the contemporary developments of Critical Theory and Environmental Justice, understanding the latter as the extension and institutionalization of recognition relationships in the face of the growing violation of collective rights and interests in situations of environmental contamination. From a pragmatist perspective, we place a three-dimensional Justice for the structuring of a law-making process that departs 
from concrete cases, experience and production of knowledge for the resolution of this public problem.

Recognition, Representation and Redistribution (Compensation) are the three dimensions considered key to respond to claims for individual, collective, and diffuse interests.

From this framework we first critically analyze aspects of the Civil and Commercial Code of the Nation; Secondly, we went to the analysis of related legislation in the region, of Mexico and Colombia, which are advancing in the conformation of an institutional system for the integral reparation of victims.

The presentation is a progress report of a work we do with a co-research methodology, in a dialogical process with groups of environmental affected people from the province of Córdoba-Argentina, academics, legal operators, legislators and other citizens, in a consistent manner with the deliberative and public nature of Environmental Justice.

Keywords: Environmental Justice. Recognition. Law. Compensation. Environmentally Affected Peoples.

\section{Introducción}

La gravedad y magnitud de la conculcación de derechos individuales y colectivos a causa de situaciones de contaminación ambiental en la Provincia de Córdoba y en Argentina, vienen siendo denunciadas y judicializadas por afectados. Estos han logrado sentencias por la aplicación de leyes penales, amparos y medidas cautelares por parte de la Administración de Justicia. Sin embargo, es recurrente la quita de responsabilidad tanto de los funcionarios públicos como de los agentes privados $\mathrm{y}$, consecuentemente, la deuda en materia de remediación del ambiente y más aún de resarcimiento para los afectados. A pesar de importantes fallos en materia de contaminación por agrotóxicos, megaminería, obras de infraestructura, no se constatan medidas de restitución, rehabilitación, compensación, satisfacción y garantías de no repetición, en sus dimensiones individual, colectiva, material, moral y simbólica.

La pregunta es entonces por la posibilidad de instaurar, vía un proceso de generación de ley, mecanismos institucionales en los tres poderes públicos para la conformación de un sistema precautorio y, ante su posible falla, el funcionamiento de mecanismos y procedimientos para atender a los afectados ambientales. La inclusión de esta temática en la gramática de la ley, constituye un avance en la autocomprensión de una sociedad democrática en el horizonte utópico de la Justicia Ambiental. Precisamente en un contexto de puesta en cuestión del derecho por el avance de la soft law de la governance corporativa, que diluye las responsabilidades públicas y privadas, estimamos relevante precisar la propuesta de una teoría de la Justicia tridimensional para la elaboración de un proyecto de ley para los afectados ambientales.

Desde una perspectiva pragmatista, que parte de contextos intersubjetivos concretos, nuestra propuesta comprende tres dimensiones consideradas fundamentales para la estructuración de un proceso de elaboración, por medio del cual las estructuras del Estado Democrático de Derecho y la sociedad civil reconozcan y garanticen derechos a los afectados.

La primera dimensión, considera las sistemáticas situaciones de menosprecio y agravio que padecen los grupos de afectados ambientales que acumulan formas de discriminación o estigmatización. La segunda dimensión considera el desigual acceso a las estructuras de representación política, y por lo tanto, las dificultades de los afectados para procesar sus demandas de manera que sean efectivamente atendidas por el sistema oficial de autoridad. La tercera dimensión da cuenta de la distribución desigual y sistemática del daño, la contaminación y consecuentemente de las posibilidades para la realización de proyectos y planes de vida.

Desde este marco en primer lugar analizamos críticamente aspectos del Código Civil y Comercial de la Nación; en segundo lugar acudimos al análisis de legislación afín en la región, de México y Colombia, 
que avanzan en la conformación de un sistema institucional para el resarcimiento integral de víctimas. La presentación constituye un informe de avance de un trabajo que realizamos con una metodología de co-investigación, en un proceso dialógico con grupos de afectados ambientales de la provincia de Córdoba- Argentina, académicos, operadores jurídicos, legisladores y otros ciudadanos, de manera consistente con el carácter deliberativo y público de la Justicia Ambiental.

\section{Marco conceptual}

Desde el análisis de casos concretos de conculcación de derechos en situaciones de contaminación, apelamos a la reconstrucción de la Teoría del reconocimiento que realiza Axel Honneth, al giro jurídico habermasiano y a la propuesta de una Justicia tridimensional de Nancy Fraser para la elaboración de un proyecto de Ley para Afectados Ambientales.

De Axel Honneth interesan sus aportes en torno al concepto de lucha basada en los sentimientos morales de injusticia, experiencias de menosprecio y agravio que son vivenciadas por todo un grupo y que influyen en la acción colectiva, exigiendo la ampliación de las relaciones de reconocimiento en el estado por medio del derecho (Honneth, 1997: 197). El derecho se comprende aquí como una forma de reconocimiento recíproco, que se extiende a todos los seres libres e iguales en tanto operaciones cognitivas de entendimiento donde los sujetos se reconocen en su responsabilidad moral. Las luchas por derechos desde situaciones de contaminación ambiental, conforman vastas redes de afectados y de actores con estos comprometidos (profesionales, académicos, activistas, operadores jurídicos, miembros de organizaciones de la sociedad civil local, nacional e internacional, etc.) (Carrizo y Berger, 2013). La pluralidad de acciones y saberes que despliegan, la conformación de públicos interesados, la diseminación de temas y procesos de articulación entre los mismos que tienen lugar en el espacio público informal y formal, así como la invocación del reconocimiento oficial estatal de dichas situaciones, conforma los mismos como densos problemas públicos que interpelan a la estructura y funcionamiento de los tres poderes del estado (Cefai, 2013; Gusfield, 2014; Naishtat, 2005). El reconocimiento y garantía de derechos de los afectados se liga así a la capacidad del Estado Democrático de Derecho (EDD) de conformar un sistema, precisando, a través de la codificación del derecho, instituciones, competencias, normas y procedimientos, así como su aplicación y funcionamiento, ampliando las relaciones de reconocimiento institucional hacia nuevas comprensiones e incluso y nuevos derechos surgidos de una lucha moralmente motivada (Habermas, 2010; Fiss, 2007).

Desde nuestra comprensión de la Justicia Ambiental, "entendemos que los flujos comunicativos que conforman una democracia deliberativa, y que avanzan en la construcción de una estructura política defensiva del ambiente y los derechos, deben encontrar su materialización en el lenguaje y la práctica del derecho en tanto medio de resolución de conflictos y por lo tanto de integración social de una sociedad compleja (Carrizo, 2012: 172).

Como señaláramos en un trabajo anterior:

Desde la reconstrucción habermasiana del derecho como medio de integración social de las sociedades complejas, recuperamos el carácter procedimental y radicalmente democrático de la generación de derecho, en tanto prácticas comunicativas del espacio público que se traducen en poder administrativo. La producción de enunciados racionales se procesan y actualizan en el marco de procedimientos del EDD como sistema de derechos, en el que se expresa la voluntad común de los miembros de una comunidad jurídica, creando un lenguaje particular para una comunidad jurídica particular por el que los miembros examinan las normas y les prestan o no su asentimiento. Desde una moral autónoma y racional posconvencional, descentrada, la racionalización del mundo de la vida viene a orientar la acción a través de un saber que permanece virtual hasta que los agentes se apropian de él y lo traducen en su práctica (Ferreyra, Carrizo y Berger, 2015: 7).

Desde la teoría de la acción comunicativa, se considera esa transferencia de saber a la acción como incierta, debido a la fragilidad propia del modo de autorregulación de los sujetos, derivada del exigente nivel de abstracción requerido y de los falibles procesos de socialización democrática habidos. En ese 
sentido, desde el giro jurídico habermasiano, adquieren nueva importancia los procesos de elaboración de ley que institucionalizan un sistema jurídico en tanto complemento de una moral racional de un modo eficaz para la acción. De nuestra lectura de Habermas consideramos que:

\begin{abstract}
el derecho es al mismo tiempo un sistema de saber y un sistema de acción. El primero, como texto de proposiciones e interpretaciones normativas; el segundo, como complejo de elementos regulativos de la acción, es decir, como institución. Desde esta perspectiva, la institucionalización jurídica de la red de discursos y negociaciones del modelo procesual, garantizan la vigencia del EDD, a través de principios de universalización y de adecuación en las decisiones judiciales articuladas según la lógica de la argumentación en cada uno de los contextos de interacción intersubjetiva, y conforme a las pretensiones de validez en juego. (Ferreyra, Carrizo y Berger, 2015: 7).
\end{abstract}

Desde este marco, la dimensión del reconocimiento, se dirige a contemplar las sistemáticas y particulares situaciones de menosprecio y agravio que padecen los grupos de afectados ambientales. En consonancia con los estudios empíricos del movimiento mundial de Justicia Ambiental (Schlosberg, 2013), que dan cuenta de una desigual distribución de las situaciones de contaminación, vislumbramos desde nuestros trabajos una acumulación de formas de discriminación, estigmatización y segregación sobre estos individuos y colectivos (de clase, raciales y de género). Consideramos que la institucionalización de formas de reconocimiento en las estructuras del estado democrático de derecho deben tomar en cuenta estas particulares formas de afectación a condiciones de vida concretas.

Una segunda dimensión comprende cuestiones de representación. El desigual acceso de estos individuos y colectivos a la estructuras de representación política, genera dificultades tanto en lo que respecta al procesamiento de sus demandas para que sean efectivamente atendidas por el sistema oficial de autoridad, como con respecto al acceso a la justicia. Desde esta dimensión se profundiza la exigencia del derecho ambiental de la efectiva participación de los afectados, la institucionalización de mecanismos de representación-participación de los mismos con criterios de inclusividad y paridad participativa ${ }^{1}$.

La tercera dimensión comprende cuestiones de redistribución. La desigual y sistemática distribución del daño, así como el carácter colectivo del mismo afecta la calidad de vida y sus entornos, la salud individual y colectiva, así como las posibilidades para la realización de planes de vida. Desde este plano, un concepto de justicia debe contemplar e institucionalizar un sistema precautorio en los tres poderes del estado y también mecanismos de compensación para responder a los reclamos ante su falla para hacer frente a los daños individuales, colectivos, intereses difusos; materiales y simbólicos.

El análisis de los procesos de elaboración de ley y de la gramática efectiva de las luchas por derechos de los afectados, nos llevan a precisar sobre estas dimensiones por su impacto/incidencia/exigencias a los tres poderes del estado. Nos interesa avanzar entonces en dilucidar cómo estas dimensiones pueden plasmarse en un proceso de juridificación - una Ley de Afectados Ambientales- para que las estructuras del Estado Democrático de Derecho reconozcan y garanticen sus derechos.

\footnotetext{
${ }^{1}$ Fraser señala que el re-enmarcamiento de las dimensiones de justicia en mundo en globalización se dirige a superar las injusticias que tienen lugar cuando reglas de decisión privan o reducen la voz política a personas que cuentan como miembros, "perjudicando su capacidad de participar como partes en la interacción social" (Fraser 2008: 22). La representación fallida, el des-enmarque o la injusta asignación de marco aportan a visibilizar la específica e implícita dimensión política de la gramática de la justicia. Desde algunos estudios sobre la governance, el aludido des- enmarque no sólo es leído como un efecto de des-localización de los poderes públicos, producto la globalización capitalista; sino también como un efecto activamente producido por la intermediación de estructuras de governance corporativa. Kjaer (2014), señala una profundización de la superposición de una pluralidad de órdenes normativos, de reglas y de tomas de decisión que ya no se fijan por las formas y fronteras institucionales del derecho y de la ley público-estatal/inter-estatal. Nuevos mecanismos se destacan: estrategias de coordinación abiertas, gobierno por objetivos, la "comitología", la responsabilidad social empresarial, la soft law, códigos de conducta voluntarios. Las estructuras de governance también avanzan sobre conceptos como esfera pública, representatividad y ley, sustituyéndolos por los de grupos de interés (multi-stakeholders), como conjunto institucionalizado de actores que ostentan el estatuto de partes afectadas que participan de procesos de toma de decisión en un orden post-westfaliano (Berger y Carrizo, 2016).
} 


\section{A. El nuevo Código Civil y Comercial de la Nación}

A continuación, indagamos críticamente algunos aspectos del nuevo Código Civil y Comercial de la Nación (CCyCN), fundamentalmente desde la dimensión del reconocimiento, a fin de precisar los límites y posibilidades de un proceso de elaboración de ley basado en las experiencias situadas de los afectados ambientales y su investigación. Nos centramos en dos cuestiones, consideradas claves para la propuesta de un proceso de elaboración de ley efectivo: la responsabilidad del estado y el criterio de causalidad.

\section{A.1. Responsabilidad del Estado}

La institucionalización del bloque jurídico ambiental en Argentina, tiene en el Art. 41 de la Constitución Nacional su clave de bóveda: "Las autoridades proveerán a la protección de este derecho (al ambiente sano)... Corresponde a la Nación dictar las normas que contengan los presupuestos mínimos de protección, $\mathrm{y}$ a las provincias, las necesarias para complementarlas, sin que aquéllas alteren las jurisdicciones locales...”.

Conforme a la etimología del verbo proveer, son las autoridades del estado democrático de derecho quienes tienen la competencia para pre-ver, la sagacidad para preparar, reunir, suministrar, disponer, mantener lo necesario o conducente a un fin, en este caso, el reconocimiento y garantía de este derecho. Desde su análisis genealógico sobre el poder en Occidente, Agamben (2008) precisa el paradigma del oficio, en el que se articula la acción humana, la ética, la política y la economía en la modernidad (Agamben, 2012). Esta tutela se ve exigida hoy ante la formulación de un sistema precautorio en la sociedad del riesgo, ante la posibilidad de ocurrencia de daños desconocidos e irreparables.

En Argentina sin embargo, apartándose del Proyecto de reforma original del año 1998 y del Anteproyecto de 2012, la reforma del Código Civil y Comercial de la Nación (CCyCN) terminó instituyendo un desigual tratamiento del daño - según este ocurra en instancias civiles o públicaseludiendo la responsabilidad civil del estado, revirtiendo una vasta jurisprudencia de la Corte. Se quiebra una tradición jurídica que regulaba la responsabilidad del Estado nacional, provincial y municipal en las disposiciones del derogado Código Civil. Desde la reforma constitucional de 1994, la tendencia había sido la restauración de la primacía del derecho constitucional, reforzada por la armonización con los tratados internacionales de Derechos Humanos; restringiendo la existencia de una división tajante entre derecho público y derecho privado, y que esferas de la vida social quedaran por debajo de dichos compromisos.

En un marco de disputas teóricas y prácticas por la orientación e impactos de los cambios en curso respecto a la forma estatal en un mundo en globalización, la modificación acontecida respecto a la responsabilidad del Estado no resulta un mero dato coyuntural, sino un hito en los intentos por instaurar una articulación diferente entre el Estado y la Sociedad y entre las instancias federales y provinciales. También en la tendencia centrífuga que asumen estas últimas respecto a las prescripciones impartidas desde el sistema institucional y particularmente de las previstas en el $\mathrm{CCyCN}$, en lo que aquí respecta de singular relevancia para pensar en la diferenciación de un sistema precautorio entre los distintos poderes y jurisdicciones del estado.

Desde esta perspectiva entendemos junto a Espeche (2017), que lo establecido por el art. 1765 del CCyCN: "La responsabilidad del Estado se rige por las normas y principios del derecho administrativo nacional o local según corresponda" y por el art. 1766: "Los hechos y las omisiones de los funcionarios públicos en el ejercicio de sus funciones por no cumplir sino de una manera irregular las obligaciones legales que les están impuestas se rigen por las normas y principios del derecho administrativo nacional o local, según corresponda", comisionan competencias exclusivas y excluyentes del Congreso Nacional (art. 75, inc. 12, de la CN) y siendo prohibida esta delegación por el art. 76 de la $\mathrm{CN}$ las mismas devienen inconstitucionales: "Las provincias no ejercen el poder 
delegado a la Nación (art. 126 de la $C N$ ), y es una atribución delegada y exclusiva en el Congreso Nacional la de dictar los Códigos Civil y Comercial (art. 75, inc. 12, de la CN) en cuerpos unificados o separados (como lo es la Ley 26.944) y la delegación legislativa sólo está autorizada al Poder Ejecutivo Nacional, no a las provincias, y en materias determinadas de administración y prohibida en lo que se refiere a responsabilidad del Estado (art.76 de la CN)."

Al respecto, Ibarlucía (2014) advierte también que el tratamiento de la responsabilidad del estado en el CCyCN se restrinja al Estado Nacional, que se prohíba expresamente la aplicación directa o subsidiaria del Código Civil y que se deje abierto a la decisión de las provincias y municipios la adhesión al mismo, abre la posibilidad de una pluralidad de soluciones y su consecuente afectación a la seguridad jurídica y al principio de igualdad ante la ley del art. 16 de la CN. Por su parte, a nuestro entender, la habilitación al particular para activar el control judicial de constitucionalidad, lejos de una garantía de acceso a la administración de justicia para casos donde lo que se trata son temas vinculados a la vida y la salud se constituye en una doble victimización y en la promoción de una litigiosidad intratable por el sistema.

¿Es valioso que la Nación, las provincias e incluso los municipios reglamenten la responsabilidad del Estado frente a los particulares a su manera? Consideramos que puede generarse una "atomización" legislativa preocupante. En lo que hace al foco de este trabajo, que es la creación de un sistema precautorio que involucre a los tres poderes del estado, interesan las obligaciones del Estado. Este es quien debe responder de modo principal y directo por las consecuencias dañosas directas de su acción u omisión, estando dicha responsabilidad basada en la falta de servicio y definida por la Corte como una violación o anormalidad frente a las obligaciones del servicio regular. Por caso, en relación a las víctimas y el grado de previsibilidad del daño, el acento está puesto aquí respecto a la necesaria prestación de un servicio de vigilancia epidemiológica por parte del sistema de salud y la efectiva realización de análisis sistemáticos a la población afectada, única forma de constituir una prueba concluyente respecto a la puesta en peligro de la población indefensa por parte de factores contaminantes (Ferreyra, 2017).

La sustitución del viejo artículo 1112 del CC: "Los hechos y las omisiones de los funcionarios públicos en el ejercicio de sus funciones, por no cumplir sino de una manera irregular las obligaciones legales que les están impuestas, son comprendidos en las disposiciones de este título", socavan a nuestro entender y en nuestro contexto, la plena vigencia del principio general alterum non laedere, en tanto disminuyen las posibilidades de los afectados ambientales de acceder a una situación justa. Prácticas profesionales indolentes (Carrizo y Berger, 2013), producen un menoscabo al acceso al resarcimiento por daños, a los sistemas especiales de responsabilidad o indemnizaciones, es decir limitan el derecho a una reparación integral derivado de la vigencia de dicho principio general que establece el art. 19 de la Constitución Nacional, según el cual se "prohíbe a los 'hombres' perjudicar los derechos de un tercero", principio que se encuentra 'entrañablemente vinculado a la idea de reparación' y que regula cualquier disciplina jurídica. ${ }^{2}$

\section{A.2. El criterio de causalidad}

Otro tema clave es la necesaria actualización del criterio de causalidad, acorde con la introducción del principio de indeterminación. En este sentido, observamos también la Ley de Responsabilidad del Estado 26.944 sancionada en el 2014. Desde nuestra perspectiva es posible observar los artículos 3 y 4 , considerando la efectiva vigencia del principio precautorio y el necesario pasaje a la creación de un sistema precautorio. Al sostenimiento de un principio de causalidad epistemológicamente, se suma en la mencionada ley la inobservancia de otro de los desarrollos claves del derecho ambiental, la

\footnotetext{
${ }^{2}$ En Brasil, la responsabilidad de los agentes públicos frente al Estado incluye un tipo especial de responsabilidad, además de las clásicas civil, penal, administrativa y política: la "responsabilidad por actos de improbidad administrativa" de base constitucional, art. 37.4 de la Constitución de 1988, reglamentado por la Lei de Improbidade Administrativa 8.429/92, lo cual constituye una gran originalidad en el ámbito latinoamericano y merece ser divulgado.
} 
inversión de la carga de la prueba. En sendos incisos a) y c) de los mencionados artículos, precisamente no solo no contemplan el principio de inversión de carga de la prueba del derecho ambiental, sino que exigen una relación de causalidad no sólo directa (en caso de actividad estatal ilegítima), sino incluso "inmediata y exclusiva entre la actividad estatal y el daño" (en caso de actividad estatal legítima). Desde estos señalamientos, sostenemos que un proceso de elaboración de ley debe apelar a desarrollos que permitan superar las limitaciones del CCyCN y la Ley de Responsabilidad del Estado, instaurando avances en la consideración del daño y el riesgo.

Es frente a estas exigencias que la noción de daño de Lukas Meyer (2017) viene a delinear un camino a indagar. Siguiendo al autor, que la persona sea dañada de acuerdo a la noción del umbral de daño, no implica necesariamente una peor condición entre un momento y otro, sino que esta persona esté en una peor condición que aquella en la que debería estar. En este sentido el compromiso normativo es que la persona venga a la existencia en un estado no dañado. Consideramos que esta definición aporta un avance respecto a la indefensión actual de víctimas inocentes y una posible base para acciones de reparación a afectados ambientales, fundamentalmente aquellos que son traídos a la existencia en un estado dañado a causa de factores de contaminación que probadamente tienen efectos genotóxicos y alteran el desarrollo embrionario (malformaciones). El debate se abre ya no sobre una indeterminada causalidad, sino sobre criterios normativos, interdisciplinarios- georeferenciados, que tomando como base el carácter situado de los casos de contaminación, provean herramientas jurídicas para la especificación de un umbral, las prioridades, el tipo de compensaciones, como exigencias y posibilidades para una justicia intergeneracional.

\section{B. Leyes de Víctimas en México y Colombia}

Tras realizar un relevamiento de marcos legales para el reconocimiento a las víctimas en América Latina, hemos identificado dos leyes paradigmáticas, la Ley de Víctimas y Restitución de Tierras de Colombia, y la Ley General de Víctimas de México. La ley colombiana tiene por objeto establecer un conjunto de medidas judiciales, administrativas, sociales y económicas, individuales y colectivas, en beneficio de las víctimas de las violaciones de derechos en relación al conflicto armado en dicho país, dentro de un marco de justicia transicional, que posibiliten hacer efectivo el goce de sus derechos a la verdad, la justicia y la reparación con garantía de no repetición, de modo que se reconozca su condición de víctimas y se dignifique a través de la materialización de sus derechos constitucionales. La ley mexicana, por su parte obliga, en sus respectivas competencias, a las autoridades de todos los ámbitos de gobierno, y de sus poderes constitucionales, así como a cualquiera de sus oficinas, dependencias, organismos o instituciones públicas o privadas que velen por la protección de las víctimas, a proporcionar ayuda, asistencia o reparación integral.

Realizamos un análisis comparativo, del cual aquí ponemos a consideración dos puntos: la definición del sujeto que realiza la ley- en este caso la noción de víctima- y luego, la institucionalidad que crean estas leyes.

\section{B.1. La definición del sujeto: ¿quién cuenta como víctima?}

En los textos analizados, las víctimas son aquellas personas individuales o colectivas (organizaciones sociales, etc.) que hayan sufrido un daño o menoscabo a sus derechos por la comisión de un delito/ violación de $\mathrm{DDHH}$, con independencia de la identificación y sanción del victimario. También indirectamente quienes se solidarizan con la situación de la víctima y al hacerlo sufren un daño.

En el caso de la Ley de Víctimas y Restitución de Tierras de Colombia: El Título I de la Ley, se ocupa del concepto de víctima: serán víctimas "aquellas personas que individual o colectivamente hayan sufrido un daño por hechos ocurridos a partir del $1^{\circ}$ enero de 1985 , como consecuencia de infracciones al Derecho Internacional Humanitario o de violaciones graves y manifiestas a las normas 
internacionales de Derechos Humanos, ocurridas con ocasión del conflicto armado"3. Víctima será toda persona que sufra un daño como consecuencia de violaciones a las normas de Derechos Humanos o infracciones al DIH, independientemente de quién fue el victimario. De la misma forma, se consideran víctimas las personas que hayan sufrido un daño al intervenir para asistir a la víctima en peligro o para prevenir la victimización. Lo que aquí interesa es que la condición de víctima se adquiere con independencia de que se individualice, aprehenda, procese o condene al autor de la conducta punible y de la relación familiar que pueda existir entre el autor y la víctima.

En el caso de la Ley de Victimas de México, se denominan víctimas directas aquellas personas físicas que hayan sufrido algún daño o menoscabo económico, físico, mental, emocional, o en general cualquiera puesta en peligro o lesión a sus bienes jurídicos o derechos como consecuencia de la comisión de un delito o violaciones a sus derechos humanos reconocidos en la Constitución y en los Tratados Internacionales de los que el Estado Mexicano sea Parte. Son víctimas indirectas los familiares o aquellas personas físicas a cargo de la víctima directa que tengan una relación inmediata con ella. Son víctimas potenciales las personas físicas cuya integridad física o derechos peligren por prestar asistencia a la víctima ya sea por impedir o detener la violación de derechos o la comisión de un delito. La calidad de víctimas se adquiere también con la acreditación del daño o menoscabo de los derechos en los términos establecidos en la presente Ley, con independencia de que se identifique, aprehenda, o condene al responsable del daño o de que la víctima participe en algún procedimiento judicial o administrativo. También incluye en el reconocimiento de víctimas a los grupos, comunidades u organizaciones sociales que hubieran sido afectadas en sus derechos, intereses o bienes jurídicos colectivos como resultado de la comisión de un delito o la violación de derechos ${ }^{4}$.

Proyectando estos aportes a la conceptualización del afectado ambiental para el proceso de elaboración de ley que hemos iniciado, consideramos que la desvinculación de la acreditación del daño respecto a la identificación de su responsable permite superar el obstáculo de la causalidad para definir la condición de afectado, a la vez que presenta nuevas dificultades, por caso ¿en manos de quién queda la definición del afectado? ¿quién queda comprendido por esta definición? Podemos recurrir a Fraser para aportar a esta nueva problematización, en tanto el foco al que alude está puesto en la formación y toma de decisiones de la comunidad política: "La cuestión clave es cómo delimitar la idea de estar afectado en su justa medida para que se convierta en norma operativa para evaluar la justicia de los diversos marcos"... "el problema es que según el llamado efecto mariposa, es posible aducir pruebas de que casi todo está afectado por todo. Lo que se requiere, por tanto, es una manera de distinguir entre los niveles y tipos de efectividad que son suficientes para conferir condición moral y los que no lo son. (...) Mi propio punto de vista es que el principio de todos los afectados está abierto a una pluralidad de razonables interpretaciones". (Fraser, 2008: 56-57). En consecuencia, para la autora no puede determinarse su interpretación monológicamente, sino que los análisis filosóficos y sociológicos de la condición de afectado deberían entenderse como contribuciones a un debate público más amplio sobre el sentido del principio.

\section{B.2. La institucionalidad para el reconocimiento, distribución y participación/ representación de las víctimas}

En el caso de Colombia, la ley instituye una serie de derechos que contemplan: Derecho a la verdad, justicia y reparación; Derecho a acudir a escenarios de diálogo institucional y comunitario; Derecho a ser beneficiario de las acciones afirmativas adelantadas por el Estado para proteger y garantizar el derecho a la vida en condiciones de dignidad; Derecho a solicitar y recibir atención humanitaria; Derecho a participar en la formulación, implementación y seguimiento de la política pública de prevención, atención y reparación integral; Derecho a que la política pública de que trata la presente

\footnotetext{
${ }^{3}$ Ley 1448 de Víctimas y Restitución de Tierras, Colombia. Fuente:

http://www.centrodememoriahistorica.gov.co/micrositios/caminosParaLaMemoria/descargables/ley1448.pdf

${ }^{4}$ Ley General de Víctimas, México. Fuente:

https://www.juridicas.unam.mx/legislacion/ordenamiento/ley-general-de-victimas
} 
ley tenga enfoque diferencial; Derecho a la reunificación familiar cuando por razón de su tipo de victimización se haya dividido el núcleo familiar; Derecho a retornar a su lugar de origen o reubicarse en condiciones de voluntariedad, seguridad y dignidad, en el marco de la política de seguridad nacional; Derecho a la restitución de la tierra si hubiere sido despojado de ella, en los términos establecidos en la presente ley; Derecho a la información sobre las rutas y los medios de acceso a las medidas que se establecen en la presente ley; Derecho a conocer el estado de procesos judiciales y administrativos que se estén adelantando, en los que tengan un interés como parte o intervinientes; Derecho de las mujeres a vivir libres de violencia, entre otros derechos que implican el acceso a los sistemas de salud, educación y de administración de justicia penal ${ }^{5}$.

La institucionalidad para la atención y reparación de las víctimas a partir del reconocimiento de los derechos anteriormente consignados son:

- Red Nacional de Información para la Atención y Reparación a las Víctimas

- Registro único de víctimas,

- Sistema Nacional de Atención y Reparación Integral a las Víctimas,

- Comités territoriales de justicia transicional,

- Plan Nacional de Atención y Reparación Integral a las Víctimas,

- Fondo de Reparación para las Víctimas de la Violencia,

- Mesas de participación de víctimas y

- Mecanismos de monitoreo y seguimiento al cumplimiento de la ley ${ }^{6}$.

En el título referido a la institucionalidad para la atención y reparación a las víctimas, la ley establece que la Red Nacional de Información para la Atención y Reparación a las Víctimas será el instrumento que garantizará al Sistema Nacional de Atención y Reparación a las Víctimas una rápida y eficaz información nacional y regional sobre las violaciones de que trata la Ley; permitirá la identificación y el diagnóstico de las circunstancias que ocasionaron y ocasionan el daño a las víctimas; Evaluará la magnitud del problema, y permitirá al Sistema Nacional de Atención y Reparación Integral a las Víctimas adoptar las medidas para la atención inmediata, elaborar planes para la atención y reparación integral de las víctimas inscritas en el Registro Único de Víctimas; la Unidad Administrativa Especial para la Atención y Reparación Integral a las víctimas deberá garantizar la interoperabilidad de los sistemas de información de registro, atención y reparación a víctimas ${ }^{7}$.

La máxima autoridad es el Comité Ejecutivo para la atención y reparación a las víctimas, conformado por el Presidente de la República, o su representante, quien lo presidirá; el Ministro del Interior y de Justicia; el Ministro de Hacienda y Crédito Público; el Ministro de Agricultura y Desarrollo Rural; el Director del Departamento Nacional de Planeación; el Director de la Agencia Presidencial para la Acción Social y la Cooperación Internacional y el Director de la Unidad Administrativa Especial para la Atención y Reparación Integral a las Víctimas. Su objetivo es materializar los derechos a la verdad, la justicia y la reparación integral y sus funciones son: 1. Diseñar y adoptar las políticas, estrategias, planes, programas y proyectos para la atención, asistencia y reparación integral a las víctimas. 2. Diseñar, adoptar y aprobar el Plan Nacional de Atención y Reparación Integral de que trata la presente Ley. 3. Disponer que las entidades del Sistema Nacional de Atención y Reparación a las Víctimas garanticen la consecución de recursos presupuestales, y gestionar la consecución de los recursos financieros provenientes de fuentes de financiación diferentes al Presupuesto General de la Nación, para garantizar la adecuada y oportuna prestación de los servicios. 4. Apoyar y gestionar la consecución de recursos presupuestales para la ejecución de las políticas, estrategias, planes, proyectos

\footnotetext{
${ }^{5}$ Ley 1448 de Víctimas y Restitución de Tierras, Colombia. Fuente:

http://www.centrodememoriahistorica.gov.co/micrositios/caminosParaLaMemoria/descargables/ley1448.pdf

${ }^{6}$ Para más información sobre procedimientos que instituye la ley, sus medidas, planes y programas:

https://www.unidadvictimas.gov.co/

${ }^{7}$ Op cit. Ley de Víctimas y Restitución de Tierras, Colombia.
} 
y programas. 5. Aprobar las bases y criterios de la inversión pública en materia de atención, asistencia y reparación integral a las Víctimas, entre otras funciones ${ }^{8}$.

En el caso de la Ley de México, su Título Sexto contempla al Sistema Estatal de Víctimas, lo relativo a la Comisión Ejecutiva como organismo público descentralizado de la Secretaría General de Gobierno, cuyo objeto es posibilitar la representación y participación de las víctimas. Prevén las disposiciones de su organización y la coordinación de acciones; destaca la creación del Fondo Estatal de Ayuda, Asistencia y Reparación Integral para brindar los recursos necesarios tendientes precisamente, a la reparación integral de las víctimas; de igual modo, se prevé la creación del Registro Estatal de Víctimas como el mecanismo administrativo y técnico que soporta el proceso de ingreso y registro de la víctimas, que incluye representación explícita de los tres poderes públicos y organismos públicos de Derechos Humanos ${ }^{9}$.

El Sistema Nacional de Atención a Víctimas será la instancia superior de coordinación y formulación de políticas públicas y tendrá por objeto proponer, establecer y supervisar las directrices, servicios, planes, programas, proyectos, acciones institucionales e interinstitucionales, y demás políticas públicas que se implementen para la protección, ayuda, asistencia, atención, acceso a la justicia, a la verdad y a la reparación integral a las víctimas en los ámbitos local, federal y municipal. El Sistema tiene por objeto la coordinación de instrumentos, políticas, servicios y acciones entre las instituciones y organismos ya existentes y los creados por esta Ley para la protección de los derechos de las víctimas. Para la operación del Sistema y el cumplimiento de sus atribuciones, el Sistema contará con una Comisión Ejecutiva y Comisiones de víctimas, quienes conocerán y resolverán los asuntos de su competencia, de conformidad con las disposiciones aplicables. Las Comisiones de víctimas también tienen la obligación de atender, asistir y, en su caso, reparar a las víctimas de delitos del fuero común o de violaciones a derechos humanos cometidos por servidores públicos del orden estatal o municipal ${ }^{10}$.

Continuando con la estructura del texto legislativo en relación a la institucionalidad para el reconocimiento y protección de las víctimas, la ley contempla la creación de un órgano desconcentrado de la Secretaría General de Gobierno, denominado "Asesoría Jurídica" cuyo objeto es operar, coordinar, dirigir y controlar la defensa especializada para víctima; al efecto, se han previsto las disposiciones relativas a la organización y funcionamiento de dicho órgano desconcentrado. En esta tesitura, el Título Quinto de la Ley que se propone prevé las obligaciones del asesor jurídico en términos generales y en supuestos particulares por materia; por su parte el Título Sexto establece la existencia del Centro de Atención e Información para todas las Víctimas y Ofendidos que requieran asistencia jurídica; finalmente, el Título Séptimo contempla las causas del retiro del patrocinio, los impedimentos para la designación de asesores jurídicos y el régimen de responsabilidades ${ }^{11}$.

Realizando nuevamente un ejercicio de proyección de las instituciones que crean las leyes analizadas para una institucionalidad específica del reconocimiento de los afectados ambientales, remarcamos en primer lugar la perspectiva de un sistema complejo que articula jurisdicciones, poderes y una diversidad de actores. Desde nuestra investigación, la reconstrucción que hemos realizado junto a los afectados ambientales en nuestro país nos presenta un escenario de fragmentación, falta de actualización e interacciones intra e inter- institucionales, rasgos que hemos caracterizado como de Estado Incivil (Carrizo y Berger, 2009). Desde la revisión realizada consideramos que una institucionalidad acorde a la complejidad y una política del reconocimiento debe orientarse por una perspectiva de integración de sistemas involucrados.

En segundo lugar, y en lo que refiere a la dimensión de la representación, consideramos clave la inclusividad de los afectados y cláusulas que garanticen la paridad participativa de todos los sujetos intervinientes, en su condición de afectados directos o indirectos. La reconstrucción realizada desde la

\footnotetext{
${ }^{8}$ Op cit. Ley de Víctimas y Restitución de Tierras, Colombia.

${ }^{9}$ Op. cit. Ley General de Víctimas, México.

${ }^{10}$ Op. cit. Ley General de Víctimas, México.

${ }^{11}$ Sitio Web del sistema estatal de víctimas: http://ceavem.edomex.gob.mx/seav
} 
investigación de casos concretos en nuestro país, da cuenta de una serie de dispositivos que modulan y o/ paralizan el ejercicio de derechos por prácticas de reorganización de la participación o de creciente burocratización. La participación ciudadana tiene la potencialidad de fungir como sensor democrático para la reflexividad de las instituciones. En general, el principio de todos los afectados debe interpretarse dialógicamente, por medio de un toma y daca de argumentos en deliberación democrática" (Fraser, 2008: 56- 57).

Por último, en relación a la dimensión de la redistribución de la Justicia Ambiental, contra la externalización de los costos ambientales injustamente sobre una población, podemos señalar dos niveles: uno, la creación de un Fondo específico para la reparación, y por otro, la efectiva asignación de partidas presupuestarias para el desarrollo de los planes y programas previstos por la ley.

\section{Consideraciones finales}

Investigando la experiencia de los afectados ambientales con las estructuras institucionales del estado, observamos una trama de negligencias y omisiones profesionales e institucionales con fuerte impacto negativo en el reconocimiento y la garantía del derecho al ambiente sano. Las acciones de la ciudadanía en defensa de sus derechos acuden tanto a la autoformación y auto- organización como a la invocación de las instituciones, tal el caso no sólo de los reclamos de intervención del Poder Ejecutivo a través de sus sistemas de salud y ambiente, sino al Poder Legislativo, con experiencias de elaboración de ordenanzas y leyes provinciales y nacionales protectivas frente a los impactos de la producción contaminante, y también en relación al Poder Judicial, vía la judicialización de numerosos conflictos ya sea por el recurso del amparo o de denuncias penales. Sin embargo, los Poderes Públicos parecieran- paradójicamente- cada vez más des-empoderados para actualizarse y avanzar en la superación de obstáculos para una actuación garantista.

Por ello, y a fin de contribuir a la autocomprensión democrática frente a las complejidades e incertezas en el abordaje de las problemáticas ambientales, apostamos a construir un sistema que trabaje institucionalizando una tutela de precaución para evitar el riesgo, anticipando la posibilidad de daño o en su defecto dirigiéndose a repararlo. A tal fin consideramos claves tanto la superación de nociones obstructivas de responsabilidades, causalidad y de la misma noción de afectado, así como intervenciones sectorializadas y fragmentadas, apostando a la construcción de un institucionalidad interministerial e interinstitucional, de amplia inserción territorial, con específicas instancias de participación y precisa implicación de los poderes públicos en los procesos de atención y reparación.

\section{Bibliografía}

Agamben, G. (2008). El Reino y la Gloria. Una genealogía teológica de la Economía y del Gobierno. Buenos Aires: Adriana Hidalgo.

(2012). Opus Dei. Arqueología del oficio. Buenos Aires: Adriana Hidalgo.

Berger, M. y Carrizo, C. (2016). Governance agro-biotecnológica y Justicia Ambiental. Tensiones en torno a la liberación de transgénicos en Brasil, México y Argentina. Política. Revista de Ciencia Política, 54(2), 127-151.

Carrizo, C. (2012). Una lectura del Fallo Horne desde la Justicia Ambiental. En Carrizo, C. y Berger, M. (comps.). Justicia Ambiental y Creatividad Democrática. Córdoba: Alción Editora.

Carrizo, C. y Berger, M. (2013). Prácticas médicas en un caso de contaminación ambiental. En Justicia Ambiental. El trabajo interdisciplinario en transgénicos y agrotóxicos (74-105). Córdoba: Edición de Autor. Disponible en: www.movimentocienciacidada.org/download/UjuZ9wWxs3E7b8sE6k0S.pdf 
Cefaï, D. (2013). L'expérience des publics: institution et réflexivité. EspacesTemps.net, Travaux. Disponible en: http://www.espacestemps.net/articles/lexperience-des-publics-institution-etreflexivite/

Echevesti, R. (2015). Código Civil y Comercial de la Nación. Diez puntos básicos en responsabilidad. Id SAIJ: DACF150819. Disponible en: http://www.saij.gob.ar/rosario-echevesti-codigo-civilcomercial-nacion-diez-puntos-basicos-responsabilidad-dacf150819-2015-11-10/123456789-0abcdefg9180-51fcanirtcod

Espeche, S.P. (2017). Análisis constitucional de la responsabilidad del Estado. MJ-DOC-11904-AR | MJD11904. Disponible en: https://aldiaargentina.microjuris.com/2017/08/23/analisis-constitucionalde-la-responsabilidad-del-estado-espeche-sebastian-p/

Ferreyra, Y. (2017). Poder Judicial y Luchas Ambientales. Análisis de dos casos paradigmáticos de contaminación por agrotóxicos: Ituzaingó Anexo, Córdoba y Leonesa- Las Palmas, Chaco. 20022012. [Tesis inédita de Doctorado]. Instituto de Investigación y Formación en Administración Pública. Universidad Nacional de Córdoba, Córdoba, Argentina.

Ferreyra, Y.; Carrizo, C. y Berger, M. (2015, noviembre). La actualización de la Administración de Justicia a través de la efectiva vigencia del Derecho Ambiental. Experiencias de Córdoba y Chaco, 2002-2015. En IPAP, Congreso Innovación en el Estado. Resistencia, Chaco..

Fiss, O. (2007). El derecho como razón pública. Madrid: Marcial Pons.

Fraser, N. (2008). Escalas de Justicia. Barcelona: Herder.

Gordillo, A. (2006). La defensa del Usuario y del Administrado. La Responsabilidad Civil de los Funcionarios. Tratado de Derecho Administrativo, tomo 2. Defensa del Usuario y del Administrado. Disponible en: https://www.gordillo.com/tomo2.php

Gusfield, J. (2014). La Cultura de los Problemas Públicos. Buenos Aires: S.XXI Editores.

Habermas, J. (2010). La idea de dignidad humana y la utopía realista de los Derechos Humanos. Anales de la Cátedra Francisco Suárez, 44 (2010), 105-121.

Honneth, A. (1997). La lucha por el reconocimiento. Por una gramática moral de los conflictos sociales. Barcelona: Grijalbo Mondadori.

Ibarlucia, E. (2014). Responsabilidad del Estado y de los funcionarios públicos. ¿Código Civil o ley provincial?. La Ley 07/07/2014, La Ley 2014-D, 739.

Kjaer, P. (2014). Towards a Sociology of Intermediary Institutions: The Role of Law in Corporatism, Neo-Corporatism and Governance. En Madsen, M. and Thornhill, C. (eds.). Law and the Formation of Modern Europe: Perspectives from the Historical Sociology of Law. Cambridge: Cambridge University Press.

Meyer, L. (2017). Justicia Intergeneracional. En Truccone Borgogno, S. (comp.). Justicia Intergeneracional: temas desde el pensamiento de Lukas H. Meyer y otros ensayos. Córdoba: UNC.

Naishtat, F. (2005). Problemas filosóficos en la acción individual y colectiva. Buenos Aires: Prometeo.

Schlosberg, D. (2013, february). Theorizing Environmental Justice: the expanding sphere of a discourse. Environmental Politics, 22(1). 


\title{
PROBLEMÁTICA JURÍDICA DE LA PRODUCCIÓN GANADERA SUSTENTABLE COMO FORMA DE MITIGAR EL CAMBIO CLIMÁTICO
}

\author{
LEGAL PROBLEMS IN SUSTAINABLE LIVESTOCK PRODUCTION AS A WAY OF \\ MITIGATING CLIMATE CHANGE
}

Martín Miguel Chalup

(Universidad Nacional del Nordeste / Argentina)

martin.m.chalup@gmail.com

Diego Eduardo Bissaro Fava

(Universidad Nacional del Nordeste / Argentina)

diemar.ciudad@gmail.com

Recibido: $11 / 09 / 2018$

Aprobado: 30/10/2018

\section{RESUMEN}

Las actividades agropecuarias, a nivel global tienen un impacto significativo prácticamente en todas las esferas del ambiente y recursos naturales. La ganadería es uno de los sectores económicos con repercusiones más graves en el ambiente, en todos los niveles, desde el local a lo mundial. En Corrientes ésta representa una de las principales actividades. En el presente trabajo abordamos la problemática de la producción ganadera en la provincia de Corrientes y reflexionamos acerca de cómo los instrumentos jurídicos que regulan ésta actividad colaboran con mitigar el cambio climático y promover una actividad ganadera sustentable. Para el trabajo utilizamos una metodología cualitativa, exploratoria, nos basamos en la observación del fenómeno, acompañado de descripciones, mediciones de organismos públicos y análisis comparativo. Las técnicas que se utilizaron fueron la revisión y exploración histórica y contextual de las normas e instrumentos jurídicos identificados. Primero abordamos la problemática desde el ámbito nacional, para luego ceñirnos en la regulación particular provincial. Por ultimo pudimos identificar mecanismos o instrumentos normativos alternativos. Esta revisión nos permitió detectar que en el ámbito de Corrientes existen normativas específicas referidas a áreas protegidas y a bosque nativos que establecen límites a la ganadería, con el fin de compatibilizar con la protección al ambiente. Sin embargo estas regulaciones no dan respuesta definitiva y solo dan soluciones parciales a las fuertes presiones que la legislación internacional demanda. Por otro lado los programas de promoción de la ganadería integrada y la certificación privada revalorizan la inclusión del recurso árbol en sistemas agro-ecológicos con énfasis en la captura de carbono, pero no quedan libres de cuestionamientos.

Palabras Claves: Actividad. Ambiente. Desarrollo Sostenible

\section{ABSCTRAC}

Agricultural activities, at the global level have a significant impact practically in all spheres of the environment and natural resources. Livestock is one of the economic sectors with more serious repercussions on the environment, at all levels, from local to global. In Corrientes, livestock represents one of the main activities. In this paper we address the 
problem of livestock production in the province of Corrientes and reflect about how the legal instruments that regulate this activity collaborate with mitigating climate change and promoting a sustainable livestock production. We use a qualitative, exploratory methodology, based on the observation of the phenomenon, accompanied by descriptions, measurements of public offices and comparative analysis. The techniques used were review and historical and contextual exploration of identified legal instruments and norms. First we address the issues from the national level, and then to focus on the particular provincial regulation. Finally, we were able to identify mechanisms or alternative policy instruments. This review allowed us to detect that there are specific rules in the field of streams referred to protected areas and forest natives to establish limits on livestock, in order to make compatible with the protection of the environment. However, these regulations do not give a definitive answer, not comprehensively address the problem of climate change and not respond to the strong pressures that international law demands. On the other hand the promotion of integrated livestock and private certification programs revalued the benefits that has the inclusion of trees in agro-ecological systems, mainly on carbon sequestration, but are not free of questioning.

Keywords: Activity. Environment. Sustainable Development

\section{Introducción}

La creciente demanda de alimentos y el aumento de tierras productivas nos obliga a pensar en un vínculo estrecho, entre la producción agropecuaria y la emisión de gases de efectos invernadero (GEI). Entonces, ¿Cómo se relaciona el cambio climático con la producción ganadera? Desde principio de tiempos el hombre transformo continuamente su entorno, logrando avances, pero también, altero ciclos propios de la naturaleza.

La producción agropecuaria es uno de los agentes determinantes del cambio climático que en los últimos años aumentó las proporciones de tierras cultivables en los países en vía de desarrollo y disminuyó en los países más desarrollados. Sector que responde a una demanda cada vez mayor y repercute directamente en los niveles de emisiones, que en los últimos años aumentó el 17\% a nivel mundial. En Argentina en el 2002 por ejemplo el 44\% de las emisiones provinieron del sector agropecuario y del cual el 60\% corresponden al ganado bovino (Santini \& Senetiner, 2011).

Las actividades tanto agrarias como pecuarias en general tienen un gran impacto significativo, prácticamente en todas las esferas del ambiente, incluyendo en el cambio climático. La ganadería es uno de los sectores económicos con repercusiones más graves en el ambiente, en todos los niveles, desde el local a lo mundial. En Argentina, esta actividad contribuye directamente a la emisión de GEI aportando el 35\% del total del País. Si bien no existe actualmente una exactitud para saber cuánto GEI emite un ganado en forma diaria, es posible obtener un aproximado a los valores de niveles de contaminación. Por ejemplo un bovino de $500 \mathrm{Kg}$ produce unos 1000 litros de gases diarios, de los cuales el $20 \%$ es gas metano. Este gas permanece en el ambiente (atmosfera) de 9 a 15 años y el poder de retención de calor ronda unas 21 veces superior al carbono en un siglo (Santini \& Senetiner, 2011; Steinfeld et al., 2009).

La práctica de la ganadería cuando es realizada de forma que sobrepasa la capacidad de recuperación del suelo y vegetación, produce consecuencias negativas al ambiente. En esta actividad, denominada sobrepastoreo, el pisoteo produce una modificación de los horizontes del suelo, generando y/o contribuyendo a fenómenos de erosión hídrica o eólica, que en algunos casos, lleva a procesos de desertificación y en ambientes vulnerables esta práctica degrada los suelos y la biodiversidad, disminuyendo el stock provocando la insostenibilidad de la práctica. (M. de A. y D. S.-R. Argentina, 2016). 
Si bien la evolución de la cantidad de cabezas de ganado bovino en Argentina tuvo un incremento hasta los años 60, y desde entonces permaneció estable (alrededor de 50 millones de cabezas), son de destacar los cambios respecto a la distribución geográfica. En las últimas décadas se registró un incremento del desplazamiento de la producción hacia las Provincias del norte del país, históricamente concentrada en la región Pampeana. Este desplazamiento se debe a la técnica de producción en feedlots aplicado al ganado bovino, así como la presión ejercida por otros usos del suelo, como la actividad agrícola por ejemplo la sojera que necesita el 100\% de los suelos y no podría ser compatible con el pastoreo (M. de A. y D. S.-R. Argentina, 2016).

En la región NEA de Argentina, encontramos áreas de más de 30 millones de hectáreas con gran diversidad de suelos y vegetación, pero con un componente común, la presencia del árbol. Dentro de la región mencionada la selva Misionera ocupa gran parte junto al bosque del parque chaqueño y también encontramos los suelos arenosos de la provincia de Corrientes y Entre Ríos (Mahecha, 2002; Joaquin \& Pérego, 2001)

En Corrientes la ganadería es una de las principales actividades económicas donde aproximadamente, pastan 4.165.000 bovinos y 2.292.000 cabezas de ganado ovino, esto tiene relevancia en la ganadería porque su stock representa el 9,9\% y $36 \%$ de las existencias bovinas a nivel nacional y del NEA. La actividad se desarrolla en la región conjuntamente con el monte natural y más recientemente como actividad complementaria en los montes implantados. Esta combinación se la define como Sistema Silvopastoril el cual es un "sistema sostenible de manejo de suelos, incrementándose el potencial productivo del mismo, ya que combina la producción de forrajeras, naturales o implantadas, árboles y animales sobre un mismo terreno" (Mahecha, 2002). Estudios realizados en Corrientes, comprobaron que 1 ha de producción conjunta de ganado y pasturas compensa la emisión de metano de cinco cabezas de ganado (Agritotal, 2017).

En el presente trabajo proponemos abordar la problemática de la producción ganadera en la provincia de Corrientes y reflexionamos acerca de ¿Cómo los instrumentos jurídicos que regulan ésta actividad colaboran con mitigar el Cambio Climático y promover una actividad ganadera sustentable? Para ello utilizamos una metodología cualitativa, exploratoria, nos basamos en la observación del fenómeno, acompañado de descripciones, mediciones de organismos públicos y análisis comparativo. Las técnicas que se utilizarán serán la revisión y exploración histórica y contextual de las normas e instrumentos jurídicos identificados.

Realizamos un abordaje de la situación actual de las normas y estándares que pretenden regular la actividad en las diferentes áreas y regiones, desde un plano nacional partiendo por nuestro ordenamiento fundamental, refiriendo a los convenios y tratados para desembarcar en la legislación local. Después de haber explorado y analizado críticamente las distintas fuentes de la actividad y las normas jurídicas, nos centramos en describir los acuerdos públicos y privados y modalidades de la actividad.

\section{Panorama jurídico Nacional}

El ambiente como bien jurídico protegido se estructura positivamente en un conjunto de normas, que simbólicamente, se consagran en múltiples instrumentos legales de diferente naturaleza que complejizan su materialidad y concreción. La norma central es el art. 41 de la Constitución Nacional de 1994 que consagra el derecho-deber a un ambiente sano, conjuntamente con los principios de preservación y de reparación, y desarrollo sustentable al establecer que deben satisfacer "las necesidades presentes sin comprometer las de las generaciones futuras". Coincidente con el concepto del informe de Brundtland, "Nuestro Futuro Común" (Brundtland, 1987). Teniendo como fuente los principales resultados de las conferencias y convenciones internacionales hasta 1994, generándose así un nuevo paradigma en el sistema productivo al que debe ajustarse la actividad económica. También el art $41 \mathrm{CN}$ impone a las autoridades como marco en la actividad productiva, proveer la "utilización 
racional de los recursos naturales", la "preservación del patrimonio natural" y "diversidad biológica" (Casella, 1997).

Por otra parte, el párrafo tercero del art. 41, dispone la "competencia nacional de dictar las normas que contengan los presupuestos mínimos de protección ambiental sin que aquellas alteren las jurisdicciones locales". Correlativamente, encomienda a las provincias dictar las normas para complementarlas, derivando en una delegación a favor de la Nación en lo que hace a la determinación de presupuestos mínimos (Sabsay \& Di Paola, 2002).

Pero el constituyente considero conveniente incorporar un límite a dicha competencia en el art. 124 de la C.N., al expresar que "corresponde a las provincias el dominio originario de los recursos naturales existentes en su territorio". Así el ejercicio de las facultades de la nación en dictar dichas normas no puede importar un vaciamiento del dominio que tienen las provincias sobre los recursos naturales en su territorio (Sabsay \& Di Paola, 2002). Esta distribución de competencia recibió el nombre de federalismo de concertación (Sabsay, 1997) o federalismo ambiental; para referirse al cambio en la forma de distribuir el poder vertical del Estado, en la concurrencia competencial entre Nación y Provincias (Esain, 2008).

A partir de la reforma constitucional de 1994 se abre camino a la internacionalización del derecho internacional (Agustín Alberto Gordillo, 2007) y nuestra Constitución reconoce a los tratados como normas vigentes en nuestro derecho en el art. $31^{1}$; Pero los ubica por encima de las leyes en el art. 72 inc. 22 generando que los tratados en materia de protección ambiental y recursos naturales adquieran una jerarquía como normas internas y superior a las leyes, siempre que estos tratados hayan sido ratificados por ley del Congreso. Esto da lugar a la ampliación de principios, reglas, restricciones e instrumentos en materia de derecho ambiental conformando un complejo entramado de normas que comprenden el bien jurídicamente protegido del ambiente.

Específicamente en materia de cambio climático en el orden internacional la temática se cristaliza con la Convención Marco de las Naciones Unidas sobre Cambio Climático (CMNUCC). Convenio que se abrió a firmas en la Conferencia de Río de Janeiro de 1992 a la que Argentina adhiere con la sanción de la ley 24295 (Congreso de la Nación Argentina, 1994).

El CMNUCC estaba basado en la equidad, traducida por el principio de responsabilidades comunes pero diferenciadas, siendo su objetivo último estabilizar las concentraciones de GEI en la atmosfera a un nivel que impida injerencia en un plazo razonable que permita a los ecosistemas recuperar su capacidad de carga y/o adaptarse naturalmente al cambio climático (Cafferatta, 2012), así brindar "un marco de cooperación de los Estados en orden a facilitar las acciones de mitigación." (Lucas Garín, 2017).

Dicho convenio, en su el art. 4 impone obligaciones a todos los Estados Parte: i) preparar inventarios nacionales de sus emisiones, ii) tomar medidas nacionales y regionales para atenuar dichas emisiones iii) adaptarse a los efectos del cambio climático, y iv) cooperar a estos fines (Cafferatta, 2012).

En 1997 se aprueba el Protocolo de Kioto, como acuerdo vinculado a la CMNUCC, con mayores exigencias elevando los compromisos de limitación y reducción de GEI.; El cual Argentina en 2001 lo aprobó como ley interna No 25438 (Congreso de la Nación Argentina, 2001)

El protocolo estableció una serie de compromisos vinculantes para las principales economías mundiales que lo hayan suscrito. Sin embargo, el modo para cumplirlo es flexible. De esta manera posibilita tres mecanismos para ayudar a las partes y promover el desarrollo sustentable: i)

\footnotetext{
1 "La Constitución de 1853/60 establecía un orden de prelación dentro del ámbito de su competencia territorial y en consonancia a los tiempos de su dictado; esa norma, más de un siglo después, debe ser entendida en consonancia con la jerarquía actualmente vigente de normas" (Gordillo, A., 2007 y N.D)
} 
implementación conjunta ii) régimen de venta de emisiones y iii) mecanismo de desarrollo limpio (MDL) (Restrepo, Tobón, \& Flórez, 2008; Rodríguez, 2007).

Los Estados pueden compensar parcialmente sus emisiones de GEI aumentando los sumideros, a partir de la implantación de bosques que suprimen el carbono de la atmósfera, lo cual es beneficioso para todos. Pueden, también, financiar proyectos en el extranjero que tengan por objeto reducción de GEI. Se establecieron varios mecanismos para el comercio de las emisiones, o mercado del carbono. Así ésta permitido que los países que no utilicen la totalidad de sus unidades de emisión, puedan vender el excedente de capacidad a los que superan sus objetivos y los país que no alcanzaran a cumplir sus compromisos pueden comprar (Restrepo et al., 2008; Steinfeld et al., 2009)

En esta lógica de mercado, se pueden obtener créditos para reducir la totalidad de GEI plantando bosques y/o ampliando la superficie forestal. Así como realizando "proyectos de aplicación conjunta" con otros países para reducir las emisiones. Los créditos obtenidos pueden comercializarse en el mercado de emisiones o reservar para el uso futuro (Steinfeld et al., 2009)

Los MDL permiten a los países desarrollados financiar proyectos con el objeto de reducir o evitar emisiones en los países no obligados y a cambio se otorgan créditos para ser utilizados en el cumplimiento de mecanismos alternativos de emisión y los receptores se benefician de la tecnología suministrada.

Con la intensión de reforzar los esfuerzos antes asumidos y en búsqueda de renovar responsabilidad, se llevó a cabo en 2016 el Acuerdo de Paris. Constituyéndose en un instrumento jurídico formado por una combinación de disposiciones jurídicamente vinculantes como no vinculantes (Victoria, 2017). Un instrumento hard law con un alto contenido de normas soft law (Nava Escudero, 2016). Argentina firmó y ratifico el Acuerdo por Ley 27.270 en 2016 (Congreso de la Nación Argentina, 2017).

Este acuerdo mantiene la visión de responsabilidad diferenciada pero común del CMNUCC; Sin embargo de una manera diferente adopta metas absolutas de reducción de emisiones para los países desarrollados, mientras que las Partes que son países en desarrollo deberían seguir aumentando sus esfuerzos de mitigación (Victoria, 2017). La principal diferencia radica que todos los Estados Parte, se encuentran obligados a presentar sus contribuciones previstas y determinadas a nivel Nacional y deberán realizarla cada cinco años (Garín, 2017). Cada Parte establece cómo será su aporte teniendo presente una "auto-calificación de justicia y ambición” (Bueno Rubial, 2016).

En esta descripción de normas, es importante agregar que a partir de 2002, la Nación ejerció su facultad de dictar normas de presupuestos mínimos como; las leyes $25.675 ; 25.688 ; 25.831 ; 26.331$ y 26639 entre otras (Congreso de la Nación Argentina, 2002, 2003a, 2003b, 2007, 2010). Específicamente la ley 25.675 que normativiza un orden publico ambiental y del desarrollo sustentable reglamentó la implementación y promoción del desarrollo sostenible y los principios e instrumentos de política y gestión ambiental.

\section{Panorama jurídico aplicable en la Provincia}

En nuestra búsqueda para el análisis y estudio de un instrumento o norma jurídica que regule de manera específica e integral la actividad ganadera en la provincia de Corrientes que promueva una actividad productiva sustentable como alternativa al cambio climático, nos hemos encontrado con su negativa o total ausencia. Sin embargo, al observar el sistema jurídico local en su totalidad, pudimos identificar normas locales que de manera dispersa y con diferente naturaleza y prelación, restringen, limitan y califican a la actividad ganadera en el ámbito de la Provincia.

Particularmente estas normas identificadas tienden a asociar la actividad al ámbito espacial donde es desarrollada. Por lo tanto, solamente serán aplicables a ciertos sectores ecosistémicos particulares de la Provincia. Esto genera una incongruencia entre el sistema jurídico normativo y la realidad al 
presuponer que los ecosistemas, los posibles daños y pasivos ambientales, presuponen límites jurídicos y políticos. Provocando una segmentación y truncamiento de la actividad sustentable ganadera en relación al ámbito espacial. Estas normas jurídicas identificadas son las que refieren a la actividad ganadera en zona de reserva y en bosque nativo, siendo esta segunda más amplia o general que la primera, pero a su vez ambas íntimamente relacionadas.

En Corrientes los Esteros del Iberá constituyen una categoría de gran relevancia no solo por su gran importancia ecosistémica, sino también por su escala económica, política y jurídica. Ocupan el centro norte de la provincia sobre el Acuífero Guaraní, y constituyen un importante reservorio en estado natural de agua dulce con ubicación estratégica mundialmente y el humedal más importante de Argentina $^{2}$ y el segundo de Sudamérica por su extensión y sus particularidades biogeográficas (Vallejos, Botana \& Pohl, 2009).

La Constitución de Corrientes reformada en 2007 en su art 66 otorga protección especial a esta zona, declarándola como Patrimonio Estratégico Natural y Cultural del Estado y Bien del Dominio Público de la provincia, "a los fines de su preservación, conservación y defensa: el ecosistema Iberá, sus esteros y su diversidad biológica, y como reservorio de agua dulce..."(Convención Constituyente de la Provincia de Corrientes, 2007).

Normativamente la reversa Iberá fue creada en 1983, por ley 3771 (Gobernador de la Provincia de Corrientes, 1983). Pero es recién a partir de la ley 4736/93 (Senado y la Cámara de Diputados de la Provincia de Corrientes, 1993) que se establece un sistema general de áreas protegidas en la Provincia, por un lado se crea el Parque Iberá, otorgándole una protección absoluta -art. 5-, por la que deberán conservarse en su estado natural, quedando prohibido todo tipo de actividad que pueda modificarlo, prohibiéndose las explotación pecuaria y cualquier otro aprovechamiento de los recursos naturales art. 6-.

Sin embargo respecto de la categoría Reservas Naturales -art. 9- permite realizar ciertas actividades productivas cuando sean compatible con la conservación de los recursos naturales y que permitan el uso racional de los mismos sin afectar las características más relevantes e importantes del área o su equilibrio ecológico. En el decreto $\mathrm{N}^{\circ} 1440 / 09^{3}$ (Gobernador de la Provincia de Corrientes, 2009a), se reglamentan las restricciones a las actividades permitidas a través de estándares generales y particulares, cuando esta actividad por sus características y/o escala superficial, implique un efecto notable dentro del área de la Reserva, deberán observar ciertas limitaciones.

Así por ejemplo, en la ganadería extensiva realizada sobre áreas de pasturas naturales deberán por un lado, dar cumplimiento a las leyes provinciales de "Bosques Nativos" № 5974 (2010) y de "Manejo y Control del Fuego" N 5590 (2004), como también se deberá cumplir una conservación mínima de los suelos con su vegetación natural, integrar la superficie destinada a la producción con corredores biológicos o franjas de amortiguación en las áreas de humedales y bosques nativos para lograr su continuidad espacial. Por ejemplo mantener $70 \mathrm{mts}$ circundantes al límite exterior del estero, bañado o planicie de inundación del valle aluvial del río principal del sistema (Gobernador de la Provincia de Corrientes, 2009a).

La ley $\mathrm{N}^{\circ} 26.331$ de Presupuestos Mínimos de Protección Ambiental de los Bosques Nativos (Congreso de la Nación Argentina, 2007), reglamentada mediante el Decreto 91/09 (PEN, 2009), genero un verdadero instrumento de límite a la propiedad sobre bosques nativos (BN), imponiendo a las Provincias la obligatoriedad de sancionar su ordenamiento territorial de BN (OTBN) existente en su territorio mediante un proceso participativo, de acuerdo a los criterios de sustentabilidad. Corrientes

\footnotetext{
${ }^{2}$ En enero de 2002 por ley 23919 (Congreso de la Nación Argentina, 1991), se incorporaron como sitio Ramsar de la Argentina a un punto central del Macrosistema del Iberá.

${ }^{3}$ Específicamente en lo referente al procedimiento administrativo del Estudio del Impacto Ambiental ha sido modificada por el Decreto 1966/09 (Gobernador de la Provincia de Corrientes, 2009b).
} 
sancionó su OTBN por ley provincial 5.974 (2010), complementando la ley nacional, conformando un régimen de protección nacional-provincial.

El régimen establece tres categorías de conservación en función del valor ambiental de los $\mathrm{BN}$ y sus servicios ambientales. Las cuales a su vez imponen diferentes restricciones en el uso y goce de los BN. Dichas categorías se clasifican, en:

I -rojo- de muy alto valor de conservación, merecen su persistencia como bosques a perpetuidad. No pueden alterarse y solo pueden realizarse actividades que no modifiquen sus atributos, como actividades de recolección, turismo responsable e investigación.

II-amarilla- mediano valor de conservación, no pueden ser sometidos a cambios en el uso del suelo. Se encuentra prohibido el desmonte, pero se permite, un uso de manejo sostenible.

III -verde- de bajo valor de conservación y pueden transformarse parcialmente o en su totalidad. Es decir está permitido el desmonte previa autorización.

En total se zonificaron 770.319 ha de $\mathrm{BN}, 63.840$ ha pertenecientes a la cat. I roja (8\%); 292.251 ha cat. II amarilla (38\%) y 414.228 ha a la cat. III verde (54\%) (Área de Ordenamiento Territorial, Área de Vinculación y Control, \& Ministerio de Ambiente y Desarrollo Sustentable de la Nación, 2015). Es decir que en gran parte del territorio de $\mathrm{BN}$-más del 50\%- es posible realizar ganadería.

La actividad ganadera en términos generales es comprendida dentro del concepto de desmonte. Por lo que solo estaría permitida en los BN cat. III. Pero en esta situación, cabe preguntarse si es posible realizar actividad ganadera en la cat. II, cuando dicha actividad sea compatible con un manejo sustentable (Carranza, 2016; Laclau, 2012; Preliasco \& Mañarro, 2016). Entendido por tal a la organización, administración y uso de los $\mathrm{BN}$ "que permita mantener su biodiversidad, productividad, vitalidad, potencialidad y capacidad de regeneración, para atender, ahora y en el futuro, las funciones" y servicios ambientales importantes a nivel local y nacional, sin producir daños a otros ecosistemas (Poder Legislativo de Corrientes, 2010).

\section{Medidas alternativas de producción de ganadera}

Ante los posibles problemas ambientales generados por las actividades agropecuarias y en particular por ganadería se fueron promoviendo, desde el ámbito técnico-practico sistemas alternativos de producción, con la finalidad de mejorar la sustentabilidad (Silberman, Albanesi, \& Grasso, 2016). Principalmente como consecuencia del incremento reciente y continuo de la deforestación en la región del Bosque Chaqueño y del Espinal afín a la actividad agropecuaria. Lo que exigió una mirada alternativa para la integridad ecosistémica (Laclau, 2012).

A esta situación es necesaria sumar la creciente preocupación jurídica-social, que hemos venido desarrollando, que demarca una gran complejidad al momento de pensar en los sistemas de producción. Al imponer un complejo entramado de restricciones generales con la finalidad de integrar y/o pacificar la tensión entre conservación y producción.

En los últimos tiempos distintos agentes públicos y privados, preocupados por el sector pecuario, advirtieron esta situación. Y en paralelo al sistema jurídico estatal, surgió un creciente interés de elaborar mecanismos o instrumentos normativos, como convenios y contratos. En los cuales estos agentes se proponen como objetivos lograr optimizar y aprovechar de forma sustentable la actividad ganadera en forma integrada a los bosques, principalmente el nativo. Sin embargo estos instrumentos, establecen de algún modo un régimen voluntario. En sentido de opción para los agentes -públicos o privados- de someterse o no a las normas técnicas de dichos instrumentos. 
En 2015 la entonces Secretaría de Ambiente y Desarrollo y el Ministerio de Agricultura, Ganadería y Pesca de la Nación, celebraron un convenio marco interinstitucional, de naturaleza técnico-político. El que se concretó en el Plan Nacional de Manejo de Bosque con Ganadería Integrada -MBGI(Ministerio de Agricultura, 2015). Sus principales objetivos son establecer el marco general y los principales lineamientos para que las actividades ganaderas en zonas de $\mathrm{BN}$, con el fin de cumplir los criterios de sustentabilidad ambiental, económica y social, pilares básicos del desarrollo sostenible y presupuesto mínimo según la ley nacional de BN.

El convenido se propone promover el fortalecimiento de las Provincias induciendo la generación de capacidades para la consumación de planes de MBGI para asegurar la provisión de los servicios ecosistémicos y evitar su fragmentación ${ }^{4}$. También se acuerda respetar tres principios básicos de la sustentabilidad en simultaneidad: "1) La capacidad productiva y la productividad del ecosistema deben mantenerse o mejorarse, 2) La integridad del ecosistema y sus servicios deben mantenerse o mejorarse y 3) El bienestar de las comunidades asociadas a su uso debe mantenerse o mejorarse" (Ministerio de Agricultura, 2015).

Otro mecanismo, pero desde el ámbito privado contractual, es el sistema de certificación del sello Carne Carbono Neutro. Concepto-marca desarrollado por Embrapa (Brasil). Un objetivo del sello es certificar la carne bovina, cuyos volúmenes de emisión de GEI fueron contrarrestados durante el proceso de producción por la representación de árboles integrados en sistemas agrosilvopastoril a través de procesos controlados (BuscaAgro, 2015).

El sello tiene un doble sentido económico-ambiental. Por un lado buscar promover el estudio de sistemas de producción ganadera más sostenible, sobre todo con introducción del árbol como factor capaz de neutralizar el metano emitido por el ganado. Y por lo que al mismo tiempo se agrega valor a la carne producida en estos sistemas. Sin embargo tenemos que destacar que esta especie de instrumentos permanece en la esfera del ámbito privado. Siendo solo aplicable aquellos productores que decidan someterse al proceso de certificación y ajuste de su producción ganadera.

Otro objetivo consiste en difundir la importancia estratégica de la sostenibilidad en las cadenas de suministro asociadas (carne, granos, silvicultura), promoviendo el uso de sistemas integrados, optimizando los insumos y factores de producción con efectos sinérgicos positivos. Algunos aspectos importantes en la producción de carne vacuna que se deben considerar, son el bienestar animal, conservación de suelos y agua, y el secuestro de carbono (I. de P. de C. V. Argentina, 2017).

Entre los criterios que deberán cumplir las empresas para la obtención de Marca C-Neutral encontramos la presentación de declaraciones del verificador ante la Dirección de Cambio Climático del Ministerio de Ambiente, con documentación oficial especificada, dicha declaración tiene una vigencia de 3 años y cada año el organismo verificador da seguimiento. De esta manera se propone una tecnificación más compleja de la actividad silvopastoril.

Con estas ideas se revalorizan, desde aspectos económico y ambiental, los beneficios que tiene la inclusión de árboles en sistemas agro-ecológicos, principalmente en el secuestro de carbono, reducción de emisiones de metano y de la presión de los desmontes sobre los bosques (Laclau, 2012). Sin embargo, estos sistema integrativos de bosques y ganadería conforman sistemas complejos de producción. Porque tiene como características su alta complejidad estructural-funcional de manejo y el equilibrio dinámico entre plantas con estructuras y actividad enérgicamente contrastantes como son los árboles y los pastos, y a éstas con el ganado (Carranza, 2016; Laclau, 2012). Complejidad que no permite realizar generalizaciones y dificulta la planificación y monitoreo (INTA, 2015).

\footnotetext{
${ }^{4}$ A la fecha, 10 provincias suscribieron al plan (M. de A. y D. S.-R. Argentina, 2016). Chaco, Santiago del Estero, Salta, Formosa, Chubut, Neuquén, Tierra del Fuego, Santa Cruz y Río Negro (Chubut, 2016).
} 


\section{Conclusión}

Como cierre podemos observar que Corrientes dedica gran parte de su territorio a la producción ganadera la cual afecta al ambiente y contribuye al cambio climático. Pero dicha actividad es económica, social y políticamente esencial en la región.

Sin embargo el derecho ambiental Argentino se consagra en un conjunto de normas jurídicas que complejizan su materialidad limitando y enmarcando la actividad productiva en el paradigma de la sustentabilidad. Esto se ve reflejado en la constitución nacional al incorporar los principios de preservación, reparación y desarrollo sustentable, el deslinde de competencias, entre otros en su art. 41 y los tratados en materia de cambio climático reconocidos por el orden interno, que establecen la responsabilidad de reducir y mitigar los GEI.

En el ámbito de la provincia de Corrientes existen normativas específicas referidas a áreas protegidas y a bosque nativos que establecen límites a la ganadería, con el fin de compatibilizar con la protección al ambiente. Sin embargo estas regulaciones no dan respuesta definitiva que permita calificar a la actividad ganadera como sustentable y no establecen mecanismos ni instrumentos enfocados en mitigar los efectos del cambio climático. Generando una incongruencia entre el sistema jurídico normativo y la realidad.

Específicamente el régimen de bosques nativos establece límites serios a este recurso restringiendo la posibilidad de realizar actividades que alteren el funcionamiento y dinámica del bosque como el sobrepastoreo. Sin embargo se discute si es posible realizar actividad ganadera sustentable. Esto tiene su origen cuando la ley establece en su categoría II de bosque nativo que se podrán realizar actividades compatibles con un manejo sustentable.

En este contexto aparecen diferentes actores preocupados por el sector pecuario que en paralelo al sistema jurídico estatal, elaboran mecanismos o instrumentos normativos alternativos. Como por ejemplo en el sector público el Plan Nacional de Manejo de Bosque con Ganadería Integrada y desde el ámbito privado la certificación de Carne Carbono Neutro.

Sin embargo, por un lado estos sistemas integrativos conforman actividades complejas de producción que dificultan realizar generalizaciones con planificación y monitoreo. Y por otro los instrumentos que lo formalizan establecen de algún modo un régimen solo obligatorio para las partes que se sometan voluntariamente. En sentido de opción para los agentes -públicos o privados- de someterse o no a las normas técnicas de dichos instrumentos.

\section{Bibliografía}

Agritotal. (2017, 9 de marzo). IPCVA y AFOA avanzan hacia la certificación de la carne carbono neutral. Recuperado de http://www.agritotal.com/nota/27303/

Área de Ordenamiento Territorial, Área de Vinculación y Control, \& Ministerio de Ambiente y Desarrollo Sustentable de la Nación. (2015). Informe de estado de implementación 2010-2015: Ordenamiento Territorial de Bosques Nativos y planes alcanzados por el Fondo Nacional para el Enriquecimiento y la Conservación de los Bosques Nativos. Buenos Aires.

Argentina, I. de P. de C. V. (2017). Numero 7 - 03/2017. Carne Argentina, 1-12.

Argentina, M. de A. y D. S.-R. (2016). Informe del estado del Ambiente, 434.

Brundtland, G. H. (1987). Our Common Future. United Nations Commission (Vol. 4). New York. https://doi.org/10.1080/07488008808408783 
Bueno Rubial, M. del P. (2016). El Acuerdo de París: ¿una nueva idea sobre la arquitectura climática internacional? Relaciones Internacionales, 33, 75-95.

BuscaAgro. (2015). El sello "Carne Carbono Neutro": producción de carne sustentable en ambiente tropical. Retrieved from http://www.buscagro.com/detalles/El-sello-_Carne-Carbono-Neutro_produccion-de-carne-sustenta..._73956.html

Cafferatta, N. A. (2012). Tratado, jurisprudencia y doctrina de derecho ambiental. Buenos Aires: La Ley.

Carranza, C. A. (2016). Manejo de bosque nativo con ganadería integrada (MBGI). In XXIV Congreso AAPRESID. Buenos Aires: Resiliar.

Casella, A. P. (1997). Derecho agrario y derecho ambiental. Perspectiva constitucional Argentina. In Cristiani, E. \& Massart Paccini, A. (eds.). Diritto agrario e ambiente. Congresso in omaggio al professor Antonio Carrozza (119-133). Pisa, Italia: Scuola Superiori di Studi Universitari y di Perfezionamento S. Anna.

Chubut, S. de I. P. (2016). Chubut se suma al Plan Nacional de Manejo de Bosque con Ganadería Integrada. Subsecretaria de Información Pública.

Congreso de la Nación Argentina. (1991). Ley 23919. Apruébase una convención relativa a los humedales de importancia internacional especialmente como hábitat de aves acuáticas, firmada en Ramsar. Boletín Oficial, 24-abr(27122), 6.

Congreso de la Nación Argentina. (1994). Ley No 24295. Apruébase la Convención Marco de las Naciones Unidas sobre el Cambio Climático. Boletín Oficial, 11 -ene(27805).

Congreso de la Nación Argentina. (2001). Ley 25438 Apruébase el Protocolo de Kyoto de 1 a Convención Marco de las Naciones Unidas sobre el Cambio Climático, adoptado en Kyoto - Japón. Boletín Oficial, 19-jul(29692).

Congreso de la Nación Argentina. (2002). Ley ${ }^{\circ}$ 25675. Ley general del medio ambiente. Boletín Oficial, 30029(19 de noviembre), 2-4.

Congreso de la Nación Argentina. (2003a). Ley 25.831. Régimen de libre acceso a la información ambiental. Boletín Oficial, 07-ene-200(30312), 1.

Congreso de la Nación Argentina. (2003b). Ley 25688. Régimen de gestión integral de aguas. Boletín Oficial, 30060(3 de enero), 2.

Congreso de la Nación Argentina. (2007). Ley 26.331. Presupuesto mínimos de protección de los bosques nativos. Boletín Oficial, 26-dic(31310), 2.

Congreso de la Nación Argentina. (2010). Ley 26.639. Régimen de Presupuestos Mínimos para la Preservación de los Glaciares y del Ambiente Periglacial. Boletín Oficial, 28-oct(32016), 7.

Congreso de la Nación Argentina. (2017). Ley 27270 . Apruébase el Acuerdo de París. Boletín Oficial, 19-sep(33464).

Convención Constituyente de la Provincia de Corrientes. (2007). Constitución de la Provincia de Corrientes.

Esain, J. J. (2008). Competencias ambientales. Buenos Aires: Abeledo Perrot. 
Gobernador de la Provincia de Corrientes. (1983). Ley 3771. Creación de la reserva natural del Iberá. Boletín Oficial, 15-04.

Gobernador de la Provincia de Corrientes. (2009a). Decreto 1440/09. Establece los objetivos del Parque y Reserva Provincial del Iberá. Boletín Oficial, 26/08/09.

Gobernador de la Provincia de Corrientes. (2009b). Decreto 1966/09. Modifica y complementa el Dto. 1440/09. Boletín Oficial, 24/11/09.

Gordillo, A. A. (n.d.). La Creciente Internacionalización del Derecho, 1-20.

Gordillo, A. A. (2007). Derecho humanos. Buenos Aires: Fund. de Derecho Administrativo.

INTA. (2015). Manejo de bosques con ganadería integrada.

Joaquin, A. N., \& Pérego, J. L. (2001). Sistemas silvopastoriles en el chaco boliviano, 1-7.

Laclau, P. (2012). Consideraciones económicas y ambientales para la toma de decisiones en sistemas silvopastoriles. In Actas del $2^{\circ}$ Congreso Nacional de Sistemas Silvopastoriles (pp. 359-370). Santiago del Estero: Ediciones INTA.

Lucas Garín, A. (2017). Novedades del sistema de protección internacional de cambio climático: el acuerdo de París. Estudios Internacionales (Santiago), 49(186), 137-167. https://doi.org/10.5354/0719-3769.2017.45222

Mahecha, L. (2002). El silvopastoreo: una alternativa de producción que disminuye el impacto ambiental de la ganadería bovina. Revista Colombiana de Ciencias Pecuarias, 15(2), 226-231.

Ministerio de Agricultura, G. y P. (2015). Convenio de articulación institucional entre la secretaría de ambiente y desarrollo sustentable de la jefatura de gabinete de ministros y el ministerio de agricultura, ganadería y pesca. Buenos Aires, Argentina.

Nava Escudero, C. (2016). El acuerdo de París. Predominio del soft law en el régimen climático. Boletín Mexicano de Derecho Comparado, 49(147), 99-135.

PEN, P. E. N. (2009). Decreto 91. Protección Ambiental de los Bosques Nativos. Apruébase la Reglamentación de la ley ${ }^{\circ}$ 26.331. Boletín Oficial, 16-feb( 31595), 1.

Poder Legislativo de Corrientes. (2010). Ley 5974. Bosques nativos. Boletín Oficial, 18/06/10, 9-7.

Preliasco, P., \& Mañarro, F. (2016). La ganadería en el bosque chaqueño, ¿amenaza y parte de la solución? In Di Pangracio, A., Nápoli, A., \& Sangalli, F. (Eds.) Informe Ambiental Anual 2016: Premio Adriana Schiffrin 14va Convocatoria (131-144). CABA: Fundación Ambiente y Recursos Naturales.

Restrepo, P. P., Tobón, D., \& Flórez, J. H. (2008, oct-dic.). Institucionalidad en torno a los mercados de carbono y los mecanismos de flexibilización derivados del Protocolo de Kioto. Revista Facultad de Ingeniería Universidad de Antioquia, 46, 46-57.

Rodríguez, S. L. (2007). Protocolo de Kyoto: debate sobre ambiente y desarrollo en las discuciones sobre cambio climátio. Gestión Y Ambiente, 10(2), 117-129.

Sabsay, D. A. (1997, July). El nuevo artículo 41 de la constitución nacional y la distribución de competencias nación-provincias. Doctrina Judicial, 783-787. Buenos Aires: La Ley.

Sabsay, D. A., \& Di Paola, M. E. (2002). El federalismo y la nueva ley general del ambiente. Anales 
de Legislación Argentina. Boletín Informativo, (32), 47-54.

Santini, E., \& Senetiner, A. (2011). Cambio Climatico Produccion Agropecuaria. Buenos Aires.

Senado y Cámara de Diputados de la Provincia de Corrientes. (2004). Ley 5590. Reglamenta todo lo referente a rozas y quemas en zonas rurales así como también la prevención y lucha contra incendios rurales. Boletín Oficial, 29/09/04.

Senado y Cámara de Diputados de la Provincia de Corrientes. (2010). Ley 5974. Bosques nativos. Boletín Oficial, 18/06/10, 9-7.

Senado y la Cámara de Diputados de la Provincia de Corrientes. (1993). Ley 4736. Régimen que se aplicará a todas las áreas del territorio provincial que sean declaradas Parque Provincial, Monumento Natural o Reserva Natural para su protección y conservación. Boletín Oficial.

Silberman, J. E., Albanesi, A., \& Grasso, D. (2016). Manejo de bosques con ganadería integrada: Impacto en las comunidades microbianas del suelo. Ciencia Del Suelo, 34(2), 211-219.

Steinfeld, H., Gerber, P., Wassenaar, T., Castel, V., Rosales, M., \& De Haan, C. (2009). La larga sombra del ganado. Problemas ambientales y opciones. Roma: FAO. https://doi.org/10.1007/s10666008-9149-3

Vallejos, V., Botana, M., \& Pohl, V. (2009). Transformaciones territoriales y problemas ambientales en la zona de los Esteros del Ibera. In X Jornadasde Investigación (1-13). https://doi.org/ISSN 18500862

Victoria, M. A. (2017, febrero). ¿El acuerdo de París sobre cambio climático recepciona a la agricultura? Revista Iberoamericana de Derecho Agrario, 5, IJ-CCLXIII-498. 


\section{PUEBLOS INDÍGENAS, INJUSTICIAS HISTÓRICAS Y PRESENTES: ENTREVISTA A TIMOTHY WALIGORE}

Por Santiago Truccone Borgogno

(Universidad de Graz / Austria) santiagotruccone@gmail.com

Traducción: Romina Frontalini Rekers

(Universidad Nacional de Córdoba / Argentina) rominarekers@gmail.com

Recibido: $18 / 09 / 2018$

Aprobado: 30/10/2018

Timothy Waligore es actualmente Profesor asistente en Ciencia Politica y coordinador de Estudios Globales de la Universidad de Pace en Nueva York. Es profesor visitante regular de la Universidad de Graz en Austria donde es co-director (junto con Lukas Meyer) de un proyecto sobre rectificación y anulación (supersession) de injusticias históricas, financiado por el FWF (Fondo Austriaco para la Ciencia). Es Ph. D. en Ciencia Política por la Universidad de Columbia. Ha publicado en Politics, Philosophy \& Economics, Moral Philosophy and Politics, Public Reason: Journal of Moral and Political Philosophy, Analyze \& Kritik, The Nation y en The New Republic. Es co-editor, junto con Barbara Buckinx y Jonathan TrejoMathys, de Domination and Global Political Justice (Routledge 2015). Su investigación se centra en resolver reclamos basados en injusticias históricas, justiciar global y ciudadanía multicultural.

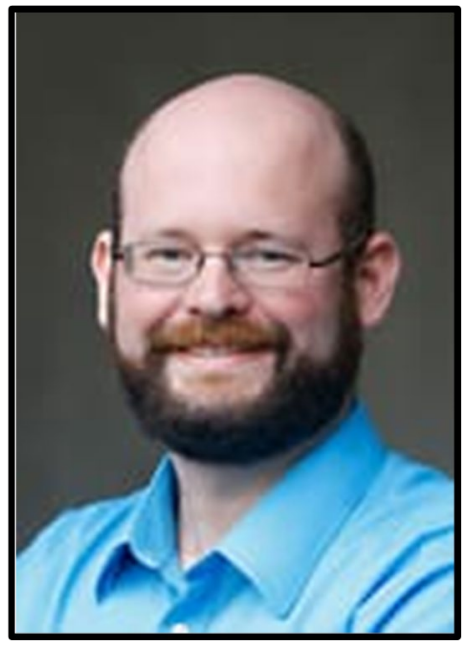

1. Una de nuestras mayores preocupaciones cuando pensamos en la justicia se refiere a su orientación temporal. ¿Por qué crees que esta característica es importante?

Algunas personas podrían estar interesadas en esto desde un punto de vista teórico más abstracto. A mí me interesa esta característica desde un punto de vista práctico: ¿cómo podrían justificarse o no las reparaciones? En relación con este problema, tres enfoques son comunes entre los teóricos políticos. En primer lugar, los enfoques prospectivos (forward-looking) pretenden aliviar las situaciones de desventaja del presente y del futuro, sin contar con una preocupación fundamental por rectificar las injusticias históricas. Este es un punto de vista muy popular y creo que es incorrecto. Este enfoque podría permitir la devolución de tierras y demás cosas a las personas históricamente desposeídas. Sin embargo, tales soluciones no capturan los males realmente cometidos. En segundo lugar, los enfoques retrospectivos (backward-looking) le otorgan una importancia moral independiente a la rectificación de males históricos, incluso si esto llegara a beneficiar a quienes están (o estarán) en las posiciones más favorecidas. Tengo simpatía por este enfoque, pero no creo que una versión no revisada tenga éxito. No podemos, por ejemplo, ignorar las necesidades actuales. En tercer lugar, los enfoques basados en la desventaja estructural se centran en que la injusticia continúa arraigada en el pasado y nos dicen cómo las desventajas estructurales tienden a persistir en el tiempo. Considero que este 
enfoque puede resolver muchos problemas importantes, pero, en última instancia, creo que está demasiado orientado al presente.

2. ¿Por qué crees que los eventos pasados pueden cambiar los requerimientos presentes de la justicia?

Esta es una pregunta difícil. Robert Nozick y otros libertarios con concepciones basadas en derechos tienen una respuesta directa. La justicia es el resultado de una serie de adquisiciones y transferencias justas. Para Nozick, la justicia no se fundamenta en patrones; no deberíamos aspirar a un patrón como el de "igualdad" o "a cada cual según su merecido". La justicia tiene una dimensión históricamente ineludible. Entonces, Nozick dice que, si algo fue tomado de modo incorrecto, debería devolverse. Aun así, para Nozick, el estándar de justicia sigue siendo el mismo antes y después de una injusticia. He argumentado que lo que públicamente se considera como injusticia puede cambiar como resultado de una injusticia pasada. El teórico liberal prospectivista, John Rawls, está preocupado por las bases sociales del autorespeto y por garantizar a ciudadanos iguales que se hará justicia. Bueno, para que pueda considerarse que se ha hecho justicia, debe ser visible que se ha hecho justicia. Así que, adaptando Rawls en función de sus propios fines, argumento que a raíz de una injusticia histórica puede ser más difícil asegurar a algunos grupos, tales como los nativos americanos y los afroamericanos, que se hará justicia. Por lo que, por ejemplo, aspirar a la igualdad entre los miembros promedio de diferentes grupos podría justificarse como una forma de asegurar a las personas que hay igualdad de oportunidades. Esto podría parecerse a las reparaciones históricas Nozickeanas, pero se fundamenta en las preocupaciones prospectivas de proporcionar las bases sociales para el autorespeto y la seguridad. Ese es un argumento que he usado. Creo que es bastante moderado, pero es interesante considerarlo y aquí me ha inspirado el trabajo de Charles Mills. Rawls es pensado como el ejemplo de los teóricos prospectivistas, aunque si estoy en lo cierto, es interesante pensar que la estructura de sus ideas podría (y debería) adaptarse en respuesta a las injusticias históricas. Creo que hay mucho trabajo interesante por hacer aquí y, realmente, solo hemos empezado a explorarlo.

3. Una gran parte de tu trabajo se ocupa de cuestiones indígenas. ¿Qué crees que deberíamos hacer sobre este asunto?

Me concentro principalmente en los Estados Unidos y Canadá, por lo que esas son las áreas con las que estoy más familiarizado. Mi punto de vista es que debe devolverse una gran cantidad de tierra y los pueblos indígenas deberían tener jurisdicción real sobre esas tierras. En términos más generales, mi enfoque supone que la tierra y la jurisdicción deben ser reconocidas y devueltas, mientras se consideren los límites fundados en principios que existen sobre esto. Un enfoque alternativo, del que no estoy a favor, considera que todas las personas, incluidos los pueblos indígenas, son simplemente miembros iguales de un estado unitario. Para este enfoque, lo que es importante es una justicia distributiva prospectiva. Sin embargo, es importante reconocer que las injusticias contra los pueblos indígenas no son solo históricas, sino que están en curso. Muchas de las decisiones de la Corte Suprema de EE. UU. en las últimas décadas han erosionado gradualmente la soberanía indígena, y eso debería revertirse.

\section{4. ¿Piensa que su respuesta anterior podría cambiar cuando consideramos lo que la justicia} requiere en países con grandes patrones de desigualdad o con altas tasas de pobreza?

Dije que debe haber límites fundados en principios sobre cuánto se puede devolver la tierra. Se podría argumentar que uno de estos límites es que todos deberían tener un nivel suficiente de bienestar (lo que se llama "suficiencia" en la filosofía liberal). Otros van más allá y dicen que todos deberían tener suficiente para no ser dominados por otros. Pero incluso con estas condiciones, hay o podría haber mucho espacio para los reclamos basados históricamente. También soy extremadamente desconfiado de la idea de que las tierras de los pueblos indígenas deban minarse por recursos que, supuestamente, ayudarán a los pobres. Primero, no creo que esto sea sostenible. Segundo, sospecho que esto no ayuda mucho a los pobres, beneficia mucho más a los ricos. Tercero, sospecho que hay mejores formas de ayudar a los pobres. Puede que no sean tan políticamente factibles porque afectan a los mejor 
acomodados, pero eso no es excusa. Los pueblos indígenas no deberían soportar el impacto de esto porque son un objetivo fácil sin tanto poder político. Cuarto, aquí hay una dimensión internacional o cosmopolita importante. En mi opinión los pueblos indígenas no son parte plena de un Estado soberano unitario y no están libres de problemas. Si uno piensa que los deberes de justicia distributiva son diferentes en el ámbito doméstico y global, entonces no está claro que los pueblos indígenas tengan las mismas responsabilidades que los ciudadanos regulares del país.

5. Una vez, cuando estaba haciendo una presentación sobre la famosa tesis de la supersession, una de los asistentes, una mujer cacique de los Comechingones, interrumpió mi exposición diciéndome que "estaba hablando como los abogados de los terratenientes extranjeros que querían quitarles sus tierras ancestrales". Le dije que, si pueblos indígenas sostenían lo que estaba presentando, entonces las tierras deberían ser entregadas a la tribu Comechingón. Sin embargo, ella me dijo algo que me dejó perplejo: "No es lo que usted está diciendo, es la forma en que habla". Creo que ella estaba diciendo que mi presentación era percibida como una especie de imposición. ¿Qué piensa de este episodio?

No puedo hablar de lo que ella estaba pensando, sobre todo porque no estaba allí y parecía querer ser escuchada con su propia voz. Pero esto me hace pensar en varias cosas que vale la pena considerar, cualquiera haya sido su intención. En primer lugar, incluso si su análisis sobre la supersession conduce a una conclusión favorable para un pueblo indígena en particular, los conceptos que utilizas para llegar a esa conclusión pueden tender a empujar en la otra dirección. Otros pueden haber usado esos conceptos en el pasado para llegar a conclusiones mucho menos favorables, y aún pueden hacerlo hoy. Hablando más concretamente en términos de lenguaje legal, en muchos contextos no todos piensan que el logro de los derechos sobre el papel es tan importante; si los derechos no pueden implementarse en la práctica, pueden valer poco o nada. Algunos grupos tienen una mayor capacidad para manipular el sistema legal por lo que, incluso si se puede presentar un argumento inteligente que reivindique los derechos indígenas, podría no significar nada en realidad. Y los pueblos indígenas pueden desconfiar de utilizar un lenguaje que ha sido utilizado históricamente para despojarlos de sus derechos. En segundo lugar, hay académicos indígenas, aunque los que tengo en mente no son de América del Sur, que piensan que las ideas indígenas deben ser una parte importante del diálogo. Poner las cosas en términos de filosofía política analítica liberal puede malinterpretar estas ideas. En Canadá, un pueblo indígena tuvo que ganar un juicio para que se reconociera su tradición oral como una forma de proporcionar pruebas del hecho de que estuvieron en su tierra por mucho tiempo. Pero incluso si los pueblos indígenas obtienen victorias en los tribunales, el sistema judicial canadiense y el sistema político tienden a afirmar que el autogobierno indígena y los reclamos de tierras deben reconciliarse con la soberanía de la Corona (Canadá todavía tiene a la Reina de Inglaterra como cabeza oficial de Estado). Entonces esto podría ser visto como una imposición colonial. Tercero, requiere mucho trabajo tratar de traducir las ideas indígenas al lenguaje del sistema legal dominante o al modo de argumentación filosófica, si esto es posible en toda su extensión. Obligar a los pueblos indígenas a hacer esto para que sean escuchados podría ser llamado imposición. Además, algunas personas pueden pensar que el uso de un determinado idioma es una imposición colonial, como usted mencionó, ya que privilegia cierto tipo de discurso. También hay otras posibilidades, por supuesto. Es importante tratar de hacerse consciente, en la medida de lo posible, de las concepciones de vida, modos de ser y modos de pensar indígenas, algo que aquellos de nosotros que trabajamos en estos temas, a menudo, no hacemos lo suficiente. 


\section{JUSTICIA INTERGENERACIONAL. ENSAYOS DESDE EL PENSAMIENTO DE LUKAS H. MEYER}

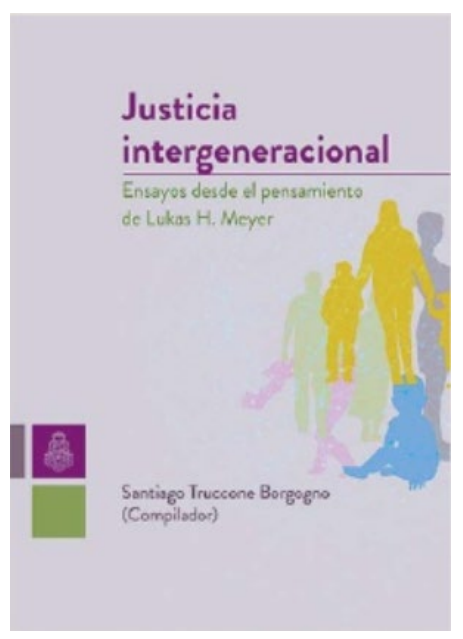

\author{
TRUCCONE BORGOGNO, SANTIAGO (COMP.) JUSTICIA \\ INTERGENERACIONAL. ENSAYOS DESDE EL \\ PENSAMIENTO DE LUKAS H. MEYER, UNIVERSIDAD \\ NACIONAL DE CÓRDOBA, 2017. ISBN: 978-987-707-063-7. \\ 290p.
}

Daniel Kalpokas

(Consejo Nacional de Investigaciones Científicas y Técnicas / Argentina) dkalpokas@gmail.com

Recibido: 06/10/2018 Aprobado: 11/11/2018

El libro, editado por Santiago Truccone Borgogno, versa sobre una cuestión bien interesante y polémica, tanto desde un punto de vista filosófico como desde un punto de vista ético/político. En la Introducción se dice que la llamada "cuestión intergeneracional" es aquella que se refriere, por un lado, al problema de cómo hemos de relacionarnos con nuestras generaciones pasadas y futuras; $\mathrm{y}$, por otro lado, a los modos en que nos comportamos, o debemos comportarnos, en relación a nuestros pares contemporáneos en asuntos que exceden el momento actual. Más específicamente hablando, el libro se ocupa de ciertos problemas de justicia que emergen de la consideración de los derechos que cabe atribuir a generaciones pasadas y futuras. Por ejemplo, ¿tenemos realmente el deber de preservar el entorno natural de modo tal que generaciones futuras puedan disfrutar del mismo entorno de modo parecido a cómo nosotros lo hacemos actualmente? ¿Qué tipo de responsabilidad nos cabe en lo tocante al desarrollo de tecnologías que, previsiblemente, harán posible la manipulación genética y el "mejoramiento" genético del ser humano? O, ¿cuál es la responsabilidad que nos cabe en el control de la natalidad y los peligros de una superpoblación del planeta? Estos son tres ejemplos de ámbitos en los que las decisiones políticas, morales y jurídicas que lleguemos a tomar afectarán a personas futuras.

Por otro lado, y de modo paralelo, se han suscitado ciertas cuestiones de justicia para con aquellas personas que ya no existen, tales como los llamados reclamos de compensación histórica (que atañen a los descendientes de personas afectadas por injusticias del pasado) y los deberes sobrevivientes (que atañen a los intereses póstumos de las personas que ya no están).

Estructuralmente hablando, el libro tiene dos partes. La primera recoge un artículo sobre justicia generacional que el filósofo alemán Lukas Meyer publicara (originalmente en el 2003, y luego, con importantes revisiones, en 2015) en la Stanford Encyclopedia. La segunda, en cambio, titulada Problemas específicos de justicia intergeneracional, está compuesta por cuatro artículos en los que se desarrollan y discuten algunos aspectos de la filosofía de Meyer. El artículo de Alessandro Pinzani se ocupa de problemas de ética reproductiva; el de Santiago Truccone Borgogno intenta precisar qué tipo 
de daño, referido a personas futuras, es más grave. El artículo de Laura García Portela versa sobre cuestiones de justicia climática; y el de Daniel Loewe, finalmente, se ocupa de la tesis de la asimetría (la tesis que sostiene que traer a la existencia un ser que tendrá una vida miserable parece incorrecto, mientras que no traer a la existencia a un ser que, previsiblemente, tendrá una vida feliz, no lo parece).

Permítaseme presentar brevemente una cuestión fundamental que es abordada en el libro y que, por diversas razones, puede resultar particularmente interesante tanto a filósofos como juristas, a saber, la de si es cierto que personas que todavía no están en el mundo, así como las que ya no están en él, tienen ciertos derechos que nosotros, ahora, deberíamos respetar. Naturalmente, esta tesis puede despertar, al menos prima facie, algunas sospechas. ¿Cómo es posible que personas que todavía no existen, o que dejaron de existir, puedan tener ciertos derechos? ¿Y cómo puede ser que nosotros, que existimos ahora, tengamos ciertos deberes para con ellas?

Al respecto, en el libro se defiende, discute y desarrolla un punto de vista particular denominado "enfoque de las personas afectadas". Según este enfoque, un acto es incorrecto sólo si daña o dañará, o puede esperarse que dañe, a una persona que existe o existirá. En el contexto de la justicia intergeneracional, se dice que las personas futuras son dañadas por las acciones de personas existentes cuando las acciones de estas últimas afectan negativamente las condiciones de vida de las primeras. La idea que está a la base de este enfoque es que podemos decir que las personas futuras tienen derechos si podemos, en efecto, atribuirles un conjunto relevante de intereses. Así pues, desde este punto de vista, las personas futuras tienen derechos en la medida en que se puede decir que tienen intereses.

Es aquí en donde, según se reconoce, pueden surgir algunas razones para el escepticismo. Al respecto, Meyer, en el artículo que aparece en el libro, identifica cinco fuentes de duda: 1) las personas futuras no pueden imponer sanciones sobre las personas actuales por el incumplimiento de sus deberes; 2) las personas futuras no tienen existencia presente y, por ende, no pueden ahora ser sujetos de derechos o poseer propiedades morales; 3) parece que, para que las personas futuras tengan algunos derechos, dentro de esos derechos hay que incluir su derecho a la existencia, y esto parece discutible: no estamos obligados a traer a la existencia a todas las personas futuras que podamos; 4) nosotros no conocemos qué intereses tendrán esas personas futuras; por tanto, ¿qué derechos podríamos atribuirles?; y 5) muchas de nuestras acciones cuentan como condiciones necesarias de su existencia. Este último punto concierne al llamado "problema de la no identidad" (o contingencia de las personas futuras en relación a nuestras decisiones actuales). El punto es que la existencia, identidad y número de las personas futuras depende de las acciones que ahora llevemos a cabo. De ahí que, tal como se aclara en el libro, tales acciones no puedan empeorar el estado de tales personas futuras que existirán como consecuencia de ellas; pues si no hubiésemos actuado como lo hicimos, esas personas no habrían existido en absoluto.

En el artículo de Meyer que se presenta en el libro, no encuentro una respuesta al primer argumento escéptico recién mencionado, aunque, sospecho, dicho argumento podría desbaratarse rápidamente señalando que, del hecho de que las personas futuras no puedan obviamente sancionar a las personas actualmente existentes por la vulneración de sus derechos, no se sigue que nosotros, normativamente hablando, no tengamos ciertos deberes para con ellas. Incluso personas indefensas, podría argüirse, actualmente existentes, gozan, de todas formas, de ciertos derechos básicos.

He aquí la respuesta de Meyer a la segunda fuente de dudas respecto de los derechos de las generaciones futuras: afirmar que ahora podemos violar los derechos de las personas futuras no implica, sin embargo, sostener que las personas futuras tengan derechos ahora. Si entiendo bien el argumento de Meyer, la idea es que, aunque no pueda decirse que las personas que existirán en el futuro posean ahora ciertos derechos, puede decirse, sin embargo, que ahora nosotros podemos violar los derechos que ellas tendrán en el futuro; pues podemos estar seguros de que, primero, las personas futuras serán portadoras de derechos en el futuro; segundo, que esos derechos estarán determinados por los intereses que las personas futuras tendrán; y tercero, que nuestras acciones y políticas presentes pueden afectar, ciertamente, sus intereses. Si podemos violar los derechos de una persona frustrando 
sus intereses, y si también podemos frustrar los intereses de las personas futuras, también podemos violar sus derechos futuros. El hecho de que la existencia de muchas personas sea únicamente futura es insuficiente, por sí mismo, para fundamentar la afirmación de que no podemos violar ahora los derechos de las personas futuras.

Por otro lado, Meyer da el siguiente argumento en respuesta a la tercera fuente de duda (que concierne al presunto derecho a la existencia futura): del hecho de que seamos capaces de violar ciertos derechos de las personas futuras (por ejemplo, derechos que conciernen a la vida en un entorno natural apropiado, con recursos naturales apropiados, etc.) no se sigue que, al violar tales derechos ahora, estemos violando también sus derechos a la existencia en cuanto tal. Nadie tiene, según Meyer, un derecho a la existencia como tal. Más aún, cuando impedimos la existencia de alguien no estamos, sostiene Meyer, dañando el interés hipotético del sujeto potencial. Por lo tanto, afirmar que las personas futuras reales tienen derechos con respecto a las personas actualmente existentes no nos compromete con la afirmación de que las personas futuras posibles tienen, además, derecho a la existencia.

La cuarta fuente de escepticismo con respecto a la atribución de derechos a personas que todavía no existen era la siguiente: ¿Cómo podríamos atribuir derechos a personas futuras cuyas identidades $\mathrm{y}$, por ende, intereses nos serían desconocidos? Parece evidente que, cuando consideramos nuestras actuales políticas sobre, por ejemplo, recursos naturales, no podemos guiarnos por los intereses concretos de personas futuras. De aquí no se sigue, sin embargo, argumenta Meyer, que no tengamos obligaciones para con las personas futuras. Todo lo que se sigue es que nuestras obligaciones no dependen de nuestro conocimiento de las identidades de las personas futuras. Tales obligaciones estarían basadas en el hecho de que las personas futuras serán seres humanos. Esto impone suficientes constricciones normativas a nuestras acciones actuales con respecto a tales personas. Si elegimos agotar los recursos naturales ahora, con toda probabilidad afectaremos negativamente el derecho a la subsistencia de las generaciones futuras. Esto ocasionará que muchos derechos básicos sean violados inevitablemente. Esta sería, pues, una consideración suficiente para no elegir una política de agotamiento de los recursos naturales.

Finalmente, veamos cómo responde Meyer al problema de la no identidad. Para responder a este desafío, Meyer ha desarrollado la noción de umbral de daño. De acuerdo a esta noción, dañar a una persona (futura) es realizar una acción que la sitúa, o situará, en una peor condición que aquella en la que debería estar. Debemos evitar que una persona, cuando venga a la existencia, esté en una condición que está por debajo del umbral de daño previamente definido. No importa aquí la identidad particular de la persona. De este modo podemos considerar que, en ciertos casos, se produce un daño a una persona trayéndola a la existencia si sabemos que esa persona estará en un estado que está por debajo del umbral de daño definido normativamente.

El umbral puede especificarse en virtud de diversas consideraciones: consideraciones igualitarias (nivel de bienestar promedio de las personas), mediante un razonamiento prioritarista (se debe priorizar a las personas que estén en peor condición, o al mayor número, o cuanto mayores sean los beneficios en cuestión), o en virtud de estándares suficientistas (debajo del umbral, el enfoque prioritario es válido; arriba del umbral, la mejora de los menos aventajados no detenta una preocupación especial).

Adicionalmente, la noción de daño defendida por Meyer, y discutida en algunos artículos del libro, es la llamada "Concepción disyuntiva de daño", que dice lo siguiente: una acción (o inacción) en el momento $t_{1}$ daña a alguien sólo si o el agente causa (permite) de ese modo que una persona esté en un estado por debajo del umbral; o el agente causa que una persona esté en una peor condición en algún momento posterior $t_{2}$ que aquella en la que esa persona habría estado en $t_{2}$ si el agente no hubiese interactuado con esa persona en absoluto.

Por otra parte, ¿cómo es posible que personas actualmente existentes puedan tener reclamos justos de compensación por injusticias cometidas en el pasado a otros? La idea de Meyer, extensamente 
desarrollada en su artículo, es que el daño cometido a personas en el pasado puede haber causado daños a personas actualmente existentes (piénsese, por ejemplo, en la expropiación de tierras en el pasado, que afectan a las generaciones subsiguientes; o en la desaparición forzada de personas perpetrada en regímenes autoritarios). Así, argumenta Meyer, beneficiar a los descendientes de personas que sufrieron injusticias en el pasado puede ser visto como una forma de compensar los daños sufridos por las generaciones pasadas.

Otra cuestión que surge con respecto a los derechos que detentan las generaciones pasadas concierne a los deberes que las generaciones actualmente existentes tendrían para con las primeras. Al respecto, la llamada "tesis de los deberes sobrevivientes" sostiene que ciertos deberes sobreviven a la muerte del portador de derechos. A pesar de que el portador de un derecho no exista más, las personas actualmente existentes pueden estar obligadas a cumplir con ciertos deberes correlativos. Según sostiene Meyer, esta tesis no descansa en la idea de que personas ya fallecidas son ahora portadoras de derechos. Simplemente, supone que las personas tienen derechos y que los deberes correlativos a ellos pueden pervivir después de la muerte del portador de esos derechos. Por ejemplo, tenemos el deber de cumplir una promesa aun si la persona a quien le hicimos la promesa ha fallecido. La razón de esto es que nos hemos comprometido con el cumplimiento de la promesa cuando esa persona todavía estaba viva. Por ende, las razones que nos obligan a cumplir una promesa así son las mismas que las que tenemos, o podemos tener, con respecto al cumplimiento de promesas para con las personas actualmente existentes.

Meyer señala una segunda razón, de índole general, para sostener que podemos tener obligaciones para con personas que ya no existen más: la protección de valores y normas cuya observancia general redunda en beneficio de la sociedad. Así, en analogía con lo que en ética normativa se denomina "utilitarismo de la regla", la idea es que el deber de cumplir con, por ejemplo, una promesa hecha en el lecho de muerte, estaría fundamentado en el deber de respetar las promesas en general, pues, precisamente, ese respeto generalizado redunda en el beneficio de todos.

Desde luego, hay mucho más para decir acerca del libro. Aunque no puedo hacer aquí una ponderación completa de los artículos que figuran en la segunda parte del libro, quisiera destacar su claridad, su carácter crítico y propositivo, su rigor argumentativo y su relevancia para las discusiones sobre justicia intergeneracional. Asimismo, hay que señalar la importancia que tiene un libro así para el ámbito local (en donde existe un grupo consolidado de investigadores interesados en cuestiones de ética, derecho y política) y, más en general, para la filosofía hispanoparlante. Por un lado, la traducción del artículo de Meyer pone al alcance de cualquier lector hispanoparlante una buena síntesis de muchas de las ideas desarrolladas por este autor y, más en general, un panorama del estado actual de discusión sobre justicia intergeneracional. Por otro lado, los artículos de la segunda parte del libro constituyen, a mi juicio, un aporte original y profundo a las discusiones actuales sobre los temas que tratan. En síntesis, el libro constituye una excelente oportunidad, tanto para ponerse al día con algunas discusiones específicas de justicia intergeneracional, como así también para adentrarse inicialmente en los problemas típicos que surgen ni bien consideramos los derechos de las generaciones pasadas y futuras. 


\title{
CLIMATE JUSTICE AND HISTORICAL EMISSIONS.
}

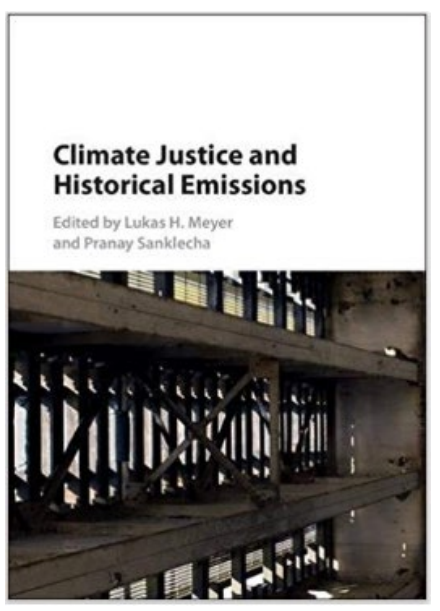

\author{
MEYER, LUKAS H. \& SANKLECHA, PRANAY. CLIMATE \\ JUSTICE AND HISTORICAL EMISSIONS. CAMBRIDGE \\ UNIVERSITY PRESS, 2017. ISBN 9781107069534. 271p.
}

Laura García Portela

(Universidad de Graz / Austria) laura.garciaportela@gmail.com

Recibido: $18 / 09 / 2018$

Aprobado: 30/10/2018

El libro Cambio Climático y Emisiones Históricas ${ }^{1}$ surge como fruto del proyecto de investigación Justicia climática. El significado de las emisiones históricas llevado a cabo en la Universidad de Graz entre los años 2010 y 2013. Es fruto también de los últimos años de intenso y concienzudo trabajo de sus editores, Lukas Meyer y Pranay Sanklecha. El libro recoge la investigación novedosa de algunos de los mejores investigadores en justicia climática de diferentes universidades del mundo. Todos ellos comparten la hipótesis que da sentido conjunto al texto, a saber: que el cambio climático debe ser analizado desde el punto de vista de la justicia intergeneracional en sus diferentes dimensiones temporales. Por ello, la justicia climática debe comprender una reflexión tanto sobre las emisiones futuras permisibles, como sobre significado moral de las emisiones del pasado.

Uno de los debates más importantes y extendidos en el campo de la justicia climática es el de la distribución justa de las cargas asociadas al cambio climático. El debate gira en torno a tres diferentes principios morales como el principio de 'los contaminadores pagan' (PCP), el principio de 'los beneficiarios pagan' (PBP) y el principio moral de 'los que tienen recursos pagan' (PRP) ${ }^{2}$. El libro que aquí presento cuenta con diferentes capítulos que ejemplifican este debate, aún vivo, entre los defensores de diferentes principios y sus detractores.

En primer lugar, David Heyd argumenta en favor de abordar los daños climáticos desde el punto de vista de la acción afirmativa con perspectiva histórica. Heyd sostiene que la acción afirmativa debe ser justificada porque un determinado grupo de personas son discriminadas por la idiosincrasia de un determinado sistema surgido en el pasado. Heyd defiende una distribución de las cargas generadas por el cambio climático basada en el principio de 'los beneficiarios pagan'. En concreto, Heyd fundamenta este principio en una concepción de los beneficios en términos de "enriquecimiento injusto". En este sentido, entiende Heyd, los beneficiarios de las emisiones históricas deben asumir las cargas generadas por el cambio climático porque los beneficios que obtuvieron del mismo tienen un origen injusto. Heyd admite también que los individuos o los estados no pueden considerarse culpables por las emisiones previas al año 1990, fecha en la que se establece que el cambio climático es un hecho

\footnotetext{
${ }^{1}$ Nótese que el título original del libro es en inglés Climate Justice and Historical Emissions. Todas las traducciones que en esta reseñan aparecen obedecen al criterio de la autora, ya que el libro no cuenta con traducción oficinal al español.

${ }^{2}$ Los principios a los que aquí me refiero aparecen en la literatura en inglés como "Polluter Pays Principle" (PPP) y "Beneficiary Pays Principle" (BPP) y "Ability to Pay Principle". Utilizo aquí, por cuestiones de coherencia, la misma traducción que ya utilicé en una publicación reciente: Garcia-Portela, "El papel de las emisiones históricas en la justicia climática. El pensamiento de Lukas Meyer" en Truccone Borgogno, Justicia Intergeneracional. Ensayos desde el pensamiento de Lukas Meyer, Universidad de Córdoba, 2017.
} 
científico contrastado a través del primer informe del Panel Intergubernamental contra el Cambio Climático. Heyd secunda, por tanto, lo que se conoce como la objeción de la 'ignorancia excusada': no podemos considerar a nadie culpable de las consecuencias de emisiones que produjeron cuando no conocían sus efectos negativos. No obstante, esto no impide reclamar, sobre la base de este principio de 'los beneficiarios pagan', que los países industrializados deban restituir los daños generados a las víctimas del cambio climático. En este sentido, Heyd favorece las demandas de restitución por las emisiones previas a 1990 y las de compensación por las emisiones que se sucedieron desde entonces hasta nuestros días.

En la misma línea de enfatizar la dimensión histórica de los daños generados por el cambio climático se sitúa Janna Thompson. Thompson presenta dos argumentos en favor de aplicar principios de justicia reparativa. El primero va dirigido contra la idea de que los individuos, actuando bajo ignorancia no negligente, no cometieron ningún acto ilícito (wrong) y por tanto no pueden ser considerados moralmente responsables. Thompson soluciona este problema tomando la distinción de Derek Bell entre el punto de vista temporalmente relativo y el punto de vista temporalmente neutral. El primero refleja el punto de vista de los agentes en el momento de actuar. En este sentido, las acciones vinculadas a las emisiones históricas no pueden considerarse moralmente ilícitas. El segundo, sin embargo, se refiere al punto de vista que sería accesible a los agentes si su posición temporal no los limitase epistémicamente. En este sentido, desde un punto de vista temporalmente neutral, las acciones sí que tienen que ser consideradas ilícitas porque desde 1990 sabemos que las consecuencias del cambio climático son devastadoras. El segundo argumento de Thompson para apoyar las demandas de justicia reparativa versa como sigue. Si los ciudadanos tienen la preocupación moral de mantener instituciones y prácticas justas, así como relaciones de respecto con otras comunidades intergeneracionales, deberán demandar a sus sucesores que así lo hagan. Pero entonces, si esto fuera así, entonces también tendrían la obligación de reparar las injusticias realizadas por sus antecesores. ¿Por qué? Porque deben aceptar los mismos deberes con respecto a las generaciones pasadas de los que le exigen a las generaciones futuras.

Daniel Butt está de acuerdo con Thompson en que la objeción de la ignorancia excusada debe ser contrarrestada. Por ello, Butt basa su artículo en un ataque a la solidez de la objeción de la ignorancia excusada sobre la base de un argumento contra fáctico. Para Butt, dos hechos muestran que los países desarrollados hubieran emitido altos niveles de gases de efecto invernadero a lo largo de la historia, incluso si hubieran sabido que las emisiones de gases de efecto invernadero generarían las conocidas consecuencias negativas del cambio climático. Primero, es de suponer que los países industrializados y altamente contaminantes no se hubieran preocupado por los efectos negativos del cambio climático sobre los habitantes de los países menos desarrollados porque así tampoco lo hicieron en tiempos coloniales. Al contrario, los países industrializados no tuvieron reparo en ejercer daño sobre los países menos desarrollados si aquello les permitía extraer recursos fósiles. Segundo, los países industrializados siguieron emitiendo gases de efecto invernadero a alto niveles (incluso más altos que los niveles de emisiones históricas) durante los años que sucedieron a 1990. Si de verdad el motivo por el que emitieron a semejantes niveles fue la ignorancia de los efectos de las altas emisiones, ¿por qué no hicieron nada inmediatamente después de conocer tales efectos? Para Butt estos dos hechos son motivo suficiente para defender que la ignorancia excusada no debe anular las demandas históricas de compensación de los países afectados por el cambio climático sino, como mucho, aminorar su fuerza.

Veíamos antes, con Heyd, un apoyo al principio de los beneficiarios. Sin embargo, otros autores en el libro muestran su rechazo. Tal es el caso de Anja Karnein y Brian Berkey. Primero, tras muchos ejemplos tratando de buscar si en nuestras prácticas cotidianas exigimos compensación a los individuos por el mero hecho de beneficiarse de una injusticia, Karnein concluye que no es así. Parece, como argumenta, que la fuerza de los beneficios se adquiere cuando esos beneficios hacen que participemos, como contribuidores, en prácticas injustas. Pero entonces es la contribución y no los beneficios lo que importa moralmente. Berkey, por su parte, argumenta que el hecho de beneficiarse de las acciones ilícitas de otro no proporciona necesariamente argumentos de justicia. Lo que proporciona demandas de justicia es el hecho de que existan sistemas que dan lugar a resultados perjudiciales para 
las víctimas. Por tanto, nuestras exigencias de justicia deben estar dirigidas a reformar aquellos sistemas que generan resultados injustos, con independencia de si se llega a esos resultados injustos por la vía de los beneficios o no.

Los artículos de Karnein y Berkey se caracterizan por no pronunciarse a favor de ningún principio de distribución de cargas asociadas al cambio climático, sino meramente en contra del principio de los beneficiarios pagan. De manera diferentes, el capítulo de Mizan Khan se pronuncia a favor del principio de 'los que contaminan pagan', por ser el único principio que hace justicia a las demandas de los países particularmente vulnerables al cambio climático. En lugar de dar un único argumento para esta defensa, Khan se basa en diferentes razones, siendo todas ellas más prospectivas que retrospectivas. Por ejemplo, Khan considera que este principio permite, en primer lugar, lidiar con las consecuencias negativas del cambio climático de una manera más eficiente puesto que se internalizarían los costes negativos producidos por las emisiones. Esto haría que los contaminadores redujesen sus emisiones. Esto tendría, en segundo lugar, un efecto pedagógico, puesto que impulsaría un sentimiento de responsabilidad por los efectos negativos causados por las emisiones. Khan considera también que el principio es sostenible desde un punto de vista legal y que, además, obedece a un principio de equidad en la distribución de los costes entre los participantes. En una línea similar, Daniel Farber también abre una ventana de posibilidad a las remandas de responsabilidad legal. Sostiene que, si bien la responsabilidad legal estricta por las emisiones del pasado es un caso difícil de sostener, principios de responsabilidad legal menos estrictos podrían sostener demandas de responsabilidad a aquellos agentes que estás conectados con las emisiones históricas de un modo u otro.

Es relevante también, para el caso de la justicia climática, que las emisiones globales y remanentes sean repartidas de una manera justa. De esto se ocupan tanto los capítulos de Christian Baatz y Konrad Ott, como el capítulo de Rudolf Schuessler. Ott y Baatz examinan si el igualitarismo de las emisiones, es decir, que todos los individuos gocen del mismo número de emisiones, es un principio válido para distribuir el total de emisiones que pueden ser emitidas sin llegar a generar daños medioambientales extremos. Baatz y Ott concluyen que este principio no puede ser defendido teóricamente, aunque en términos prácticos puede llegar a ser una buena opción para lidiar con los escollos políticos e institucionales. Por este motivo, y concibiendo su propuesta siempre en términos de transición justa, acaban por apoyar un principio de igualitarismo de las emisiones complementado con un esquema de adaptación. Rudolf Schuessler piensa también en términos de transición hacia un régimen climático más justo. No obstante, nos llama la atención, en el camino de la justicia en transición necesitamos no solo tener en cuenta las demandas de las víctimas del cambio climático, sino también las de los individuos que viven hoy en países cuyas vidas están regidas por actividades altamente contaminantes. Existe, claro, una tensión entre ambos. Los individuos de los países contaminantes viven vidas basadas en el consumo de altas emisiones porque así se han desarrollado sus sociedades. A nivel colectivo, las sociedades industrializadas necesitan seguir, al menos por un tiempo, niveles de vida con emisiones similares para no colapsar. Si recortásemos el nivel de emisiones permisible drásticamente, esto haría que sus vidas se vieran fuertemente dañadas. Eso sería también injusto, puesto que los individuos de las sociedades industriales no tienen la culpa de haber nacido en ellas. Por ello, Schuessler adopta lo que se conoce como grandfathering moderado o, en otras palabras, una estrategia de contracción y convergencia. Esto quiere decir que, para respetar las demandas de justicia de ambos grupos, la mejor estrategia es ir reduciendo emisiones progresivamente, en lugar de radicalmente, a la par que las emisiones de aquellos que menos han emitido y que necesitan emisiones para desarrollarse crecen también progresivamente. El estadio final de este proceso sería un mundo donde todos pudieran emitir lo mismo a niveles compatibles con la sostenibilidad del planeta. Finalmente, el texto de Kenehan ahonda en cuestiones abordadas por los dos últimos capítulos citados, a saber, aquellas que tienen que ver con la viabilidad de las propuestas que podemos realizar en materia de justicia climática. Su capítulo podría describirse como una llamada a la practicidad: al final y al cabo, las teorías ideales no importan tanto como que seamos capaces de llegar a acuerdos y medidas para reducir el cambio climático extremo. 
El libro Cambio climático y Emisiones Históricas recoge, como hemos visto, puntos de vista diferentes sobre el significado de las emisiones históricas. Mientras algunos capítulos adoptan una postura más ideal sobre cómo entender la justicia climática, otros muestran una perspectiva más pragmática. No obstante, todos comparten la idea de que la justicia climática debe tener en cuenta el hilo temporal que va desde el desarrollo de la Revolución Industrial hasta nuestros días y la forma en la que nuestras sociedades se han desarrollado. Todos los autores son conscientes de que el pasado importa, aunque para algunos su importancia debe ser puesta en el contexto de la necesidad de avanzar para impedir que el cambio climático acabe por destruir nuestro planeta. Otros piensan, no sin argumentos, que sin una reconciliación con el desarrollo injusto de nuestras sociedades industriales el futuro será igualmente desolador. 
1) Los artículos y reseñas remitidos deberán ser inéditos (esto incluye publicaciones digitales como blogs, actas online, etc.) y no podrán ser postulados de forma simultánea para su publicación en otros periódicos. Al someter a la plataforma de la Prometeica, el autor afirma su anuencia a esa exigencia.

2) Los artículos no deberán exceder los 40.000 caracteres. Las reseñas no deberán exceder los 10.000 caracteres.

3) Todos los artículos deberán estar acompañados de un resumen y un abstract equivalente en inglés, cada uno de no más de 1.500 caracteres, incluyendo tres palabras claves.

4) Los idiomas aceptados para los artículos serán:
a) castellano,
b) portugués,
c) inglés.

5) Los artículos deben ser enviados a la revista a través de lo que el acceso del usuario a la plataforma OJS. Las presentaciones deben estar en dos archivos con formatos doc, docx o.odt. La primera debe ser el artículo y el resumen, y sin los datos del autor. El segundo debe contener los datos del autor: un breve curriculum, afiliación académica e información de contacto. Los metadatos de los archivos deben ser borrados por el autor para garantizar una evaluación ciega, es decir, el autor no ve el nombre del parecerista y el parecerista no ve el nombre del autor.

6) Una vez enviado el artículo/reseña el autor recibirá un e-mail de Prometeica acusando recibo. Desde la recepción de ese mensaje el comité editorial tendrá un máximo de 4 meses para evaluar si el artículo/reseña será publicado/a en la revista. El tiempo máximo previsto entre el envío del artículo y su publicación, en caso de aceptación sin reformulaciones, es de 6 meses.

7) En cuanto al sistema de referencias Prometeica adopta las Normas APA - 2016 - $6^{\text {a }}$ edición, de la American Psychological Association.

8) Para las notas aclaratorias se empleará la referencia al pie. Preferentemente se sugiere no abusar de este recurso.

9) En el caso de artículos que incluyan imágenes, deben enviarse en un archivo separado. Las imágenes deben tener una resolución de 300 dpi, en formato *.jpg o *.tiff. El copyright de la imagen ya debe ser concedido, o el autor debe usar imágenes sin derechos de autor.

10) En cuanto a la evaluación de los artículos, los mismos serán remitidos al miembro del consejo editorial responsable del área del trabajo en cuestión. Los artículos serán enviados a dos especialistas externos y evaluados en el sistema de revisión doble ciega en que el autor no ve el nombre del evaluador y el evaluador no ve el nombre del autor. En el caso de haber desacuerdo entre ellos, un tercer árbitro podrá ser consultado, por decisión del consejo editorial.

11) Los trabajos pueden tener tres resultados posibles que constan en el formulario de evaluación que completará junto a otras observaciones el evaluador:

a) recomendado para su publicación sin alteraciones,

b) recomendado para su publicación con modificaciones,

c) no recomendado para su publicación.

12) En el caso 11 (b), la publicación del mismo quedará sujeta a que el autor esté dispuesto a realizar las modificaciones y las remita para su nueva evaluación.

13) Todos los trabajos aprobados serán publicados en un idioma aceptado por la revista. Si el original no está escrito en uno de estos idiomas y demandas de traducción, puede resultar en un retraso de la publicación.

14) El contenido de los originales publicados es responsabilidad exclusiva de sus autores.

15) Los artículos presentados a la revista deben ser escritos utilizando el Modelo_Prometeica_Autor_verde.dotx para seguir los estilos y formatos descritos en Formato Prometeica.doc

16) Prometeica adopta una política antiplagio sometiendo todos los artículos enviados a un primer análisis por el software Plagius. 